

\title{
Geological and hydrological histories of the Argyre province, Mars
}

J.M. Dohm, T.M. Hare, S.J. Robbins, J.-P. Williams, R.J. Soare, M.R. El-Maarry, S.J. Conway, D.L. Buczkowski, J.S. Kargel, M.E. Banks, et al.

\section{- To cite this version:}

J.M. Dohm, T.M. Hare, S.J. Robbins, J.-P. Williams, R.J. Soare, et al.. Geological and hydrological histories of the Argyre province, Mars. Icarus, 2015, 253, pp.66-98. 10.1016/j.icarus.2015.02.017. insu-02274347

\section{HAL Id: insu-02274347 https://hal-insu.archives-ouvertes.fr/insu-02274347}

Submitted on 8 Jan 2021

HAL is a multi-disciplinary open access archive for the deposit and dissemination of scientific research documents, whether they are published or not. The documents may come from teaching and research institutions in France or abroad, or from public or private research centers.
L'archive ouverte pluridisciplinaire HAL, est destinée au dépôt et à la diffusion de documents scientifiques de niveau recherche, publiés ou non, émanant des établissements d'enseignement et de recherche français ou étrangers, des laboratoires publics ou privés. 


\section{Geological and Hydrological Histories of the Argyre Province, Mars}

J. M. Dohmª, T. M. Hare ${ }^{\text {b }, ~ S . ~ J . ~ R o b b i n s ~}{ }^{\mathrm{c}}$, Jean-Pierre Williams ${ }^{\mathrm{d}}$, R. J. Soare ${ }^{\mathrm{e}}$, M. R. El Maarry ${ }^{\mathrm{f}}$,

S. J. Conway ${ }^{\mathrm{g}}$, Debra L. Buczkowski ${ }^{\mathrm{h}}$, Jeffrey S. Kargel ${ }^{\mathrm{i}}$, M. E. Banks ${ }^{\mathrm{j}, \mathrm{k}}$, Alberto G. Fairén', D. Schulze-Makuch $^{\mathrm{m}}$, G. Komatsu ${ }^{\mathrm{n}}$, Hirdy Miyamoto ${ }^{\mathrm{a}}$, R.C. Anderson ${ }^{\mathrm{o}}$, A.F. Davila ${ }^{\mathrm{p}}$, W.C.

Mahaney $^{\mathrm{q}}$, W. Fink ${ }^{\mathrm{r}}$, H. J. Cleaves ${ }^{\mathrm{s}, \mathrm{t}}$, J. Yan ${ }^{\mathrm{u}}$, B. Hynek ${ }^{\mathrm{v}}$, S. Maruyama ${ }^{\mathrm{s}}$

${ }^{a}$ The University Museum, The University of Tokyo, Hongo 7-3-1, Bunkyo-ku, Tokyo 113-0033, Japan

${ }^{b}$ U.S. Geological Survey, Flagstaff, AZ 86001, USA

'Southwest Research Institute, Boulder CO 80302, USA

${ }^{\mathrm{d}}$ Department of Earth and Space Sciences, University of California, Los Angeles, CA 90095, USA

e'Department of Geography, Dawson College, 3040 Sherbrooke St. W., Montreal, Canada, H3Z

$1 \mathrm{~A} 4$

fPhysikalisches Institut, Bern Universität, Berne, Switzerland 3012

${ }^{g}$ Department of Physical Sciences, Open University, Milton Keynes, UK, MK7 6AA

${ }^{h}$ Applied Physics Laboratory, Johns Hopkins University, Laurel, MD, 20723, USA

iDepartment of Hydrology and Water Resources, University of Arizona, Tucson, AZ 85721, USA

${ }^{\mathrm{j} S}$ Smithsonian Institution, National Air and Space Museum, Center for Earth and Planetary Studies, Washington, DC 20013, USA

${ }^{k}$ Planetary Science Institute, Tucson, AZ 85719, USA

'Department of Planetology and Habitability, Centro de Astrobiología, Madrid 28850, Spain

${ }^{\mathrm{m}}$ Center of Astronomy and Astrophysics, Technical University Berlin, 10623 Berlin, Germany

"International Research School of Planetary Sciences, Università d'Annunzio, 65421 Pescara, Italy

${ }^{\circ}$ Jet Propulsion Laboratory, California Inst. Of Technology, Pasadena, CA 91109

PSETI Institute, Mountain View, California 94043, USA

${ }^{q}$ Quaternary Surveys, 26 Thornhill Ave., Thornhill, ON L4J 1J4, Canada

${ }^{\mathrm{r}}$ College of Engineering, Department of Electrical and Computer Engineering, University of Arizona,

Tucson, AZ 85721, USA

${ }^{s}$ Earth-Life Science Institute, Tokyo Institute of Technology, Meguro, Tokyo, Japan, 152-8551

'The Institute for Advanced Study, Princeton, NJ 08540 USA

"RISE Project Office, National Astronomical Observatory of Japan, Oshu 0230861, Japan

'Laboratory for Atmospheric and Space Physics and Geological Sciences, University of Colorado, 80309, USA

E-mail: jmd@um.u-tokyo.ac.jp

Manuscript pages (double space including references): $* *$

Figures: 20

Tables: 4 
Proposed running title: Argyre basin, Mars.

\section{Editorial correspondence to:}

Dr. James M. Dohm

Project Associate Professor

Branch of Space Exploration Education \& Discovery (SEED) UMUT (University Museum, University of Tokyo)

Tokyo, Japan

E-mail: jmd@um.u-tokyo.ac.jp 


\section{ABSTRACT.}

2 The geologic history of the multi-ringed Argyre impact basin and surroundings has been

3 reconstructed on the basis of geologic mapping and relative-age dating of rock materials and

4 structures. The impact formed a primary basin, rim materials, and a complex basement structural

5 fabric including faults and valleys that are radial and concentric about the primary basin, as well

6 as structurally-controlled local basins. Since its formation, the basin has been a regional

7 catchment for volatiles and sedimentary materials as well as a dominant influence on the flow of

8 surface ice, debris flows, and groundwater through and over its basement structures. The basin is

9 interpreted to have been occupied by lakes, including a possible Mediterranean-sized sea that

10 formed in the aftermath of the Argyre impact event. The hypothesized lakes froze and

11 diminished through time, though liquid water may have remained beneath the ice cover and

12 sedimentation may have continued for some time. At its deepest, the main Argyre lake may have

13 taken more than a hundred thousand years to freeze to the bottom even absent any heat source

14 besides the sun, but with impact-induced hydrothermal heat, geothermal heat flow due to long-

15 lived radioactivities in early Martian history, and concentration of solutes in sub-ice brine, liquid

16 water may have persisted beneath thick ice for many millions of years. Existence of an ice-

17 covered sea perhaps was long enough for life to originate and evolve with gradually colder and

18 more hypersaline conditions. The Argyre rock materials, diverse in origin and emplacement

19 mechanisms, have been modified by impact, magmatic, eolian, fluvial, lacustrine, glacial,

20 periglacial, alluvial, colluvial, and tectonic processes.

21 Post-impact adjustment of part of the impact-generated basement structural fabric such as

22 concentric faults is apparent. Distinct basin-stratigraphic units are interpreted to be linked to

23 large-scale geologic activity far from the basin, including growth of the Tharsis magmatic- 
24 tectonic complex and the growth into southern middle latitudes of south polar ice sheets. Along

25 with the migration of surface and sub-surface volatiles towards the central part of the primary

26 basin, the substantial difference in elevation with respect to the surrounding highlands and

27 Tharsis and the Thaumasia highlands result in the trapping of atmospheric volatiles within the

28 basin in the form of fog and regional or local precipitation, even today. In addition, the impact

29 event caused long-term (millions of years) hydrothermal activity, as well as deep-seated

30 basement structures that have tapped the internal heat of Mars, as conduits, for far greater time,

31 possibly even today. This possibility is raised by the observation of putative open-system pingos

32 and nearby gullies that occur in linear depressions with accompanying systems of faults and

33 fractures. Long-term water and heat energy enrichment, complemented by the interaction of the

34 nutrient-enriched primordial crustal and mantle materials favorable to life excavated to the

35 surface and near-surface environs through the Argyre impact event, has not only resulted in

36 distinct geomorphology, but also makes the Argyre basin a potential site of exceptional

37 astrobiological significance.

KEYWORDS: Mars, Argyre, impact basin; water; early Mars; sedimentary; geology,

40 stratigraphy, geomorphology, sedimentology, lakes, tectonics, glaciation, astrobiology, mapping. 


\section{1. Introduction}

A detailed reconstruction of the geologic history of the Argyre impact basin and

3 surroundings $\left(30^{\circ} \mathrm{S}\right.$ to $65^{\circ} \mathrm{S}, 290^{\circ} \mathrm{E}$ to $340.0^{\circ} \mathrm{E}$; Figs. 1-2), referred to hereafter as the Argyre

4 province, is presented through a preliminary United States Geological Survey (USGS) map

5 based on stratigraphic, structural, and geomorphic mapping using Viking Orbiter, Mars Global

6 Surveyor (MGS), Mars Odyssey (ODY), and Mars Reconnaissance Orbiter (MRO) data (Fig. 3).

7 The Argyre province includes the primary impact basin, basin floor and rim materials, the

8 transition zone (region between the Thaumasia highlands mountain range and the Argyre basin

9 and rim materials), and the southeastern margin of the Thaumasia plateau (Figs. 1-2). The large

10 impact event resulted in the construction of the primary Argyre basin and the uplift of a

11 mountainous rim. It also produced deep-seated and shallow basement structures such as radial

12 structurally-controlled valleys and concentric ring scarps, as well as local (i.e., secondary) basins

13 occurring among the rim materials and away from the primary basin and rim materials; impact-

14 related deformation occurred as much as 2,000 kilometers away from the impact site (Dohm et 15 al., 2001a) (Fig. 2).

16 Since the formation of the impact basin, erosional and depositional processes have 17 substantially modified the Argyre basin and rim materials, including the emplacement of five 18 major and distinct basin-stratigraphic units (units NAb1, NAb2, NAb3, ANb4b, HAb4a, which 19 are detailed in Section 3.1 and in Fig. 3 and Tables 1-3). As shown below, the Argye impact 20 event has been a significant influence on the geologic and hydrologic history of the region from 21 when the basin formed until now. Unraveling the history of the Argyre province is important to 22 understanding the overall influence of the Argyre impact event on the regional and local geology 
23 and hydrology. Being one of the largest impact basins on Mars, it also offers a unique

24 opportunity to peer deep into the crust and upper mantle and to discern hydrological processes

25 and depositional surface environments across a span of billions of years.

26 Previous geologic mapping investigations of all or parts of the Argyre province, which

27 involved data from the Mariner and Viking missions, resulted in: (1) maps of Coprates

28 (McCauley, 1978), Magaritifer Sinus (Saunders, 1979), Argyre (Hodges, 1980), Thaumasia

29 (McGill, 1978), and Mare Australe (Condit, 1978) quadrangles at 1:5,000,000-scale based

30 mainly on Mariner 9 images; (2) the global map of Mars at 1:25,000,000 scale (Scott and Carr,

31 1978) compiled largely from the 1:5,000,000-scale geologic maps; (3) maps of the western

32 equatorial and south polar regions of Mars at 1:15,000,000-scale based on Viking images (Scott

33 et al., 1986-1987); and (4) the Viking-based map of the Thaumasia region at 1:5,000,000 scale,

34 which covers the extreme northwestern part of the Argyre basin (Dohm et al., 2001a).

35 Study of the hydrogeologic evolution of the Argyre province through Viking Orbiter data

36 (images at resolutions ranging from $\sim 50-150 \mathrm{~m} /$ pixel) indicated that post-impact basin

37 development has been heavily influenced by lacustrine, fluvial, and glacial processes (Parker,

38 1985, 1989, 1994; Parker and Gorsline, 1991, 1992, 1993; Kargel and Strom, 1992; Parker et al.,

39 2000; Dohm et al. 2001a; Kargel, 2004). These investigations revealed evidence of a broad

40 integration of hydrogeologic activity within the basin extending to headwaters in the highlands

41 south and east of the basin. In particular, the multiple Parker et al. (Parker, 1985, 1989, 1994;

42 Parker and Gorsline, 1991, 1992, 1993; Parker et al., 2000) found evidence for deep water

43 ponding in the basin and water drainage northward both into Argyre from the south and from

44 Argyre through Uzboi Vallis into the northern plains; this included basin filling to a spillpoint

45 (refer to Figs. 1-3 for locations of highlighted features of interest). In addition, Kargel and Strom 
(1992) detailed a role of wet-based alpine and continental scale glaciation in southern Argyre and

47 adjoining highlands, with the glacial system extending as far as the south polar region and

48 eastward halfway to Hellas. Baker et al. (1991) suggested a latitude limit of south polar

49 glaciation having been roughly halfway through the Argyre basin, making the southern part

50 glaciated and the northern part unglaciated.

51 Subsequent to these Mariner- and Viking-era mapping investigations, using image data at

52 what is now considered low resolutions, there has not been a new, detailed geologic map

53 produced of the Argyre province using more recently available higher resolution data (e.g.

54 images acquired by the High Resolution Imaging Science Experiment (HiRISE), on MRO, with

55 a scale as small as $0.25 \mathrm{~m} /$ pixel). Post-Viking-era topographic, geomorphologic, and

56 spectroscopic investigations (e.g., Hiesinger and Head, 2002; Kargel, 2004; Buczkowski et al.,

57 2008a,b, 2010; Banks et al., 2008, 2009; Jones et al., 2011) have provided helpful information

58 for this investigation.

59 Here, we discuss the results of our systematic geologic mapping of the Argyre province

60 (Figs. 1-3). This work will be portrayed in a USGS geologic map product at 1:5,000,000 scale in

61 both digital and print formats (Dohm et al., USGS map, in preparation). Although earlier

62 geologic maps include all or parts of the Argyre province, none focuses on understanding the

63 geologic and hydrologic histories of the province using post-Viking-era data. Additionally,

64 detailed studies that did make use of post-Viking-era data did not make use of a systematic map-

65 based approach and did not encompass the breadth of landscapes mapped in this geologic

66 mapping investigation. We present the stratigraphic, hydrologic, and tectonic histories of the

67 Argyre province as reconstructed from our geologic mapping, with particular focus on: (1)

68 whether the Argyre basin contained lakes; (2) the extent of flooding and glaciation; (3) the origin 
69 of the narrow ridges located in the southeastern part of the basin floor and how the ridges fit into

70 the context of the geologic mapping results; (4) the extent of Argyre-related tectonism and its

71 influence on the surrounding regions and conversely the role of tectonics in adjoining regions in

72 affecting the Argyre basin and its deposits; and (5) possible very Late Amazonian modifications

73 by periglacial (cold-climate and non-glacial) processes.

\section{Geologic setting}

The Argyre province (Figs. 1-3) is located in the southern cratered highlands, which occur

77 across nearly half of Mars; the highlands comprise the majority of exposed ancient Noachian

78 rocks (Scott et al., 1986-87; Tanaka, 1986; Tanaka et al., 2014). The Martian highlands also

79 contain the Hellas basin and surroundings. Unlike the Argyre province, the latter has received

80 significant attention and is mapped in great detail (e.g., Crown et al., 1992; Mest and Crown,

81 2001; Leonard and Tanaka, 2001; Moore and Wilhelms, 2007; Glamoclija et al., 2011).

82 The southern highlands display geologic terrains that involved high rates of geologic and

83 hydrologic activity during the Noachian Period (e.g., Scott et al., 1986-87; Tanaka, 1986; Tanaka

84 et al., 1988, 2014; Dohm et al., 2001a, 2013; Hartmann and Neukum, 2001; Hynek et al., 2010).

85 Dynamic activity, including mountain building, formation of structurally-controlled basins, and

86 possible plate tectonism (Sleep, 1984; Maruyama et al., 2001a; Dohm et al., 2001c, 2002a,

87 2005a, 2013; Anguita et al., 2001; Fairén et al., 2002; Baker et al., 2002, 2007; Fairén and

88 Dohm, 2004; Connerney et al., 2005; Yin, 2012a,b), is pronounced prior to the incipient

89 development of the Tharsis rise, a long-lived (nearly $4.0 \mathrm{Ga}$ ) magmatic complex (Dohm et al.,

90 2001b; Anderson et al., 2001), interpreted here to be a superplume (Maruyama et al., 2001b,

91 2008; Dohm et al., 2001d, 2007a; Baker et al., 2002, 2007). This pre-Tharsis activity is also 
92 prominent before the Argyre, Hellas, and Isidis impact events (Dohm et al., 2002a,b, 2005a,

93 2013; Baker et al., 2002). This dynamic activity was followed by sporadic magmatic, tectonic,

94 climatic, and hydrologic activity driven mainly by endogenic activity from the growth of Tharsis

95 superplume until present-day (Dohm et al., 2007a; Baker et al., 2007) (Fig. 4), but also by the

96 giant impact events such as Argyre, and to the development of the Elysium superplume (Baker et

97 al., 2007). Other influences including changes in the spin axis magnitude and precession and

98 orbital eccentricity of Mars (Touma and Wisdom 1993, Laskar et al. 2004), steadily brightening

99 solar luminosity (Kasting et al. 1993), and volatile releases from other large impacts (Segura et

100 al., 2002) also have contributed to climate change and the geomorphology and surficial deposits

101 of Mars (Head et al. 2003, Kargel 2004).

102 Dominant in the geologic, hydrologic, and climatic histories of Mars since its incipient 103 development, Tharsis superplume locates to the northwest of and adjacent to the Argyre basin.

104 Based on topographic, stratigraphic, paleoerosional, and paleotectonic information, Tharsis is 105 interpreted to have recorded five major stages of magmatic-driven activity (Fig. 4) (for details on

106 the major stages of development of Tharsis, please refer to Dohm et al. (2001b, 2007a, 2009a)

107 and Anderson et al. (2001), and for general stratigraphic information and time-chronologic

108 information of Tharsis and the rest of Mars, the new global map of Mars by Tanaka et al.

109 (2014)). The five major stages of development and a representative features of each stage (from

110 oldest to youngest with some overlap largely due to uncertainty in the crater statistics) include:

111 Stage 1 (Early to Middle Noachian) - Tharsis basin with subsequent uplift of the Thaumasia

112 Plateau and incipient development of Syria Planum; Stage 2 (Late Noachian to Early

113 Hesperian) - opening of Valles Marines cutting the northern part of the Thaumasia Plateau, as

114 well as major development of Syria Planum; Stage 3 (Early Hesperian) —early development of 
115 the prominent volcanoes of Tharsis Montes and Alba Mons; Stage 4 (Late Hesperian to Early

116 Amazonian) — major magmatic outgassing of Tharsis, including related major growth of the Alba

117 Mons, Olympus Mons, the Tharsis Montes, and associated major incisement of the circum-

118 Chryse outflow channel system that began to form as early as and associated with major Stage 2

119 Tharsis activity; and Stage 5-(Amazonian) all of the components of Tharsis forged by this time

120 with concentrated magmatic-driven tectonic activity in parts into the Late Amazonian.

121 These five major thermal pulses of Tharsis activity, which includes magmatism and 122 associated release of volatiles, major outflows, inundations of the northern plains to form oceans, 123 and hydrological cycles, have manifested themselves at regional and possibly global scales at 124 least since the Middle Noachian epoch (Fig. 4). This includes the influence of the topography 125 and stratigraphy of the northern plains (Tanaka et al., 2005), which correlate with the timing of 126 the major pulses (Fairén et al., 2003). In the new global geologic map of Mars by Tanaka et al. 127 (2014), the Hesperian and Noachian transition unit (unit HNt) links to Stages 1 and 2 (i.e., larger 128 and older ocean; Fairén et al., 2003), the Early Hesperian transition unit (unit eHt) to Stages 2 129 and 3 (i.e., either the waning of the larger and older ocean, or possibly another ocean-inundation 130 phase of the northern plains; Fairén et al., 2003), and the regional Late Hesperian lowland unit 131 (unit $1 \mathrm{Hl}$ ) and Late Hesperian transition unit (unit $\mathrm{lHt}$ ) to Stages 4 and 5 (i.e., the smaller ocean 132 inset within the larger older ocean; Fairén et al., 2003). Tharsis-driven activity has also been a 133 major influence on the adjacent Argyre impact basin and surroundings as revealed in this 134 geologic investigation.

135 The primary Argyre impact basin is more than 1,200 kilometers in diameter and more than 4 136 kilometers in depth (Fig. 2). The basin formed during the Noachian Period, or an absolute age 137 estimated to be 3.93 Ga (Robbins and Hynek, 2012; Robbins et al., 2013); the upper terminus 
138 of the Noachian Period (see Tanaka et al. (2014) for details and references therein) is estimated

139 to have started at about 3.85 Ga (Hartmann, 2005) or $3.83 \mathrm{Ga}$ (Ivanov, 2001; Hartmann and

140 Neukum, 2001). Argyre is the best preserved of the large multi-ringed impact basins on Mars,

141 comparable to the $\sim 327 \mathrm{~km}$-diameter Orientale basin of the Moon when viewed at resolutions

142 less than one kilometer per pixel. The profound differences of the Argyre and Orientale basins

143 due to pervasive post-impact modification of the former by geologic, hydrologic, and aeolian

144 processes, are evident at higher resolutions. Unlike the Moon, there is no absolute radiometric

145 chronology of Mars. However, a wide range of circumstantial evidence, including

146 comprehensive impact crater statistics, points towards the formation of Argyre, and similar large

147 Martian basins (including Hellas and Isidis), at about the same time as large and distinct multi-

148 ring impact basins on the Moon such as Oriental (i.e., somewhere between about 3.8-4.0 billion

149 years ago) (based on Wilhelms (1987) for the Moon and Robbins and Hynek (2012) and Robbins

150 et al. (2013) for Mars).

151 Compared to the Hellas basin, which is estimated to have formed at about $4.0 \mathrm{Ga}$, the

152 Argyre basin, occurring nearly 70 million years later than the Hellas impact event (both

153 estimated ages based on Robbins et al. (2013)), is much more pristine than Hellas, including the

154 impact-induced radial and concentric structures that can be more readily mapped and

155 characterized (Dohm et al., 2002a). This difference in degradational state is interpreted to mark

156 major changing planetary conditions at a time when the internal dynamo of Mars had shut down

157 due to planetary cooling, putative plate tectonism was nearing its end, and the atmosphere was

158 thinning (Baker et al., 2007).

159 Other basin examples, though much older than Hellas, include putative Utopia (e.g., McGill, 160 1989) and Arabia Terra (Dohm et al., 2007b) impact basins, largely subdued to the untrained 
161 eye. The putative Arabia Terra basin, for example, is not visible in present-day topography, but

162 its hypothesized existence is supported by distinct characteristics such as stratigraphy,

163 physiography, paleotectonism, and geomorphology, as well as notable structural, albedo, thermal

164 inertia, gravity, magnetic, and elemental signatures (Dohm et al., 2007b). Similarly, ancient

165 basins on Earth, particularly those tectonically-derived, that have been all but destroyed, are

166 revealed through geologic investigation. Another example of an ancient, heavily eroded basin is

167 the Chryse impact basin infilled by sediments derived from adjoining chaotic terrains and

168 outflow channels (Rotto and Tanaka 1997; Rodriguez et al. 2011). There are also relatively large

169 features referred to as quasi-circular depressions interpreted to be impact in origin (Frey et al.,

170 2002). Similar to Hellas, the younger Argyre impact event appears to have taken place after the

171 shutdown of the planetary dynamo; the remanent magnetic anomalies (Acuña et al., 1999, 2001;

172 Connerney et al., 1999, 2001; Arkani-Hamed, 2003, 2004; Roberts et al., 2009; Roberts and

173 Arkani-Hamed, 2012), distinct in the extremely ancient geologic provinces of Mars (e.g., Terra

174 Cimmeria, Terra Sirenum, Arabia Terra, Xanthe Terra, and the Thaumasia highlands and

175 Coprates rise mountain ranges), are not observed in and nearby the giant impact structure (Dohm

176 et al., 2005, 2013). "Extremely ancient" refers to pre-Hellas Mars, or estimated to be > 4.0 Ga

177 (Robbins et al., 2013), equivalent to the Hadean of Earth, of which the rock record has been all

178 but destroyed aside from traces, such as zircon grains in meta-sandstones (Harrison, 2009). There

179 are other post-dynamo-shutdown geologic provinces such as Tharsis, Syrtis, Malea Planum, and

180 Tyrrhena/Hadriaca volcanic provinces and the northern plains, which includes the

181 Tharsis/Elysium corridor region (Dohm et al., 2008, 2013). The termination of the global

182 magnetic field may have occurred between the formation of Ladon and Hellas impact basins

183 (Lillis et al., 2008) and the formation of Ladon and Prometheus basins (Fig. 1), the latter of 
184 which is dated to be older than Hellas through comprehensive global crater statistics (Robbins et 185 al., 2013).

186 The multi-ringed Argyre impact structure appears to have influenced the geophysical and 187 geological development of a large part of Mars. This includes modification of the southeastern 188 part of the Thaumasia plateau and control of the Uzboi drainage system and other systems of 189 surface and subsurface movement of liquid water and water-ice (Parker and Gorsline 1991, 1993; 190 Kargel and Strom, 1990, 1992; Dohm et al., 2001a, 2011a; Kargel, 2004;). The influence of the 191 Argyre impact has even been proposed to have fixed the location of the Tharsis superplume 192 through impact-induced subduction and slab rollback during an incipient plate tectonic period 193 (Yin, 2012a). Though the onset and origin of Tharsis still remains in question according to 194 various working hypotheses, such as focused subduction of hydrated crustal slab materials 195 (Baker et al., 2007), the Argyre impact event and the development of the Tharsis superplume had 196 an influence on one another. While the Argyre impact influenced the development of the 197 southeast margin of the Thaumasia plateau, Tharsis-superplume-driven outgassing, flooding, and 198 associated climate and environmental change significantly contributed to the modification of the 199 Argyre basin (Figs. 2 and 4).

200 Impact-induced features such as rim-forming mountains (e.g., the Charitum and Nereidum 201 Montes), local basins among the mountains, radial and concentric structures (including valleys), 202 and the primary basin floor have all been altered by diverse processes since their formation both 203 within and outside of the Argyre province. These include magmatic, impact cratering, tectonic 204 (e.g., reactivated basement structures), eolian, fluvial, alluvial, colluvial, periglacial, glacial, and 205 lacustrine (e.g., Parker, 1985, 1989, 1994; Scott et al., 1986,87; Tanaka, 1986; Parker and 206 Gorsline, 1991, 1992, 1993; Kargel and Strom, 1992; Dohm and Tanaka, 1999; Parker et al., 
2000; Hiesinger and Head, 2002; Siebert and Kargel, 2001; Banks et al., 2008, 2009; Jones et al.,

208 2011; Soare et al., 2012a, 2014a, 2014b; El Maarry and Dohm, 2013; El Maarry et al., 2013).

209 Geologically recent activity is highlighted by high-resolution data sets such as the Context

210 Camera (CTX) at $\sim 6 \mathrm{~m} /$ pixel and the High Resolution Imaging Science Experiment (HiRISE). It

211 has involved liquid water, water-ice, and wind that suggest distinct and significant changes in

212 regional environmental conditions (including both surface and near-surface modifications in

213 temperature, moisture, hydrology, and surface morphology) generally in geologically recent

214 time, including the very Late Amazonian (within the last roughly thousands of years) (e.g., El

215 Maarry et al., 2013; Soare et al., 2014a,b).

216 Henceforth, "geologically recent activity" refers to Middle Amazonian and younger activity.

217 This is in part based on the superposed crater counts (i.e., those impact craters which are 218 superposed and pristine with distinct rims and ejecta blankets that are not visibly resurfaced) of 219 many of the units in the Argyre province shown in Table 3, which give crater-retention ages of 220 Late Hesperian and Early Amazonian epochs. This retention age is coeval with major Tharsis221 driven activity during the Late Hesperian and Early Amazonian epochs (i.e., Stages 4 and 5; Fig. 222 4). In a marked shift from most Viking Orbiter-era geochronologies of Mars, in recent years it 223 has been increasingly evident that intensive or widespread episodes of Martian hydrogeologic 224 activity took place at intervals throughout the Amazonian, even into the very Late Amazonian 225 (Kargel et al., 1995; Head et al., 2003; Madeleine et al., 2009; Skinner et al., 2012; Rodriguez et 226 al., 2014). Thus, "geologically recent" should be considered here as activity correlative in time 227 with the latter part of Stage 5 Tharsis activity (schematically depicted in Fig. 4 through a 228 narrowing of the solid area representative of decreased Stage-5 activity). Other processes 229 documented during recent years include seasonal deposition and sublimation of a thin $\mathrm{CO}_{2}$ ice 
230 cover and locally intense and frequent dust devils which distinctly leave their marks (Kargel,

231 2004). The rich and diverse history of the Argyre province, and its far-reaching record in terms

232 of both time and space at local to regional and even global scales, is detailed below.

\section{3. Mapping investigation}

\section{$235 \quad 3.1$ Mapping overview and data}

236 Geologic units and tectonic and erosional structures primarily were identified and mapped

237 using Odyssey Thermal Emission Imaging System (THEMIS) data (100 m/pixel near-infrared

238 (IR) daytime and nighttime images and $18 \mathrm{~m} /$ pixel visible multi-band images) (Christensen et al.,

239 2004), images from the HiRISE camera (McEwen et al., 2007) and CTX on MRO (Malin et al.,

240 2007), and Viking Mars Digital Image Mosaic 2.1 information (generally 100 m-200 m/pixel)

241 (e.g., Archinal et al., 2002, 2003).

242 The MGS Mars Orbiter Laser Altimeter (MOLA) has provided an unprecedented 243 topographic information in the form of a digital-elevation model at $1 / 128^{\circ}$ resolution $(\sim 460$ 244 m/pixel) (e.g., Smith et al., 1999). The MOLA data have helped: (1) define stratigraphic units;

245 (2) determine the stratigraphic relations among the map units; (3) evaluate whether an impact 246 crater or deposit was superposed or embayed or partly buried; and (4) assess spatial and temporal 247 relations among map units, structures, terraces, valleys incised into existing valleys at distinct 248 elevation ranges around parts of the basin, and possible equipotential surfaces.

249 Geologic information was assembled into a Geographic Information System (GIS) database, 250 which enables the attribution of individual geologic features according to type and size, 251 comparative analysis of the spatial and temporal relations among the rock outcrops and 
252 topography (Fig. 5), and area calculations of the map units for compiling crater statistics (Tables 2531 and 3).

254 The materials of the Argyre province are divided into 20 distinct geologic units, as discussed 255 in Section 4.2, shown in Fig. 3, and detailed in Tables 1-3. The map units are categorized into 256 Argyre basin stratigraphic units (units HAb4a, NAb4b, NAb3, NAb2, and NAb1, in which H 257 refers to the Hesperian Period, $\mathrm{N}$-Noachian Period, Ab-Argyre basin materials divided into 258 members 4a, 4b, 3, 2, and 1), Argyre rim materials (units NAr, NArb, NAbr, and NArsp, in 259 which $\mathrm{N}$ refers to the Noachian Period, A-Argyre, $\mathrm{r}$ - rim, b-basin, and sp-smooth plains), 260 highlands materials (units AHtp, HNTh, HNh4, HNh3, Nhb, Nh2, and Nh1, in which A refers to 261 the Amazonian Period, H-Hesperian Period, N-Noachian Period, tp-Thaumasia plateau, 262 Th-Thaumasia highlands, and h-highlands divided into members 4-1), and impact crater 263 materials post-dating the Argyre impact event (units C1, C2, Cfs, and Cfr, in which C stands for 264 crater, C1-older crater materials, C2-younger crater materials, Cfs-smooth crater floor 265 materials, and $\mathrm{Cfr}$-rough crater floor materials) (Fig. 3, Tables 1-3). The map units are 266 delineated based on stratigraphic relations, topography, and morphologic characteristics. 267 Morphologic characteristics include albedo and bedform types such as valleys, terraces, 268 knobs/massifs/plateaus, ridges, scarps, flow features, and pristine and highly degraded impact 269 craters and other topographic lows such as Argyre-induced topographic basins.

270 By merging daytime THEMIS data and MOLA topography, distinct topographic levels with 271 spatially associated bedforms were observed, aiding in the identification, characterization, and 272 mapping of the basin units. The geologic contacts of the basin units are generally gradational due 273 to major resurfacing through time, and have been delineated approximately on the geologic map.

274 For example, there are distinct topographic levels evident where valleys incise into older valley 
275 segments often at terraces and erosional scarps. These topographic levels are particularly distinct

276 along the floors of the three valleys that debouch into the southern and southeast parts of the

277 Argyre basin; from west to east, they are: Surius Vallis, Dzigai Vallis, and Nia Valles,

278 respectively (Figs. 3 and 6). These levels are interpreted to indicate changing hydraulic head

279 (depth to the water table) and associated major changes in basin conditions.

280 The relative ages of rock materials were derived from stratigraphic and structural relations

281 and crater densities. The formal stratigraphic systems (Noachian, Hesperian, and Amazonian)

282 devised by Scott and Carr (1978) and the series (upper, middle, and lower divisions of systems)

283 defined by Tanaka (1986) are used in this work.

284 The stratigraphic, hydrologic, and tectonic histories in the Argyre province, as discussed in

285 Section 4, are based on stratigraphic and crosscutting relations among rock materials and 286 structures (i.e., that are tectonic, erosional, and depositional in origin), and relative ages are 287 further constrained through detailed impact crater investigations detailed in the following Section 288 3.2. We mapped the stratigraphy and structure including: channels, troughs, scarps, broad ridges, 289 wrinkle ridges, crater rims, lineaments that may have a tectonic origin, graben, and faults. 290 Mapped tectonic features with lengths ranging from hundreds of kilometers to more than a 291 thousand kilometers are referred to as macrostructures and are interpreted to be major deep292 seated (lower crust and possibly upper mantle) dislocations (faults) produced by the giant Argyre 293 impact event and other dynamic geologic activity mostly prior to the development of Tharsis.

\section{$295 \quad 3.2$ Impact crater dating}

296 To evaluate the formation and modification ages of the Argyre rock units, crater statistics 297 were compiled for 16 of the 20 units; this accounted for approximately $90 \%$ of the map region 
298 (Tables 1 and 3, and corresponding Fig. 3). Impact craters with diameters generally $>50 \mathrm{~km}$ 299 and their associated ejecta blankets were mapped, but crater statistics not tallied. This included 300 units C1 (older crater materials), C2 (young crater materials), Cfr (rough crater floor materials), 301 and smooth crater floor materials (Cfs). This age information was derived by counting all craters 302 having rim diameters larger than or equal to $3 \mathrm{~km}$ and by calculating unit areas from our digital 303 geologic map (Fig. 3). The crater populations were compiled using the global data base of 304 Robbins and Hynek (2012). At the time of the compiling, the global data base was complete for 305 impact craters with diameters down to $3 \mathrm{~km}$. Thus, our counts included those craters with 306 diameters $\geq 3 \mathrm{~km}$.

307 Though crater statistics used in geologic investigations often include impact craters with $\geq 2$ $308 \mathrm{~km}$ (e.g., Scott et al., 1986-87), we believe that $\geq 3 \mathrm{~km}$-diameter craters are better for assessing 309 the minimum relative ages of the rock materials. We have greater confidence using larger 310 diameter craters for determining the minimum relative ages of the rock materials due to the 311 major resurfacing reported here for the Argyre province; i.e., part of the crater populations have 312 been destroyed by magmatic-, tectonic-, water-, wind-, gravity- (e.g., colluvial deposition), 313 and/or subsequent impact-driven resurfacing especially at smaller diameters. Results of Irwin et 314 al. (2013) point to major resurfacing and destruction of crater populations on Mars during the 315 Noachian Period, highlighted through stratigraphy and impact crater statistics; this geologic 316 investigation of the Argyre province shows that the Argyre impact event among other activity 317 would have contributed to the resurfacing of extremely ancient terrains, which includes 318 destruction of part of the global crater population. Barlow (1990, 2004, 2005) reported greater 319 confidence using larger impact craters $(>5 \mathrm{~km}$ ) for relative-age dating, also because of the 320 recognized major resurfacing. Here, we have compiled cumulative crater densities for 3-km- 
321 diameter, 5-km-diameter, and 16-km-diameter impact craters (Table 3). Kargel et al. (1995)

322 considered the crater population in southern Argyre Planitia larger than $4 \mathrm{~km}$ diameter to be

323 indicative of the basement rock materials or early massive basin deposits, whereas the crater

324 population between 1.0 and 1.41 (square-root of 2) $\mathrm{km}$ to be indicative of modification (e.g., by

325 glacial and lacustrine processes). Similar to those findings, $2 \mathrm{~km}$-diameter and smaller diameter

326 impact craters have been shown to be useful in analyzing resurfacing ages (Platz and Michael,

327 2011; Platz et al., 2013). In a study related to this geologic investigation, detailed analysis using

328 HiRISE and CTX images of parts of the basin included counts down to 50-meter-diameter

329 craters (El Maarry et al., 2013).

330 The crater statistics consist of total crater populations (including partly buried, degraded,

331 and pristine impact craters), which may indicate minimum emplacement ages (since part of the

332 population is destroyed due to resurfacing through time). The crater statistics also include

333 pristine craters only (i.e., craters and their associated ejecta blankets that have not been visibly

334 resurfaced at resolution, which includes dissection, tectonic deformation, or partial burial by lava

335 flows and fluvial, alluvial, and colluvial deposits), which indicate ages of Hesperian and

336 Amazonian resurfacing depending on the particular map unit and estimated absolute chronology

337 systems (Table 3). A similar approach proved to be useful in unraveling the geologic evolution

338 of the Thaumasia region (Dohm et al., 2001a). In addition, our approach of defining primary

339 depositional and modification ages based on total crater populations and pristine-only crater

340 counts is somewhat similar to that employed by Kargel et al. (1995). Though, here we have

341 much more robust results afforded through the combined comprehensive mapping, GIS-based

342 area calculations of the map units for compiling crater statistics, and usage of THEMIS, CTX,

343 and MOLA data, in addition to Viking data. 
Cumulative size-frequency diagrams (SFDs) were created (Crater Analysis Techniques

345 Working Group, 1979) and isochrons were fitted from both the Hartmann (2005) and Neukum et

346 al. (2001) production functions (Table 3). Estimated absolute ages are based on the Hartmann

347 (2005) and Neukum et al. (2001) chronology systems. These ages were assigned a range of

348 chronostratigraphic epochs based on the boundaries defined in Neukum et al. (2001), Hartmann

349 (2005), and Werner and Tanaka (2011), and compared with that shown in Tanaka et al. (2014)

350 (Table 3). This range of assignments is an attempt to encompass the uncertainty and error

351 inherent in the varied models, conservatively. As with all crater counts, these should be treated as

352 an approximate guide, and the relative differences between each unit are more certain than the

353 actual model ages (for more discussion, see section 4.2 of Robbins et al. (2013)). Also, a part of

354 the crater populations of the ancient terrains (particularly Early Amazonian or older) have been

355 destroyed, and thus the range of chronostratigraphic epochs for a specific unit includes the rock

356 materials with estimated minimum age of emplacement and subsequent modification.

357 Using THEMIS, CTX, and MOLA data, a total of 82 impact craters (Table 4) were either

358 deleted from the total count of a specific geologic unit (if embayed or buried by the geologic-unit

359 materials) or added to older adjacent polygons (if they formed part of the basement of an

360 adjacent unit). For example, an impact crater that forms part of the floor of a glaciated valley but

361 is embayed and partly buried by valley-fill materials was not included in the valley-fill materials;

362 instead, it was compiled with the valley-forming materials. The valley infill deposits would

363 otherwise be errantly given older ages. Such a revision to crater populations of specific unit

364 polygons is unique from existing geologic mapping investigations, as the total number of impact

365 craters are normally tallied for determining the relative age of the rock materials without scrutiny

366 of whether they are associated with underlying materials. 
The geologic information was critical for estimating ages of several of the units. For 368 example, unit HAb4a includes major emplacement of materials within the primary Argyre basin

369 from Late Hesperian activity, with underlying basin materials extending at depth to the basin

370 floor emplaced by earlier post-Argyre-impact activity, including Argyre-impact-related lake

371 formation and subsequent climate/environmental conditions detailed below; i.e., part of the

372 impact population includes exposed parts of the underlying craters and their rims. Coupled with

373 the stratigraphic and cross-cutting relations, identification of the superposed (i.e., pristine and not

374 visibly resurfaced; Table 3) >3-km-diameter impact craters using CTX data clearly indicates that

375 a late stage of major resurfacing occurred during the Late Hesperian and Early Amazonian 376 epochs, corresponding to Stages 4-5 (Late Hesperian-Early Amazonian) Tharsis development 377 (Fig. 4).

379 4. Discussion

380 Here we give a brief overview of pre-Argyre and Argyre impact activity in the Argyre 381 province. We then discuss: (1) the stratigraphic record of the Argyre province; (2) the basin 382 conditions through time since the Argyre impact event, such as ancient surface modification 383 including the timing and origin of the putative eskers located in the southeast part of the basin 384 floor, new evidence for a paleolake within the Argyre basin that sourced Uzboi Vallis, and 385 geologically-recent surface modification; and (3) the extent of Argyre-related tectonism and its 386 influence on the surrounding regions, which includes a geophysical perspective.

\subsection{Overview of pre-Argyre and Argyre impact activity}


The giant Argyre impact event led to major resurfacing of the extremely ancient cratered highlands in the Argyre province, which includes destruction of the remanent magnetic

391 signatures (Acuña et al., 1999, 2001; Connerney et al., 1999, 2001; Arkani-Hamed, 2003, 2004;

392 Roberts et al., 2009; Roberts and Arkani-Hamed, 2012). Pre-Argyre deformation and uplift of

393 the extremely ancient crustal materials included the formation of extremely ancient mountain

394 ranges (e.g., the Thaumasia highlands and Coprates rise; Figs. 1-2), marking a dynamic ancient

395 phase (i.e., during an active dynamo (Baker et al., 2007; Dohm et al., 2013; Ruiz, 2014)) of

396 Mars. This includes major crustal contraction and shortening exemplified by thrust faults

397 (Schultz and Tanaka, 1994; Dohm et al., 2001a, 2002a; Nahm and Schultz, 2011) and other

398 prominent features (Dohm and Maruyama, 2014a; Dohm et al., 2014a,b).

399 The Argyre impact resulted in the formation of the primary Argyre basin, rim materials, 400 deep-seated basement structures including faults, and structurally-controlled valleys and basins 401 which have routed subsurface and surface water and rock materials. In addition, the impact event 402 appears to have deformed the Thaumasia highlands mountain range and the southeast part of the 403 Thaumasia plateau, as their southeast margins parallel the shape of the basin and outer ring 404 structures (Dohm et al., 2001a) (Figs. 1-2). The Thaumasia highlands comprise distinct remanent 405 magnetic signatures, large tectonic structures, and a relatively high density of impact craters 406 distinct from the younger Tharsis lavas to the north-northwest and Argyre impact basins and 407 mesas to the south-southeast.

\subsection{Overview of the stratigraphic record}

410 The oldest units of Early-Middle Noachian age consist of ancient, heavily cratered rock 411 materials that form plateaus, hills, rugged mountains such as of the Thaumasia highlands 
412 mountain range which extend west to east for nearly $2,400 \mathrm{~km}$, approximately the length of the

413 Himalayas, prominent ridges, and highly degraded crater rims (unit Nh1; see Tables 1-3 and Fig.

4143 for this and other units) away from the Argyre basin and rim. A relatively small part of the

415 Thaumasia highlands, located in the northwest part of the map region, is composed of mountain-

416 range-forming materials, which have been highly modified by water-, wind-, gravity- magmatic-,

417 and tectonic-driven activity and impact cratering. These materials have been mapped as unit

418 HNTh, and interpreted as highly resurfaced basement complex, among other materials associated

419 with the formation of an orogenic complex (Table 2).

420 This varied landscape was likely blanketed by ejecta from the Argyre impact event, at least

421 within the Argyre province. Complex modification of these ancient rock materials due to

422 cratering, tectonic deformation, erosional processes, and volcanic and sedimentary burial has

423 degraded or destroyed many of the older morphologic features. This includes a substantial

424 proportion of the superposing crater populations, which makes it difficult to constrain the onset

425 of unit formation (see Section 3.2). Thus, in many cases, morphologic features and rocky mantles

426 postdating the rock-unit materials characterize the surfaces of these ancient units.

427 The giant Argyre impact event created distinct rim materials, mapped as units NAr, NArb,

428 NAbr, and NArsp, likely excavated from deep within the mantle, and/or including primordial

429 lower crustal materials transferred at and near the Martian surface by the impact event and 430 associated overturn and inversion of stratigraphy. Subsequently they were sculpted by liquid 431 water, water-ice, wind, and mass wasting. The impact also formed a primary basin, which served 432 as a catchment of rock materials and water since the event. Source regions of the materials and 433 water include the nearby rim materials to at least as far away as Tharsis to the northwest and the 434 South Pole to the south. 
There are several indications of a high-standing lake that fed the Uzboi system, supportive

436 of the original hypothesis presented through the multiple Parker et al. (Parker, 1985, 1989, 1994;

437 Parker and Gorsline, 1991, 1992, 1993; Parker et al., 2000). Distinct from this original

438 hypothesis, which includes the system having formed at a time when there reportedly was

439 change from a warm/wet climate to a drier climate that allowed surface water (channels and

440 lakes) during the Late Noachian (see Parker, 1996), this geologic investigation points to the

441 Argyre lake-Uzboi system having formed much earlier due to the giant Argyre impact event and

442 the associated regional melting of ice (water inundation in the Argyre province maps out at least

443 within the dark blue regions shown in Fig. 1). The indications include impact-crater retention

444 ages of the high-standing materials in the primary basin identified, mapped, and interpreted to be

445 the oldest basin-filling materials emplaced through major hydrological and environmental

446 change directly associated with the giant impact event, which includes lake formation (i.e.,

447 member 1 of the Argyre basin infill materials designated as unit NAb1; Fig. 3 and Tables 1-3).

448 Also, there are spatial associations (including stratigraphic and elevation) among the source

449 region of Uzboi Vallis, terraces, benches, a possible spillway of a local basin shown in Figs. 7

450 and 8, and the mean elevation of unit NAb1 (Fig. 5), all of which near an elevation of $0 \mathrm{~km}$ (as a

451 potential equipotential surface (compare Figs. 5-9)). The close timing of the Argyre impact event

452 and lake formation is corroborated by similar crater retention ages amongst the Argyre-rim

453 materials (e.g., units NAbr and NArb) and the older, higher-standing unit Nab1 materials. An

454 older retention age of the latter (see Table 3) could be explained by the rim-forming materials

455 having undergone greater erosion due to their greater relief. An extensive impact-associated lake

456 could have existed well above $0 \mathrm{~km}$, nearing an elevation of $1.5 \mathrm{~km}$. This is particularly evident

457 when using GIS to visualize the potential water extent beyond the primary Argyre basin, which 
458 includes mapped elongated basins with valley networks along their margins and dendritic valleys

459 (Fig. 9), further detailed in Section 4.3.2.

460 In addition to the primary basin resulting from the Argyre impact event, local structurally461 controlled basins also formed among rim materials and adjacent to the primary basin and its rim, 462 as well as served as catchments for liquid water, water-ice, and sediments. For example, 463 drainages, which include valley networks, mark the margins of and debouch into many of the 464 local basins indicating that many contain sedimentary, lacustrine, and evaporite deposits, mapped 465 as units NHb and NArsp (e.g., Figs. 3, 7-8; See also Section 4.3). Hydrothermal deposits related 466 to the Argyre impact event, eolian deposits sourcing from nearby (rim materials) and distant 467 provenances (e.g., Tharsis), and lower crustal materials and/or upper mantle materials also likely 468 contribute to the rim materials and basin infill deposits of the basins structurally controlled by 469 the Argyre impact. Consistent with this is the CRISM-based identification of olivine, prehnite, 470 chlorite, low-calcium pyroxene, high-calcium pyroxene, and phyllosilicates such as iron471 magnesium smectite among some of the local basins and rim materials, as well as parts of the 472 primary basin margin (Figs. 10-11; also see Poulet et al., 2007; Buczkowski et al., 2008a,b, 473 2010; Lane and Goodrich, 2010; Ody et al., 2012). In addition, phyllosilicates are relatively 474 common in the cratered highlands as observed by both Omega instrument onboard the Mars 475 Express spacecraft (e.g., Bibring et al., 2004, 2005; Poulet et al., 2005, 2007) and CRISM 476 instrument onboard the Mars Reconnaissance Orbiter (Murchie et al., 2007, 2009a,b; Mustard et 477 al., 2008), and in particular, exemplified in structurally-controlled basins such as in Terra 478 Sirenum (e.g., Davila et al., 2011) and those Argyre-impact-induced in the Argyre province (e.g., 479 Buczkowski et al., 2008b). 
Following the Argyre impact event, climatic perturbations away from the prevailing cold and dry conditions (Fairén et al., 2003; Baker et al., 2007; Hynek et al., 2010; Rossi et al., 2011), 482 related to the major stages of growth of the Tharsis superplume such as exemplified by the 483 opening of Valles Marineris, major activity at Syria Planum, and the uplift of Thaumasia plateau 484 and associated circum-Chryse and putative northwestern slope valleys development (Stages 1-3 485 of Tharsis evolution as shown in Fig. 4), resulted in transient hydrological cycling and related 486 dynamic landscape modification of the Argyre province. This included major etching of the rim 487 materials, units NAr, NArb, NAbr, NArsp, as well as resurfacing of the cratered highlands away 488 from the Argyre rim materials, such as the rock materials of unit Nh1 which includes extremely 489 ancient crustal materials which were blanketed by extensive Argyre impact ejecta in the Argyre 490 province. Resurfacing of the ancient cratered highland materials included erosion and the 491 emplacement of deposits on the Argyre-impact-controlled landscape well into the Hesperian 492 Period, contributing to units Nh1-Nh3, HNh4, Nhb, HNTh, AHTp. Both endogenic and exogenic 493 activity contributed to the resurfacing of the terrains within and marginal to the Agyre basin and 494 rim materials, including precipitation and the growth of glaciers and the formation of gullies 495 within impact craters, even into the very Late Amazonian epoch (El Maarry et al., 2013; Soare et 496 al., 2014a,b).

497 Associated with the major resurfacing described above are Argyre basin infill deposits (units $498 \mathrm{NAb} 2, \mathrm{NAb} 3, \mathrm{NAb} 4 \mathrm{~b}$, and HAb4a) which overly unit NAb1 materials, as the Argyre basin has 499 served as a large repository of the eroded Argyre rim materials and cratered highland materials 500 away from the rim materials following the Argyre impact event. The spiked hydrologic activity 501 related to Tharsis activity resulted in the migration of groundwater and surface water and the 502 eventual formation of ice-covered lakes which would wane in volume and transition into frozen 
503 ice bodies, as well as the growth of glaciers, but to a lesser extent than the former impact-

504 induced lake. Pronounced growth of Argyre's neighboring prominent Martian feature, Tharsis

505 superplume, during the Middle Noachian to Early Hesperian, had accompanying flooding, ocean

506 formation, hydrological cycling, and dissection of the Martian landscape which included the

507 rugged rim materials. This Tharsis-driven resurfacing shed materials into the basin distinctly

508 recorded in units Nab2, Nab3, and Nab4b (see Table 2 for details, including descriptions and 509 interpretations).

510 Near the upper left corner of the geologic map shown in Fig. 3, at an apparent break

511 between the Thaumasia highlands and the Coprates rise mountain ranges near the southeastern

512 margin of the Thaumasia plateau, networking troughs source from a rift system. The troughs

513 appear to dissect friable materials interpreted to be ignimbrites (unit HNplt of Dohm et al., 514 2001a-see Fig. 9a), mapped and identified here as unit AHtp of the Thaumasia plateau. Such 515 geologic and hydrologic activity (including fluvial, alluvial, colluvial, and glacial), which 516 includes the formation of the troughs, resulted in a transferal of water and rock materials from 517 the Thaumasia highlands and Coprates rise mountain ranges and the Thaumasia plateau to the 518 transition zone at lower elevations (Figs. 1-2). The emplacement of the materials along the break 519 in slope is evident by partial burial of wrinkle ridges, with only ridge crest exposed in places.

520 Major Tharsis activity during the Late Hesperian (Stage 4) included major outgassing 521 associated with the development of the Tharsis Montes shield volcanoes, Olympus Mons, and 522 Alba Mons, as well as rapid emplacement of circum-Chryse floodwaters and sediments to form 523 an ocean inset within the extent of the previous larger ocean and associated hydrological cycling 524 (Baker et al., 1991; Fairén et al., 2003). This would have driven environmental change in the 525 giant catchment basin, resulting in the emplacement of fluvial, lacustrine, and glacial deposits on 
526 the basin floor, mapped and defined as unit HAb4a. Unit HAb4a records the final major

527 sedimentary sequence in the Argyre basin, with the deeper floor deposits underlying this unit

528 likely to be related to the initial Argyre-impact-related lake (unit Nab1) and Stages 1-3

529 (Noachian-Early Hesperian) of Tharsis development (Fig. 4), correlating in age with units Nab2,

$530 \mathrm{NAb3}$, and NAb4b (unit NAb4b occurs along a part of the northern and northeastern margins of

531 the central basin floor materials, being distinctly embayed by unit HAb4a). This final sequence

532 included flooding and emplacement of sediments and burial of volatiles and eventual release to

533 form vent structures. For example, related to this geologic investigation, Argyre Mons is a newly

534 identified feature interpreted to have formed from subterranean gas releases (e.g., mud

535 volcanoes), magmatic-driven activity, or an impact event, with gas release being the favored

536 hypothesis (Fig. 12; Williams et al., 2014). Numerous and widespread vent structures in the

537 northern plains, interpreted to be mud volcanoes, are likely the result of rapid emplacement of

538 circum-Chryse floodwaters and sediments and associated ocean formation (Skinner and Tanaka,

539 2007; Skinner and Mazzini, 2009; Oehler and Allen, 2010; Komatsu et al., 2011, 2012), related

540 to Stage-4 Tharsis-driven activity.

541 The emplacement of unit HAb4a is coincident with the development of equatorial glacial

542 landscapes in the Aeolis Mensae region (Davila et al., 2013) and possibly along parts of Mount

543 Sharp (Fairén et al., 2014), all of which could be tied to Stage-4, Tharsis-driven environmental

544 change (Fig. 4). Magmatism and associated flooding sourcing from the Tharsis superplume, with

545 floodwaters more acidic and briny at the source of the superplume-driving heat engine, included

546 ponding of sediment-laden floodwaters in the northern plains (Dohm et al., 2009b). We

547 hypothesize here that the Tharsis-induced transient hydrological cycling included precipitation

548 over the promontories of Tharsis and away from Tharsis such as at the south pole and Argyre 
549 with the concentration of more neutral water; i.e., the initial water outbursts were more acidic 550 due to its magmatic source resulting in magma-water-related deposits such as sulfates vs. latter 551 phases of the magmatic-induced transient hydrological cycle such as snowfall and related ice 552 sheet, glacial, and ground ice accumulations. Such relatively cold hydrological cycling beyond 553 the Tharsis Superplume may have contributed to the growth of glaciers in Gale Crater and 554 elsewhere (Davila et al., 2013; Fairén et al., 2014)

555 In addition to late-stage Tharsis superplume activity, but to a lesser extent, the growth of 556 Elysium superplume (e.g., Baker et al., 2007) and changes in obliquity and eccentricity (e.g., 557 Touma and Wisdom, 1993; Laskar et al., 2004), may have also contributed to the youngest 558 mapped basin unit (member HAb4a), as well as resurfacing of most of the surfaces within and 559 outside of the Argyre basin. This includes the partial infill of topographic lows of the modified 560 highlands terrain largely through sedimentary processes, as well as rock materials being shed 561 from the Thaumasia highlands into the transition zone (Figs. 1-2). Corroborating this, the 562 superposed-only crater statistics point to final major resurfacing during the Late Hesperian/Early 563 Amazonian for most of the geologic units (i.e., that which could destroy crater populations 564 exceeding $3 \mathrm{~km}$; Table 3).

565 Basin-forming events are not limited to the Early-Middle Noachian, as there were impact 566 events such as the formation of Lowell Crater (Late Hesperian and possibly much more recent) 567 that post-dated the Argyre basin-forming one; this would have resulted in local to regional 568 deformation and flooding (Lias et al., 1997). Another example includes Galle Crater. Not only 569 does it deform the southeast part of the Argyre basin, but also appears to have contributed to the 570 formation of valleys that debouch into the southeast part of the basin (south of the impact crater; 
571 see the features mapped as troughs in Fig. 3 located along the southern margin of the central part

572 of the ejecta blanket of Galle) and disrupted floor deposits.

573 The volatile enrichment of the Argyre basin and its associated structures and rock materials,

574 resulting from the climatic perturbations and environmental changes discussed above, largely

575 shielded from atmospheric conditions by dry mantles similar to ancient glacial ice in Antarctica,

576 would play a significant role in shaping a dynamic landscape in geologically recent time, and

577 possibly presently. Relatively recent atmospheric precipitation is likely to have played a role in

578 the modification of the regional landscape, including the flow of materials from high reaches

579 towards the basin floor pronounced in the basin materials (El Maarry et al., 2013). Such

580 evidence, possibly indicative of glacial, colluvial, and/or alluvial activities, corroborates earlier

581 investigations that indicated widespread glacial activity in Martian history, some of it

582 comparatively recent, perhaps as late as the Middle or even Late Amazonian (Kargel et al., 1995;

583 Head et al., 2003; Kargel, 2004; Madelaine et al., 2009).

584 Periglacial activity, climate-controlled and influenced by such long-term (i.e., since the

585 Argyre impact event), water-enrichment in the basin and surroundings, has been and continues to

586 be a major resurfacing agent (El Maarry et al., 2013; Soare et al., 2014a,b). The primary basin,

587 local basins, and structurally-controlled valleys may contain Antarctic-like paleosols that record

588 far-reaching environmental information dating back billions of years (Mahaney et al., 2001,

$5892009,2011)$. In addition, internal heat and volatiles migrating along basement structures may

590 contribute to geologically recent and even possibly present-day modification of parts of the

591 basin, expressed in the form of fault and fracture systems, gullies, and open-system-pingo-like

592 structures (Soare et al., 2014b). Characteristics of multiple Argyre gullies are consistent with an

593 origin involving liquid water (Conway and Soare, 2013), which could involve brines, a 
594 hypothesis consistent with features elsewhere on Mars interpreted to involve brines such as dark

595 slope streaks (Ferris et al., 2002; Miyamoto et al., 2004) and slope linea (McEwen et al., 2013).

596 The impact-influenced dynamic landscape during ancient and geologically recent times is further

597 discussed in Section 4.3.

\subsection{Basin conditions from impact to today}

Ancient (Argyre impact and post-impact) and geologically recent activity induced by 601 magmatic-, orbital-, impact-, weathering-, and climatic-driven phenomena (some of which are 602 often interlinked) are recorded in the fluvial-, lacustrine-, glacial-, and periglacial-sculpted

603 terrains of the Argyre province. For example, there is a wide array of landforms suggestive of a 604 dynamic landscape modified by wind, liquid water,- water ice, and gravity-driven processes. 605 This includes dune deposits in topographic lows, valleys that dissect the Argyre basin rim 606 materials and the margins of local basins, alluvial fans, valley-filling deposits with flow features, 607 crevasse-like fractures, tarns, cirques, megaflutes, drumlins, eskers, gullies, and terraces, and 608 small-scale polygonal-patterned ground comprising high and low-centered polygons (e.g., 609 Hiesinger and Head 2002; Kargel, 2004; Banks et al., 2008, 2009; Soare et al., 2014a,b). The 610 polygons mark relatively young and possibly ice-rich mantled terrain that is extant in wide611 ranging and pristine in some instances and truncated and/or dissected in others (see discussion in 612 Section 4.3.3).

613 During ancient times (Noachian-Early Amazonian: > $1.23 \mathrm{Ga}$ based on the model of 614 Hartmann and Neukum (2001)), hydrological cycling due to major geologic activity outside of 615 the Argyre province, following the Argyre-basin-filling lake (Argyre-impact induced, as further 616 discussed below), exchanged water from both the atmosphere and groundwater. This is 
617 exemplified by sharp, transient climatic changes triggered by igneous activity of the Tharsis

618 superplume (Baker et al. 1991, 2000, 2002; Dohm et al., 2000, 2007a, 2009b; Fairén et al., 2003;

619 Kargel 2004) (Fig. 4). This water cycling in the Argyre basin could have included south-to-north

620 hydraulic gradients in the groundwater system built up over time by south polar glacial activity

621 (e.g., Head and Pratt, 2001).

622 Other geologic activities outside of the Argyre province, such as the growth of Elysium and 623 impacts events such as Lowell and Galle would have also influenced hydrological and 624 environmental conditions in the deep Argyre impact basin. Lowell crater, a relatively pristine, 625 double-ring impact crater, located to the west of the Argyre basin, is interpreted to have formed 626 during the Late Hesperian-Early Amazonian. This crater in particular may have contributed to 627 environmental change in and surrounding Argyre basin following its formation. The diameters of 628 the outer and inner rings are about $195 \mathrm{~km}$ and $85 \mathrm{~km}$, respectively, comparable to the 180-km629 diameter Chicxulub crater, which is associated with profound global-scale environmental 630 changes that most likely contributed to the demise of the dinosaurs at the boundary of the 631 Cretaceous and Tertiary Periods (Alvarez et al., 1980). The Lowell impact triggered a series of 632 events: (1) formation of secondary craters on surrounding rock outcrops in the Lowell and 633 Thaumasia regions as much as $800 \mathrm{~km}$ from the rim of the impact crater, (2) production of 634 meltwater and associated channel dissection of rock outcrops to the northeast and southwest, 635 indicating ice-enriched target materials, and (3) a massive debris flow, which embayed and 636 partly buried structures to the southeast (Lias et al., 1997).

637 Depending on climatic conditions and the nature of the cycling processes, whether 638 endogenic or exogenic, the cycling may have involved groundwater discharges into an ice639 covered lake, spring-fed activity, catastrophic outburst floods, ponding to form lakes in the 
640 primary basins that would eventually freeze, gelifluction of rock materials, debris flow and

641 alluvial fan development, and glacier accumulation and inflow into the basin. The water

642 reservoirs would eventually ablate and be mantled and shielded from atmospheric conditions.

643 During geologically recent times, the atmospheric cycling of water through late-stage

644 volcanism, such as from the Tharsis/Elysium corridor region (Dohm et al., 2008 and the

645 references therein), may have contributed to environmental changes in the Argyre basin and 646 surrounding regions as well, especially when considering the physiographic setting of the deep

647 Argyre basin and the adjacent Tharsis. In addition, variations in orbital and spin parameters

648 within the last tens of millions of years, and associated hydrological cycling, may be responsible

649 for the development of glacial deposits down to the mid latitudes (Head et al., 2003), and

650 potentially would have had a bearing on changing environmental conditions of the Argyre basin 651 and surrounding regions.

652 Orbital and spin parameters have been invoked by numerous authors to explain various sets 653 of features on the surface of Mars. These include the presence of debris aprons and potential 654 dust-covered glaciers at the mid-latitudes, latitude-dependent mantling, and aureole deposits 655 associated with Olympus Mons and other volcanoes in the Tharsis region, as well as very recent 656 (i.e., within thousands of years) landscape changes putatively ascribed to periglacial processes 657 and freeze-thaw cycling (e.g., Costard et al., 2002; Banks et al., 2008, 2009; Fastook et al., 2008; 658 Raack et al., 2012). The first comprehensive solutions for the variation in obliquity and 659 eccentricity for Mars were presented by Laskar et al. (2004) and remain the most accurate 660 solutions for the last $\sim 20$ million years.

661 Periods of high obliquity (> 30 degrees) are usually invoked in order to trigger the 662 sublimation of ice deposits at the poles into the atmosphere and their deposition at the mid- 
663 latitudes (e.g., Laskar et al., 2004). Such periods of high obliquity would have affected

664 environmental conditions in the Argyre basin including possibly allowing the melting of ice-rich

665 materials (i.e., interstitial ice in the pore space of sediments, lenses of ground ice, and mantled

666 covered glaciers and ice) (Kargel, 2004). Contributions in geologically recent times from

667 precipitation, and possibly present-day fog (Neumann et al., 2003) and snow, all may have

668 contributed to surface modification, including periglacial activity, as well as life if existing. The

669 above conditions make the Argyre province a prime astrobiologic target on Mars, but due to its

670 vastness, new mission designs will likely be required to optimize the search for life (Fink et al.,

671 2005, 2007a,b, 2008; Schulze-Makuch et al., 2012).

\section{4.3.1. Ancient surface modification}

674 On Earth, large and often structurally-controlled basins act as catchments for volatiles and

675 sediments. They record geologic and hydrologic activity including environmental changes and

676 perturbations in climate at local and global scales. Basement structures, including faults,

677 fractures, and joints, often serve as conduits for the movement of volatiles in both the subsurface

678 and surface environments. Even in arid deserts on Earth water can be routed along basement

679 structures at depth, as occurs in the Atacama Desert; here, water runoff from the Andes is

680 channeled to the Pacific Ocean along deep-seated basement structures in which microbial life

681 may thrive (Dohm et al., 2011b).

682 In the case of the Argyre impact event that resulted in a complex of basement faults, 683 fractures, and joints, including deep-seated and shallow faults concentric and radial about the 684 basin, the structural control of volatile migration likely played a significant role in the 685 hydrogeologic history of the Argyre province. This includes the formation of the hypothesized 
686 Argyre impact-induced lake and linked Uzboi Vallis, as well as subsequent hydrogeologic 687 activity such as related to major pulses of Tharsis-driven activity (Fig. 4). Groundwater models 688 by Harrison and Grimm (2009) corroborate structurally-controlled migration of groundwater into 689 the Argyre basin highlighted by this geologic investigation.

690 If the basin filled during a glacial climate period, ice accumulation and glacial inflow into an 691 ice-covered lake or sea may have taken place (Kargel and Strom 1992, Kargel 2004). The ice 692 cover may have acted to dam the Uzboi outlet, but periodic disruptions of the dam may have 693 generated megafloods, which helped to carve Uzboi Vallis and could have contributed to 694 environmental and marine depositional changes in the northern plains (Parker and Gorsline, 695 1991; Dohm et al., 2011a).

696 The influence of the Argyre impact extends well beyond the basin, rim, and adjoining 697 cratered plateau regions. For example, impact-influenced terrain and regional drainage is 698 observed along the southeastern margin of the Thaumasia plateau and the transitional zone that 699 separates the Thaumasia plateau from the Argyre basin and rim regions (Dohm et al., 2001a). 700 Also, major drainages originate on plateaus $1600 \mathrm{~km}$ to the south (to Dorsa Argentea's system of 701 sinuous ridges; Kargel and Strom (1990, 1992)), over $700 \mathrm{~km}$ to the southeast, and $900 \mathrm{~km}$ east 702 of Argyre; these ancient valley systems incise the Charitum Montes and terminated near the 703 margin of the primary basin near sinuous ridges in the southern Argyre Planitia.

704 Deposits, which partly infill the impact-derived structurally-controlled primary and 705 secondary basins and modified valleys, record surface modification in the Argyre province 706 resulting from major changes in environmental and hydrological conditions detailed above. 707 These include the initial Argyre impact event and associated lake formation followed by 708 endogenic activity largely related to major stages of growth of the Tharsis superplume (Fig. 4), 
709 with lesser activity such as related to other volcanic provinces such as Elysium, the

710 Tharsis/Elysium corridor, impact events such as Lowell and Galle, and changes in obliquity and

711 eccentricity. Possible lake formation in the immediate aftermath of the Argyre impact event may

712 have been followed by progressive deep freezing of the lake as hydrothermal activity decreased

713 over time, as radiogenic heat flow then also declined, and sublimation of ice gradually thinned

714 the frozen lake until the cold climate froze it completely to its base. Climatic oscillations may

715 have caused debris-covered glaciers to wax and wane episodically and gradually erode the rim

716 mountains and transfer sediment deeper into the basin.

717 Detailed topographic analysis of the sinuous ridges located in the southern Argyre basin was

718 completed for three of the main ridges of the southeast part of the Argyre basin (Fig. 3): Cleia

719 Dorsum, Pasithea Dorsum, and Charis Dorsum (Banks et al. 2009). Results of this analysis

720 indicated that the Argyre sinuous ridges cross topography and that the ridges tend to have

721 sharper crested shapes and increasing ridge heights on descending slopes, and low, broad, and

722 more rounded shapes and decreasing ridge heights on ascending slopes (see Fig. 5 of Banks et al.

723 (2009) for location within basin and profiles). These results indicated that the Argyre sinuous

724 ridges may have been formed by a pressurized flow as opposed to an open air, gravity-driven

725 flow such as in an open river channel (Banks et al., 2009). The characteristics of the southern

726 Argyre sinuous ridges are therefore consistent with those of terrestrial eskers and are related to

727 flow processes associated with meltwater flowing in tunnels beneath or within a large ice deposit

728 (Shreve, 1985). Terrestrial eskers commonly climb and cross topographic divides because water

729 flowing within or beneath a large ice mass is under hydraulic pressure. In descending ice tunnels,

730 viscous heat produced by flow of meltwater causes melting of the tunnel walls increasing the

731 height of the tunnel and the resulting, sharper esker ridge. Meltwater flowing in ascending 
732 tunnels has less viscous energy resulting in freezing of water onto the walls and particularly the

733 top of the tunnel and, consequently, the formation of shorter, broader, and more rounded ridge

734 heights (Shreve, 1985). Conversely, the ascending and descending undulations of the sinuous

735 ridges appear to be inconsistent with the shoreline origins hypothesized by Parker (1994) and

736 Parker and Gorsline (1992). However, some local ponding of water may have contributed to the

737 layering observed in terrain surrounding many of these ridges (Kargel and Strom 1992; Kargel,

738 2004; Banks et al. 2009). Altogether, these observations support the hypothesis that the Argyre

739 sinuous ridges are eskers that formed from meltwater flowing at times in tunnels beneath a large

740 ice deposit and at times in open channels within the ice deposit in the southern Argyre basin

741 (Kargel and Strom, 1992; Hiesinger and Head 2002; Kargel, 2004; Banks et al. 2009).

742 Mapping efforts of this geologic investigation indicate that the esker-like narrow ridges

743 would have been associated with the late-stage emplacement of basin sediments mapped as unit

744 HAb4a, which is interpreted to be related to Stage-4 Tharsis (Late Hesperian-Early Amazonian)

745 development (Fig. 4), or the last major stratigraphic sequence of the basin infill deposits (NAb1,

746 Nab2, Nab3, NAb4b, HAb4a) discussed above.

748 4.3.2. New evidence for a lake within the Argyre basin that sourced Uzboi Vallis

749 Did a large Argyre lake source the Uzboi Vallis drainage system during the Noachian

750 Period, as hypothesized during a Viking-era investigation (Parker and Gorsline, 1991)? This very

751 important question, being a main focus of this geologic investigation, is addressed through

752 comparative analysis among the stratigraphic, geomorphologic, structural, and MOLA

753 topographic information. For example, spatial and temporal relations amidst the possible

754 equipotential surface of the Uzboi spillway (Fig. 8) can be readily compared to features around 
755 the basin. These features include high-standing unit NAb1 materials, which are mapped as the

756 oldest valley- and basin-filling materials (member 1 of the Argyre basin sequence; Tables 1-3,

757 Figs. 3, 5, and 6), terraces and benches (Fig. 7-8), and valleys incised into existing valleys at

758 certain elevations (Figs. 3 and 6). There is a direct correlation between these feature types,

759 indicating that the base level of a water body played a significant role in resurfacing the basin.

760 The base level hovers around the zero-elevation level (Fig. 5) due to a likely change in a 761 fluctuating hydraulic head following the formation of the Argyre lake, as well as extensive

762 resurfacing (i.e., both erosional and depositional processes) since the lake formed directly 763 following the impact event $(\sim 3.93 \mathrm{Ga})$, and isostatic adjustment since the impact event 764 interpreted based on stratigraphy and impact crater statistics.

765 A possible key piece of evidence that the base level of the putative Argyre lake may have 766 reached the height of the spillway of Uzboi Vallis (including the surface of the lake and 767 associated groundwater system) is a recently identified lake basin located on the western margin 768 of the Argyre impact basin (Figs. 1, 7-8); this is referred to as the Argyre western-margin769 paleolake basin (AWMP; Dohm et al., 2011a). A paleolake is inferred by the series of distinct 770 drainage systems that debouch into the basin (Fig. 7). Drainage systems terminate near a possible 771 bench that occurs at a topographic interval ranging from 1 to $1.5 \mathrm{~km}$, an elevation range which 772 corresponds with a possible spillway that separates the paleolake basin from the Argyre basin 773 (Fig. 8). The spillway divide occurs at an elevation of $\sim 1.5 \mathrm{~km}$. It must be noted that 774 paleotopography may vary significantly from the present-day topography due to factors such as 775 post-impact isostatic adjustment, which includes tectonic uplift or subsidence, and erosion.

776 The paleolake, alternatively, may be independent of the Argyre lake, having formed later in 777 time and with no link to an Argyre-lake-related hydrologic system. But if the water was as high 
778 as $1 \mathrm{~km}$ as shown in Fig. 9, or more, or ranging between $0 \mathrm{~km}$ and $1 \mathrm{~km}$, then a linkage is

779 possible. In addition to the high-standing unit Nab1 materials and terraces and benches in part

780 formed by valleys that dissect these oldest basin infill deposits within existing valleys (Figs. 3

781 and 6), by considering a water column of the lake that would reach the $0 \mathrm{~km}$ contour interval

782 (Figs. 5, 7-9) - a conservative value (nearly the base of AWMP) based on geomorphic and

783 topographic analysis of different parts of the Argyre basin - the extent of the lake would link to

784 distinct dendritic valley systems, broad valley systems, and local basins that occur among the

785 basin rim materials, as well as the Uzboi drainage system (Fig. 9-left). If the hypothesized

786 Argyre lake reached an elevation of $1.0 \mathrm{~km}$, then it would have an estimated volume of 3.1

787 million $\mathrm{km}^{3}$. For comparison, this closely approximates the volume of the Mediterranean Sea,

788 estimated to be 3.75 million $\mathrm{km}^{3}$ (Fig. 9-right; also compare with the dark blue region of Fig.

789 1). Such a relatively high-standing water body makes sense when compared to other topographic

790 basins outside of the Argyre basin, including the basin in the bottom-left part of Fig. 9 (compare

791 left and right scenes with the latter highlighting a lake, marked as SWB, that would infill the

792 basin), which displays drainages along its margin. But where did water come from to form such

793 a large water body? One plausible explanation is that an impact event generated hydrogeologic

794 conditions that would have resulted in the formation of the relatively large water body, such as

795 the melting of surface and subsurface ice, migration of surface and subsurface water from great

796 distances, and impact-induced precipitation.

797 A figure of merit regarding the impact-melting hypothesis can be obtained by considering

798 some basic energy considerations. The estimated volume of water- $3.05 \times 10^{6} \mathrm{~km}^{3}$, would

799 require about $1.0 \times 10^{24} \mathrm{~J}$ of thermal energy to produce the water by melting ice, or a bit more if

800 the ice was initially much colder than the freezing point. For an Argyre impact energy of around 
$8016 \times 10^{25} \mathrm{~J}$ (Williams and Greeley, 1994), only about $1.7 \%$ of the Argyre impactor's kinetic 802 energy is needed to melt ice to make a sea the size of Argyre's. For comparison, Braslau (2012)

803 found that $26 \%$ of a $6 \mathrm{~km} / \mathrm{s}$ bolide impact's kinetic energy was transferred into heating of a 804 granular target. The energy partitioning varies depending on details of the impact and target. 805 Most partitioning relations require $<10 \%$ of the Argyre impact's heat energy going into melting 806 ice in order to generate the Mediterranean Sea-size quantity of liquid water. Thus, from an 807 energy perspective melting the needed amount of melted ice is entirely plausible. Of course it 808 would require the target to be extremely ice-rich, for example, an ice sheet or polar layered 809 deposit or ice-rich permafrost extending kilometers deep. This calculation raises a possibility 810 that Argyre's glacial and lacustrine history may have started immediately upon impact into an icy 811 region. The geomorphology and crater counts further require that renewed glacial and lake 812 processes then continued afterward in much more recent times.

813 This geologic mapping investigation and geomorphic analysis of the Argyre province, 814 therefore, ties the lake that formed shortly following the Argyre impact event with Uzboi Vallis 815 and the northern plains, which includes a possible northern plains ocean, and thus pointing to an 816 extensive hydrological system. The putative existence of a giant lake indicates that Mars was a 817 highly water-enriched planet at the time of the $~ 3.93 \mathrm{Ga}$ Argyre impact event, supported by the 818 stratigraphy and accompanying crater statistics such as the relatively high-standing oldest basin 819 unit (unit Nab1) (Table 3 and Figs. 3 and 6). Thus, we provide strong support for and add new 820 details to the hypothesis of Parker and Gorsline (1991).

821 The source of water of the initial highest-standing lake is hypothesized to be from the 822 Argyre impact event, an event which would have induced major environmental change in the 823 Argyre province and surroundings, including the melting of ice, as well as the formation of a 
824 complex of basement faults, fractures, and joints, including deep-seated and shallow faults

825 concentric and radial about the basin. These structures controlled the migration of water in the 826 subsurface as conduits and surface as structurally-controlled valleys, focusing water migration to 827 the basin from great distances (thousands of kilometers) from the impact site.

\subsubsection{Geologically-recent surface modification}

At HiRISE resolution $(\sim 25-50 \mathrm{~cm} / \mathrm{pixel})$, the terrain in parts of the Argyre province often

831 appears mantled by material that exhibits a high albedo, is relatively smooth (although meter-

832 sized boulders often overlie it), and varies in ground coverage from continuous to dissected to

833 discontinuous. This type of terrain is ubiquitous at the middle to high latitudes in both

834 hemispheres and commonly is referred to as the latitude-dependent mantle (LDM) (i.e., Mustard 835 et al. 2001; Milliken et al. 2003; Morgenstern et al. 2007; Lefort et al. 2009, 2010; Madeleine et 836 al., 2009; Zanetti et al., 2010; Mangold, 2011; Raack et al., 2012; Wilmes et al., 2012). The LDM

837 is hypothesized to be water-ice rich and either comprised uniquely of ice-dust accumulated by 838 air-fall deposition (i.e., Morgenstern et al., 2007; Levy et al., 2009, 2011; Lefort et al. 2009, 839 2010; Madeleine et al., 2009; Zanetti et al., 2010; Wilmes et al., 2012) or of ice-dust and loess 840 that is transformed epigenetically into ground ice (Mustard et al., 2001; Soare at al., 2012b;

841 Skinner et al., 2012). Based on age estimates derived from crater-retention rates, the $L D M$ could 842 have been emplaced during the very Late Amazonian Epoch, in response to changes of obliquity 843 and eccentricity (i.e., Mustard et al. 2001; Milliken et al. 2003; Madeleine et al. 2009; Mangold, 844 2011; Wilmes et al., 2012).

845 Recent water-related modifications (Fig. 13-14) of the landscape putatively comprise three 846 assemblage types: (1) glacial; (2) periglacial; and, (3) crater-wall "wet-debris" flows. The glacial 
847 assemblages comprise landforms whose shape, size, and geological traits, i.e. terminal and

848 recessional lobes, lateral and medial ridges, slope-side location, and esker-like lineations, would

849 be indicative of glaciation were they collectively observed on Earth (i.e. Kargel and Strom, 1990,

850 1992; Baker, 2001; Kargel, 2004; Banks et al., 2008; El Maarry et al., 2013). See Kargel et al.

851 (2014) for a thorough review of glaciation on Earth as viewed from space, with field validations.

852 Possible periglacial landforms include: multi-metre and non-sorted polygons with high

853 and low-centres, formed by thermal-contraction cracking and possibly underlain at the margins

854 by water ice; multi-metre and sorted polygons that are the work of freeze-thaw cycling and

855 cryoturbation; and, decametre-scale mounds whose shape, height, occasional summit-

856 depressions and slope-side location coincide with the traits of open-system pingos on Earth, i.e.

857 perennial (water) ice-cored mounds formed by hydrostatic pressure (Seibert and Kargel, 2001;

858 Kargel, 2004; Soare et al., 2014a-b, 2015; Banks et al., 2008; Raack et al., 2012). Lineaments,

859 which we interpret to be faults and fractures, also are commonly observed at OSP locations (Fig.

860 15). Based on field investigation of pingos on Earth, Soare et al. (2014b) propose that the

861 candidates could be the result of a glacially-driven hydraulic gradient (e.g., Liestöl, 1975), a

862 topographically-driven hydraulic gradient (e.g., Müller, 1959), and a tectonic hydraulic gradient

863 (i.e., regional faults and structural-discontinuities which channel and concentrate groundwater,

864 possibly deeply-seated water, to form a pingo (e.g., Müller, 1959)). The third possibility could

865 indicate flow along deep-seated basement structures associated with the ancient giant impact

866 basin and possibly internal heat flow of Mars vented through the structural conduits.

867 Throughout the region gully-like landforms observed on crater-walls exhibit significant

868 channel sinuousity, braiding and benches or levees. The depositional fans show multiple

869 superpositions (Fig. 14) and often are incised by channels or channel segments (Soare et al., 
870 2014a-b, 2015; Conway et al., 2015). On Earth, these traits would be markers of "wet-debris" 871 flows.

\section{4.4. Impact-induced tectonism and geophysical assessment}

874 The Argyre impact event excavated a broad, deep basin and produced small and large 875 extensional and compressional structures; these include structurally controlled fault scarps, broad 876 ridges, valleys, and mountain ranges within several hundred kilometers of the basin margin 877 which are generally oriented radially and concentric to the basin. Farther away, toward the 878 Thaumasia plateau, more subtle basins and broad rises may in part have resulted from Argyre879 related deformation (also compare with Craddock et al. (1990)). Some 2,000 km away from the 880 basin, the outline of the southeast margin of the Thaumasia plateau is roughly concentric with the 881 Argyre basin, suggesting that the margin could be controlled by the impact-related crustal 882 structure (Figs. 1-2) (e.g., Dohm et al., 2001a; Yin, 2012a).

Structurally-controlled local basins among the rim material and outside of the primary

884 Argyre basin also resulted from the large impact event. These small exterior basins served as 885 local catchments for water and sediments. Isostatic adjustments following the formation of the 886 Argyre basin (Thomas and Masson, 1984; Wichman and Schultz, 1989; Dohm et al., 2001a) 887 include normal faulting possibly related to the reactivation of some of the impact-induced older 888 basement structures. An example is the deformation of a structurally-controlled basin and its 889 sedimentary deposits (Fig. 16).

890 Argyre-induced basement structures have not only controlled major watersheds, but also 891 have influenced the geometric patterns of some subsequent impact craters, i.e. the observed 892 polygonal impact craters (Öhman et al., 2008). The simple polygonality of craters is formed 
893 early in the cratering process and is somewhat similar to the structure-controlled square planview

894 shape of Meteor Crater, Arizona (Shoemaker, 1963; Quaide et al., 1965), whereas the complex

895 craters' polygonal planview forms later in the cratering process (Öhman et al. 2008, and

896 references therein). The Argyre impact-resulting structures are distinct in the MOLA map (Fig.

897 17a) and topographic profile (Fig. 18a), and their general signatures can be observed in the 898 gravity map data as gravity highs and lows (Fig. 17b).

The interior of the Argyre basin, for example, is characterized by a positive free-air gravity anomaly (mascon) with a magnitude $\sim 140 \mathrm{mGal}$ surrounded by an annulus of low gravity at the

901 basin's inner periphery (Figs. 17b and 18b). This is observed for the Isidis basin and commonly 902 observed for lunar impact basins (Muller and Sjogren, 1968; Konopliv et al., 2001; Matsumoto et 903 al., 2010). Such mascons have been attributed to the super-isostatic uplift of the Moho beneath 904 the basin (Neumann et al., 1996; Wieczorek and Phillips, 1999) and/or the infilling and partial 905 burial of the basins by material, such as flood basalts and sediments, that are at least partially 906 flexurally supported (Solomon and Head, 1980).

907 The floor deposits of the Argyre basin are comprised of sedimentary rocks that, depending 908 on their thickness, porosity, and state of compensation, may contribute to the gravity anomaly if 909 accumulation occurred without complete isostatic compensation. Based on the observed relation 910 between crater depth to diameter for large crater basins (Howenstine and Kiefer, 2005), the inner 911 basin diameter of Argyre, $\sim 915 \mathrm{~km}$, implies an unfilled basin depth of $\sim 6 \mathrm{~km}$. The actual basin 912 depth of $\sim 4 \mathrm{~km}$ suggests $\sim 2 \mathrm{~km}$ of burial if flexure of the basin floor is minimal. Several quasi913 circular features are apparent on the interior floor of Argyre basin and are likely buried impact 914 craters. The largest of these features has a diameter of $\sim 60 \mathrm{~km}$ (Fig. 19). The crater depth to 915 diameter power law fit to craters between 7 and $110 \mathrm{~km}$ in diameter (Garvin et al., 2002) yields a 
916 depth of $\sim 2 \mathrm{~km}$ indicating at least $2 \mathrm{~km}$ of material filling this crater to its rim. Taking $h=2 \mathrm{~km}$

917 as the thickness of deposits in the basin, the magnitude of the resulting gravity anomaly is

918 estimated assuming a simple slab model (Schubert and Turcotte, 2002):

919

$920 \Delta g=2 \pi G \rho h\left[1-C\left(r_{p} /\left(r_{p}+t_{c}\right)\right)^{2}\right]$,

922 where $G$ is the gravitational constant, $\rho$ is the fill density, $h$ is the thickness of deposits in the 923 basin, $\mathrm{r}_{p}$ is the radius of Mars, $\mathrm{t}_{c}$ is the crust thickness assumed to be $50 \mathrm{~km}$, and $C$ is the degree 924 of compensation which is zero for a completely rigid lithosphere and approaches unity for Airy 925 isostasy. The resulting gravity anomaly is shown in Fig. 20. The $\sim 140 \mathrm{mGal}$ mascon within the

926 basin can be explained by post-impact deposition alone if the compensation of the load is no 927 greater than $\sim 45 \%$. A fill density $<1670 \mathrm{~kg} \mathrm{~m}-3$ results in a gravity anomaly $<140 \mathrm{mGal}$ for any 928 compensation state suggesting this is an approximate lower bound on the fill density.

\section{5. Conclusions.}

931 Detailed geologic investigation using Viking and post-Viking data has revealed the 932 evolutional history of the Argyre province. This includes distinct basin units most likely marking

933 a lake that formed as a result of the Argyre impact event, as well as subsequent perturbations in 934 environmental conditions (climate, surface, and subsurface) associated with major stages of 935 Tharsis superplume development among other lesser endogenic-driven activity such as Elysium 936 rise. It has also revealed newly identified lake-containing basins, mapped the extent of Argyre937 related tectonism and the influence of the giant impact on the surrounding regions, corroborated 938 the esker hypothesis, with details on the timing of formation being the Late Hesperian, and 
939 highlighted ancient, geologically-recent, and possibly present-day surface modification.

940 Examples of geologically-recent landforms and possible present-day activity include polygonal-

941 patterned ground, gullies, open-system pingos, and flow-like features of the valley-fill materials,

942 including glacier-like landforms. Possible contributors to the water enrichment and

943 remobilization of water and sediment in Argyre in geologic recent time could include local

944 precipitation related to atmospheric cycling of water vapor such as from the south pole into the

945 deep basin and an intrabasinal water cycle including fog.

946 A hypothesized generalized summary of the geologic evolution of the Argyre province

947 based on this geologic investigation includes: (1) the Argyre impact event and related formation

948 of the Argyre basin, rim materials, ejecta blanket, basement structures (faults and structurally-

949 controlled valleys, basins, and mesas) radial and concentric about the basin, and lake and

950 associated sedimentation (marked by unit Nab1) with connecting Uzboi Vallis, (2) waning and

951 eventually frozen Argyre lake with associated glaciers extending away from the lake, (3)

952 mantling of basin and rim materials including the ice bodies due primarily to wind- and gravity-

953 driven processes, (4) Stages 1-3 Tharsis-driven activity and associated transient hydrological

954 cycling and major environmental change and landscape modification in and surrounding the

955 Argyre basin, including melt and associated flooding and spring activity, gelifluction, and

956 alluvial, colluvial, lacustrine, glacial, and periglacial activity (recorded by units Nab2, Nab3,

957 Nab4b), (5) Stage 4 Tharsis-driven activity and related hydrological cycling and major

958 environmental change and landscape modification, including lake formation and associated

959 sedimentation (marked by unit HAb4a), though much less in extent when compared to the

960 Argyre-impact-related lake that sourced Uzboi Vallis, and subsequent freezing and esker

961 development distinct in the southeast part of the Argyre basin, as well as the development of 
962 glaciers such as those that were directed through Surius Vallis, Dzigai Vallis, and Nia Vallis and

963 that linked to the basin environment, (6) impact events such as Lowell, Galle, and Hale

964 contributed to environment change and surface modification, and (7) ice enrichment of the rock

965 materials of the Argyre province, environmental changes related to changes in orbital parameters

966 (spin axis and orbital eccentricity) and endogenic activity such as in the Tharsis/Elysium corridor

967 region, relatively steep slopes, and Agryre-impact-induced structures as conduits for the

968 transferal of heat and volatiles also has contributed to surface modification in geologic recent

969 times. This history points to Argyre as a prime target for the search for life on Mars.

970

971 Acknowledgements

972 J.M. Dohm was supported by the National Aeronautics and Space Administration (NASA)

973 Planetary Geology \& Geophysics Program. Professors Dohm and Miyamoto express their

974 gratitude to the Tokyo Dome Corporation for their support of the TeNQ exhibit and the branch of

975 Space Exploration Education \& Discovery, the University Museum, the University of Tokyo.

976 We are grateful for the thoughtful reviews by T. Öhman and an anonymous reviewer which

977 ultimately resulted in an improved manuscript.

978

979 
980

981

982

983

984

985

986

987

988

989

990

991

992

993

994

995

996

997

998

999

1000

1001

1002

1003

1004

1005

1006

1007

1008

1009

1010

1011

\section{References}

Abramov, O., Kring, D.A., 2005. Impact-induced hydrothermal activity on early Mars. J. Geophys. Res. 110, E12S09, doi:10.1029/2005JE002453.

Acuña, M.H., Connerney, J.E.P., Ness, N.F., Lin R.P., Mitchell, D., Carlson, C.W., Mcfadden, J., Anderson, K.A., Reme, H., Mazelle, C., Vignes, D., Wasilewski, P., Cloutier, P., 1999. Global distribution of crustal magnetization discovered by the Mars Global Surveyor MAG/ER experiment. Science 284, 790-793.

Acuña, M.H., Connerney, J.E.P., Wasilewski, P., Lin, R.P., Mitchell, D., Anderson, K.A., Carlson, C.W., McFadden, J., Réme, H., Mazelle, C., Vignes, D., Bauer, S.J., Cloutier, P., Ness, N.F., 2001. Magnetic field of Mars: Summary of results from the aero-braking and mapping orbits. J. Geophys. Res. 106, 23,403-23,417.

Alvarez, L.W., Alvarez, W., Asaro, F., Michel, H., 1980. Extraterrestrial cause for the Cretaceous-Tertiary extinction. Science 208, 1095-1108.

Anderson, R.C., Dohm, J.M., Golombek, M.P., Haldemann, A., Franklin, B.J., Tanaka, K., Lias, J., Peer, B., 2001. Significant centers of tectonic activity through time for the western hemisphere of Mars, J. Geophys. Res. 106, 20,563-20,585.

Anguita, F., Farelo, A.,-F., López, V., Mas, C., Muñoz-Espadas, M.-J., Márquez, Á., Ruiz, J., 2001. Tharsis dome, Mars: new evidence for Noachian-Hesperian thick-skin and Amzonian thin-skin tectonics. J. Geophys. Res. 106, 7577-7589.

Archinal, B.A., Colvin, T.R., Davies, M.E., Kirk, R.L., Duxbury, T.C., Lee, E.M., Cook, D., Gitlin, A. R., 2002. A MOLA-controlled RAND-USGS control network for Mars (abs.). Lunar Planet. Sci. XXXIII, Abstract \#1632 (CD-ROM). (PDF: 110k).

Archinal, B.A., Kirk, R.L., Duxbury, T.C., Lee, E.M., Sucharski, R., Cook, D., 2003. Mars Digital Image Model (MDIM) 2.1 control network. ISPRS Working Group IV/9 Workshop "Advances in Planetary Mapping 2003", Houston, March 2003. (PDF: 285k).

Arkani-Hamed, J., 2003. Thermoremanent magnetization of the Martian lithosphere. J. Geophys. Res. 108, 10.1029/2003JE002049.

Arkani-Hamed, J., 2004. Timing of the Martian core dynamo. J. Geophys. Res. 109, doi:10.1029/2003JE002195.

Aubrey, A. et al., 2006. Sulfate minerals and organic compounds on Mars. Geology 34, 357-360, doi:10.1130/g22316.1.

Baker, V.R., 2001. Water and the Martian land-scape. Nature, 412, 228-236. 
1012

1013

1014

1015

1016

1017

1018

1019

1020

1021

1022

1023

1024

1025

1026

1027

1028

1029

1030

1031

1032

1033

1034

1035

1036

1037

1038

1039

1040

1041

1042

1043

1044

1045

Baker, V.R., Strom, R.G., Gulick, V.C., Kargel, J.S., Komatsu, G., Kale, V.S., 1991. Ancient oceans, ice sheets and the hydrological cycle on Mars. Nature 352, 589-594.

Baker, V.R., Strom, R.G., Dohm, J.M., et al., 2000. Mars' Oceanus Borealis, ancient glaciers, and the MEGAOUTFLO hypothesis. Lunar Planet. Sci. Conf. [CD-ROM], XXXI, abstract 1863.

Baker, V.R., Maruyama, S., Dohm, J.M., 2001b. Tharsis superplume (3): Implications on the role of water, environmental change and life. Geol. Soc. America Abstracts with Programs, 33(7), A432.

Baker, V.R., Maruyama, S., Dohm, J.M. 2002. A theory of plate tectonics and subsequent longterm superplume activity on Mars. in International Workshop: Role of superplumes in the Earth System, Electronic Geosciences, 312-316.

Baker, V.R., Maruyama, S., Dohm, J.M., 2007. Tharsis superplume and the geological evolution of early Mars. In Superplumes: beyond plate tectonics. D.A Yuen, S. Maruyama, S-I Karato, and B.F. Windley (eds.). Springer, pgs. 507-523.

Banks, M.E., McEwen, A.S., Kargel, J.S., Baker, V.R., Strom, R.G., Mellon, M.T., Pelletier, J.D., Gulick, V.C., Keszthelyi, L., Herkenhoff, K.E., Jaeger, W L., the HiRISE Team, 2008. High Resolution Imaging Science Experiment (HiRISE) observations of glacial and periglacial morphologies in the circum-Argyre Planitia highlands. J. Geophys. Res. 113, E12015, doi:10.1029/2007JE002994.

Banks, M. E., Lang, N. P., McEwen, A. S., Kargel, J. S., Baker, V. R., Strom, R. G., Grant, J. A., Pelletier, J. D., and the HiRISE Team, 2009. An Analysis of the Sinuous Ridges in the Southern Argyre Planitia, Mars using HiRISE and CTX Images and MOLA Data. J. Geophys. Res. 114, E09003, doi:10.1029/2008JE003244.

Barlow, N.G., 1990. Constraints on early events in Martian history as derived from the cratering record. J. Geophys. Res. 95, 14,191-14,201.

Barlow, N.G., 2004. Martian subsurface volatile concentrations as a function of time: Clues from layered ejecta craters. Geophys. Res. Lett. 31.

Barlow, N.G., 2005. A review of Martian impact crater ejecta structures and their implications for target properties. In: Kenkmann, T., Hörz, F., Deutsch, A. (Eds.), Large Meteorite Impacts III. Geological Society of America Special Paper 384, 433-442.

Bibring, J.-P., Soufflot, A., Berthé, M., Langevin, Y., Gondet, B., Drossart, P., Bouyé, M., Combes, M., Puget, P., Semery, A., Bellucci, G., Formisano, V., Moroz, V., Kottsov, V., Bonello, G., Erard, S., Forni, O., Gendrin, A., Manuad, N., Poulet, F., Poulleau, G., Encrenaz, T., Fouchet, T., Melchiori, R., Altieri, F., Ignatiev, N., Titov, D., Zasova, L., 
1046

1047

1048

1049

1050

1051

1052

1053

1054

1055

1056

1057

1058

1059

1060

1061

1062

1063

1064

1065

1066

1067

1068

1069

1070

1071

1072

1073

1074

1075

1076

1077

1078

1079

1080

Coradini, A., Capacionni, F., Cerroni, P.F., Mangold, N., Penit, P., Schmitt, B., Sotin, C., Hauber, E., Hoffmann, H., Jaumann, R., Keller, U., Arvidson, R., Mustard, J.F., and Forget, F., 2004. OMEGA: Observatiore pour la Minéralogie, l'Eau, les Glaces et l'Activité, in Mars Express: the scientific payload. Edited by A. Wilson, pp. 37-49, ESA, Noordwijk, Netherlands.

Bibring J.-P., Langevin, Y., Gendrin, A., Gondet, B., Poulet, F., Berthé, M., Soufflot, A., Arvidson, R.E., Mangold, N., Mustard, J.F., Drossart, P., the OMEGA team, 2005. Mars surface diversity as revealed by the OMEGA/Mars Express observations. Science 307(5715), 1576-81.

Braslau, D., 2012, Partitioning of energy in hypervelocity impact against loose sand targets, Jour. Geophys. Res. Atmospheres, 75(2): 3987-3999.

Buczkowski, D.L., Murchie, S., Seelos, F., Malaret, E., Hash C., the CRISM science team, 2008a. CRISM analyses of Argyre basin. LPSC XXXIX, abs. 1030, (CD-ROM), Lunar Planet. Inst., Houston, TX.

Buczkowski D.L., Murchie, S., Clark, R., Seelos F., the CRISM Science Team, 2008b. Mineralogic and morphologic signatures of Noachian water in the Argyre impact basin. EOS Trans., AGU Fall Mtg., San Francisco, CA.

Buczkowski, D.L., Murchie, S., Clark, R., Seelos, K., Seelos, F., Malaret, E., Hash, C., 2010. Investigation of an Argyre basin ring structure using Mars Reconnaissance Orbiter/Compact Reconnaissance Imaging Spectrometer for Mars. J. Geophys. Res. 115, E12011, doi:10.1029/2009JE003508.

Christensen, P.R., Jakosky, B.M., Kieffer, H.H., et al., 2004. The Thermal Emission Imaging System (THEMIS) for the Mars 2001 Odyssey mission. Space Science Reviews 110, 85130.

Condit, C.D., 1978. Geologic map of the Mare Australe area of Mars. US Geol. Survey Map Misc. Invest. Ser. Map I-1076, scale 1:5,000,000.

Connerney, J.E.P., Acuña, M.H., Wasilewski, P.J., Kletetschka, G., Ness, N.F., Rème, H., Lin, R.P., and Mitchell, D.L., 1999. The global magnetic field of Mars and implications for crustal evolution. Science 284, 790-793.

Connerney, J.E.P., Acuña, M.H., Wasilewski, P.J., Kletetschka, G., Ness, N.F., Rème, H., Lin, R.P., Mitchell, D.L., 2001. The global magnetic field of Mars and implications for crustal evolution. Geophys. Res. Lett. 28, 4015-4018.

Connerney, J.E.P., et al., 2005. Tectonic implications of Mars crustal magnetism. Science 102, $14970-14975$. 
1081 Conway, S.J., Soare, R.J., 2013. Gully morphometrics as indicators of degradation intensity 1082 around the Argyre basin. LPSC 44th, abstract \#2488.

1083 Conway, S.J., Balme, M.R., Soare, R.J., 2015. Using gullies to estimate the thickness of the 1084 latitude-dependent mantle. Lunar Planet. Sci. Conf. XXXXVI, Houston, Texas. Abstract \# 10852964

1086 Costard, F., Forget, F., Mangold, N., Peulvast, J.P., 2002. Formation of recent Martian debris 1087 flows by melting of near-surface ground ice at high obliquity. Science 295, 5552, 110-113. 1088 doi:10/1126/science.1066698.

1089 Craddock, R.A., Greeley, R., Christensen, P.R., 1990. Evidence of an ancient impact basin in 1090 Daedalia Planum, Mars. J. Geophys. Res. 95, 10,729-10,740.

1091 Crater Analysis Techniques Working Group, 1979. Standard techniques for presentation and 1092 analysis of crater size-frequency data. Icarus 37, 467-474.

1093 Crown, D.A., Price, K.H., Greeley, R., 1992. Geologic evolution of the east rim of the Hellas 1094 basin, Mars. Icarus 100, 1-25.

1095 Davila, A.F., Gross, C., Marzo, G.A., et al., 2011. A large sedimentary basin in the Terra 1096 Sirenum region of the southern highlands of Mars. Icarus 212, 579-589.

1097 Davila, A.F., Fairén, A.G., Stokes, C.R., Platz, T., Rodriguez, A.P., Lacelle, D., Dohm, J., 1098 Pollard, W., 2013. Evidence for Hesperian glaciation along the Martian dichotomy boundary. 1099 Geology 41, 755-758, doi:10.1130/G34201.1.

1100 Dohm, J.M., Tanaka, K.L., 1999. Geology of the Thaumasia region, Mars: plateau development, valley origins, and magmatic evolution. Planet. \& Space Sci. 47, 411-431.

1102

Dohm, J.M., Maruyama, S., 2014a. New evidence for plate tectonism on Mars: accreted terrains. Japan Geoscience Union meeting, April 28-May 2, 2014, PPS02-02, \#418.

Dohm, J.M., Maruyama, S., 2014b. Habitable Trinity. Journal of Geoscience Frontiers, DOI: 10.1016/j.gsf.2014.01.005.

Dohm, J.M., Anderson, R.C., Baker, V.R., et al., 2000. Pulses of magmatic activity through time: potential triggers for climatic variations on Mars. Lunar Planet. Sci. Conf. XXXI, abstract \# 1632 (CD-ROM).

1111 Dohm, J. M., Tanaka, K. L., Hare, T. M., 2001a. Geologic map of the Thaumasia region of Mars. 1112 US Geol. Survey Map I-2650.

1113 Dohm, J.M., Ferris, J.C., Baker, V.R., Anderson, R.C., Hare, T.M., Strom, R.G., Barlow, N.G., 1114 Tanaka, K.L., Klemaszewski, J.E., Scott, D.H., 2001b. Ancient drainage basin of the Tharsis 
region, Mars: Potential source for outflow channel systems and putative oceans or paleolakes. J. Geophys. Res. 106, 32,943-32,958.

1117 Dohm J.M., Maruyama, S., Baker, V.R., 2001c. Mars plate tectonics: surface geology and analyses of topographic and geophysical data. AGU, 82(47), F713.

1119 Dohm, J.M., Maruyama, S., Baker, V.R., et al., 2001d. Earth-like evolution of the Tharsis Magmatic Complex: Traits of a Terrestrial Superplume (2). Geol. Soc. America Abstracts with Programs, 33(7), A309.

Dohm, J.M., Maruyama, S., Baker, V.R., Anderson, R.C., Ferris, J.C., Hare, T.M., 2002a. Plate tectonism on early Mars: Diverse geological and geophysical evidence. Lunar Planet. Sci.

1125 Dohm, J.M., Maruyama, S., Baker, V.R., Anderson, R.C., Ferris, J.C., Hare, T.M., $2002 b$. Evolution and traits of Tharsis superplume, Mars. Superplume International Workshop, Abstracts with Programs, Tokyo, 406-410.

1128 Dohm, J.M., Kerry, K., Keller, J.M., Baker, V.R., Maruyama, S., and Anderson, R.C., Ferris, J.C., Hare, T.M., 2005. Mars geological province designations for the interpretation of GRS data. Lunar Planet. Sci. Conf. XXXVI, \#1567 (abstract) (CD-ROM)

Dohm, J.M., Maruyama, S., Baker, V.R., Anderson, R.C., 2007a. Traits and evolution of the Tharsis superplume, Mars. In Yuen, D.A., Maruyama, S., Karato, S.-I., and Windley, B.F., eds., Superplumes: Beyond plate tectonics: Springer, p. 523-537.

Dohm, J.M., Barlow, N.G., Anderson, R.C., et al., 2007b. Possible ancient giant basin and related water enrichment in the Arabia Terra province, Mars. Icarus 190, 74-92, doi: 10.1016/j.icarus.2007.03.006.

Dohm, J.M., Anderson, R.C., Barlow, N.G., et al., 2008. Recent geological and hydrological activity on Mars: The Tharsis/Elysium Corridor. Planet. Space Sci. 56, 985-1013. influence on the origin of Valles Marineris, Mars. Journal of Volc. Geoth. Res. 185, 12-27, doi:10.1016/j.jvolgeores.2008.11.029.

Dohm, J.M., Baker, V.R., Boynton, W.V., et al., 2009b. GRS evidence and the possibility of ancient oceans on Mars. Planet. Space Sci. 57, 664-684. T.M., Mahaney, W.C., Kim, K.J., Davila, A.F., Fairén, A.G., 2011a. Did a large Argyre lake source the Uzboi Vallis drainage system?: Post-Viking-era geologic mapping investigation. Lunar Planet. Sci. Conf. XXXIII, Abstract \#2255 (CD-ROM). 
1148

1149

1150

1151

1152

1153

1154

1155

1156

1157

1158

1159

1160

1161

1162

1163

1164

1165

1166

1167

1168

1169

1170

1171

1172

1173

1174

1175

1176

1177

1178

1179

1180

1181

Dohm, J.M., Miyamoto, H., Ori, G.G., et al., 2011b. An inventory of potentially habitable environments on Mars: geological and biological perspectives. In Garry, W.B., and Bleacher, J.E., eds., Analogs for Planetary Exploration: Geological Society of America Special Paper 483, 317-347, doi:10.1130/2011.2483(21).

Dohm, J.M., Miyamoto, H., Maruyama, S., et al., 2013. Mars Evolution. In Mars: Evolution, Geology, and Exploration. A.G. Fairén (ed.). Book entitled: "Mars: Evolution, Geology and Exploration", Nova Science Publishers, Inc., pgs. 1-33.

Dohm, J.M., Maruyama, S., Miyamoto, H., Viviano-Beck, C.E., Anderson, R.C., 2014a. Accretionary complexes: recorders on Earth and possibly Mars. 2014 GSA Annual Meeting in Vancouver British Columbia, Paper No. 25-9.

Dohm, J.M., Maruyama, S., Miyamoto, H., Viviano-Beck, C.E., Anderson, R.C., 2014b. Accretionary complexes: recorders on Earth and possibly Mars. 2014 AGU Fall Meeting in San Francisco, Paper No. P33E-07.

El Maarry, M.R., Dohm, J.M., 2013. Regional morphologies of the smooth deposits in the mountainous regions of Argyre, Mars: Results from high resolution mapping. Lunar Planet. Sci. Conf. XXXXIV, \#2806 (abstract) (CD-ROM).

El Maarry, M.R., Dohm, J.M., Michael, G., Thomas, N., Maruyama, S., 2013. Morphology and evolution of the ejecta of Hale crater in Argyre basin, Mars: results from high resolution mapping. Icarus 226, 905-922.

Fairén, A.G., Dohm, J.M., 2004. Age and origin of the lowlands of Mars. Icarus 168, 277-284, doi:10.1016/j.icarus.2003.11.025.

Fairén, A.G., Ruiz, J., Anguita, F., 2002. An origin for the linear magnetic anomalies on Mars through accretion of terranes: implications for dynamo timing. Icarus 160, 220-223, doi:10.1006/icar.2002.6942.

Fairén, A.G., Dohm, J.M., Baker, V.R., de Pablo, M.A., Ruiz, J., Ferris, J.C., Anderson, R.C., 2003. Episodic flood inundations of the northern plains of Mars. Icarus 165, 53-67, doi:10.1016/S0019-1035(03)00144-1.

Fairén, A.G., Stokes, C.R., Davies, N.S., Schulze-Makuch, D., Rodríguez, J.A.P., Davila, Alfonso F., Uceda, Esther R., Dohm, J.M., Baker, V.R., Clifford, S.M., McKay, Christopher P., Squyres, S.W., 2014. A cold hydrological system in Gale Crater, Mars. Planetary and Space Science 93, 101-118.

Fastook, J.L., Head, J.W., Marchant, D., Forget, F., 2008. Tropical mountain glaciers on Mars: Altitude-dependence of ice accumulation, accumulation conditions, formation times, glacier dynamics, and implications for planetary spin-axis/orbital history. Icarus 198, 305-317. 
1182 Feldman, W.C., Boynton, W.V., Tokar, R.L., et al., 2002. Global distribution of neutrons from 1183 Mars: Results from Mars Odyssey. Science 297, 75-78.

1184 Ferris, J.C., Dohm, J.M., Baker, V.R., and Maddock, T. (2002) Dark slope streaks on Mars: Are 1185 aqueous processes involved? Geophysical Research Letters 29, doi:10.1029/2002GL014936.

1186 Fink, W., Dohm, J.M., Tarbell, M.A., Hare, T.M., Baker, V.R., 2005. Next-generation robotic planetary reconnaissance missions: a paradigm shift. Planet. Spa. Sci. 53, 1419-1426.

1188 Fink, W., Dohm, J.M., Tarbell, M.A., Hare, T.M, Baker, V.R, Schulze-Makuch, D., Furfaro, R., Fairén, A.G., Ferre, T.P.A., Miyamoto, H., Komatsu, G., Mahaney, W.C., 2007a. Tierscalable reconnaissance missions for the autonomous exploration of planetary bodies. IEEE Aerospace Conference Proceedings, paper \#1199; DOI: 10.1109/AERO.2007.352715

1192 Fink, W., George, T., Tarbell, M.A., 2007b. Tier-scalable reconnaissance: the challenge of sensor optimization, sensor deployment, sensor fusion, and sensor interoperability. Proc.

1195 Fink W., Tarbell, M.A., Jobling, F.M., 2008. Tier-Scalable Reconnaissance - A Paradigm Shift in Autonomous Remote Planetary Exploration of Mars and Beyond. Chapter 1 in "Planet Mars Research Focus", Ed. L. A. Costas. Nova Science Publishers, Hauppauge, NY. ISBN: 1-60021-826-1.Frey, H.V., Roark, J.H., Shockey, K.M., Frey, E.L., Sakimoto, S.E.H., 2002. Ancient lowlands on Mars. Geophys. Res. Lett., 29, 10.1029/2001GL013832.

1200 Garvin, J.B., Sakimoto, S.E.H., Frawley, J.J., and Schnetzler, C., 2002. Global geometric properties of Martian impact craters. Lunar Planet. Sci. Conf. XXXIII, abstract 1255. Insights into the recent geothermal history based on geological mapping. Planet. Space Sci. 59, 1179-1194, 10.1016/j.pss.2010.09.017.

1207 Harrison, K.P., Grimm, R.E., 2009. Regionally compartmented groundwater flow on Mars. J. 1208 Geophys. Res. 114, doi:10.1029/2008JE003300.

1209 Hartmann, W.K., 2005. Martian cratering 8: isochron refinement and the chronology of Mars. 1210 Icarus 174, 294-320.

1211 Hartmann, W.K., Neukum, G., 2001. Cratering Chronology and the Evolution of Mars. Space 1212 Sci. Rev. 96,165-194. 
1213 Head, J.W., Pratt, S., 2001. Extensive Hesperian-aged south polar ice sheet on Mars: Evidence for massive melting and retreat, and lateral flow and ponding of meltwater. J. Geophys. Res. $106,12,275-12,299$.

Head, J.W., Mustard, J.F., Kreslavsky, M.A., Milliken, R.E., Marchant, D.R., 2003. Recent ice ages on Mars. Nature 426, 797-802.

Hiesinger, H., Head J.W., 2002. Topography and morphology of the Argyre basin, Mars:

Implications for its geologic and hydrologic history. Planet. and Space Sci. 50, 939-981.

1220

Hodges, C.A., 1980. Geological map of the Argyre quadrangle of Mars. U.S. Geol. Sur. Misc.

1222 Howenstine, J.B, Kiefer, W.S., 2005. Morphometry of large Martian impact craters. Lunar $1223 \quad$ Planet. Sci. Conf. XXXVI, abstract 1742.

1224 Hynek, B.M., Beach, M., Hoke, R.T., 2010. Updated global map of Martian valley networks and 1225

Irwin, R.P., III, Tanaka, K.L., Robbins, S.J., 2013. Distribution of Early, Middle, and Late Noachian cratered surfaces in the Martian highlands: Implications for resurfacing events and processes, J. Geophys. Res. Planets, 118, 278-291, doi:10.1002/jgre.20053

1230 Ivanov, B.A., 2001. Mars/Moon cratering rate ratio estimates. Spa. Sci. Rev. 96, 87-104.

Jones, A.P., McEwen, A.S., Tornabene, L.L., Baker, V.R., Melosh, H.J., Berman, D.C., 2011. A geomorphic analysis of Hale crater, Mars: The effects of impact into ice-rich crust. Icarus 211, 259-272.

1234 Kargel, J.S., 2004. Mars: A warmer wetter planet. Praxis-Springer, 557 p.

1235 Kargel, J.S., Strom, R.G., 1990. Ancient glaciation on Mars. Lunar Planet. Sci. 597- 598.

1236 Kargel, J.S., Strom, R.G., 1992. Ancient glaciation on Mars. Geology 20, 3-7.

1237 Kargel, J.S., Baker, V.R., Beget, J.E., Lockwood, J.F., Pewe, T.L., Shaw, J.S., Strom, R.G., 1995. Evidence of ancient continental glaciation in the Martian northern plains. J. Geophys. Res.100, 5351-5368.

1240 Kargel, J.S., Leonard, G.J., Bishop, M.P., Kaab, A., Raup, B. (Eds), 2014. Global Land Ice 1241 Measurements from Space (Springer-Praxis), Heidelberg-e-book and hard-cover print publication, LXXIX, 876 p., 409 illus., 336 illus. in color. With extra online material.

1243 Kasting, J. F., Whitmire, D. P., Reynolds, R. T., 1993. Habitable Zones around Main Sequence 1244 Stars. Icarus 101, 108-128. 
1245 Komatsu, G., Ori, G.G., Cardinale, M., et al., 2011. Roles of methane and carbon dioxide in geological processes on Mars. Planet. Spa. Sci. 59, 169-181, doi:10.1016/j.pss.2010.07.002.

1247 Komatsu, G., Okubo, C.H., Wray, J.J., Gallagher, R., Orosei, R., Cardinale, M., Chan, M.A., and Ormö, J., 2012. Small mounds in Chryse Planitia, Mars: Testing a mud volcano hypothesis. Lunar Planet. Sci. Conf. XXXXIII, abstract \#1103.

1250 Konopliv A.S., Asmar S. W., Carranza E., et al., 2001. Recent gravity models as a result of the 1251 Lunar prospector mission. Icarus 150: 1-18.

1252 Konopliv, A.S., Asmar, S.W., Folkner, W.M., Karatekin, Ö., Nunes, D.C., Smrekar, S.E., Yoder, 1253 C.F., Zuber, M.T., 2011. Mars high resolution gravity fields form MRO, Mars seasonal 1254 gravity, and other dynamical parameters. Icarus 211, 401-428.

1255 Lane, M.D., Goodrich, C.A, 2010. High-magnesian olivine in the Argyre rim: derived from a 1256 primitive magma? LPSC XLI, abs. 2094, (CD-ROM), Lunar Planet. Inst., Houston, TX.

1257 Laskar, J., Correia, A.C.M., Gastineau, M., Joutel, F., Levard, B., Robutel, P., 2004. Long term 1258 evolution and chaotic diffusion of the insolation quantities of Mars. Icarus 170, 343-364.

Lefort, A., Russell, P.W., McEwen, A.S., Dundas, C.M., Kirk, R.L., 2009. Observations of periglacial landforms in Utopia Planitia with the High Resolution Imaging Science Experiment (HiRISE). J. Geophys. Res. 114, E04005, doi:10.1029/ 2008JE003264.

1262 Lefort, A., et al., 2010. Scalloped terrain in the Peneus and Amphritrites Paterae region of Mars 1263 as observed by HiRISE. Icarus 205, 1, 259-268, doi:10.1026/j.icarus.2009.06.005.

Leonard, G.J., Tanaka, K.L., 2001. Geologic map of the Hellas region of Mars, US Geol. Survey Map I-2694.

1266 Levy, J., Head, J., Marchant, D., 2009. Thermal contraction crack polygons on Mars: classification, distribution and climatic implications from HiRISE observations. J. Geophys. Res. 114, E01007, doi:10.1029/2008JE003273.

Levy, J.S., Head, J.W., Marchant, D.R., 2011. Gullies, polygons and mantles in Martian permafrost environments: cold desert landforms and sedimentary processes during recent Martian geological history. in Martini, I.P., French, H.M., Perez Alberti, A., (eds.) Ice marginal and periglacial processes and sediments, Geological Society of London, 354, 167182 doi:10.1144/SP35410 0305-8719.

1274 Liestol, O., 1975. Pingos, springs, and permafrost in Spitsbergen, Nor. Polar Årbook, 7-29.

1275 Lias, J.H., Dohm, J.M., Tanaka, K.L., 1997. Geologic history of Lowell impact. Lunar Planetary 1276 Science Conference, XXVIII, \#1650 (abstract) [CD-ROM]. 
1277

1278

1279

1280

1281

1282

1283

1284

1285

1286

1287

1288

1289

1290

1291

1292

1293

1294

1295

1296

1297

1298

1299

1300

1301

1302

1303

1304

1305

1306

1307

1308

1309

Lillis, R.J., et al., 2008. An improved crustal magnetic field map of Mars from electron reflectometry: Highland volcano magnetic history and the end of the Martian dynamo. Icarus 194, 575-596. doi: 10.1016/j.icarus.2007.09.032.

Madeleine, J.B., Forget, F., Head, J.W., Levrard, B., Montmessin, F., Millour, E., 2009. Amazonian northern mid-latitude glaciation on Mars: a proposed climate scenario. Icarus 203, 390-405, doi:10.1016/j.icarus.2009.04.037.

Mahaney, W.C., Dohm, J.M., Baker, V.R., et al., 2001. Morphogenesis of Antarctic paleosols: Martian analog. Icarus 154, 113-130.

Mahaney, W.C., Dohm, J.M., Kapran, B., et al., 2009. Secondary Fe and Al in Antarctic paleosols: Correlation to Mars with prospect for the presence of life. Icarus 203, 320-330, doi:10.1016/j.icarus.2009.05.007.

Mahaney, W.C., Hart, K.M., Dohm, J.M., Hancock, R.G.V., Costa, P., O’Reilly, S.S., Kelleher, B.P., Schwartz, S., Lanson, B., 2011. Aluminum extracts in Antarctic paleosols: proxy data for organic compounds and bacteria and implications for Martian paleosols Sedimentary. Geology 237, 84-94.

Malin, M.C., Bell, J.F., III, Cantor, B.A., and 11 others, 2007. Context Camera investigation on board the Mars Reconnaissance Orbiter. J. Geophys. Res. 112, doi:10.1029/2006JE002808.

Mangold, N., 2011. Ice sublimation as a geomorphic process: a planetary perspective. Geomorph. 126, 1-17, doi:10.1016/2010.11.009.

Maruyama, S., 1997. Pacific-type orogeny revisited: Miyashiro-type orogeny proposed. Island Arc 6, 91-120, doi:10.1111/j.1440-1738.1997 .tb00042.x.

Maruyama, S., Isozaki, Y., Kimura, G., Terabayashi, M., 1997. Paleogeographic maps of the Japanese Islands: plate tectonic synthesis from 750 Ma to the present. The Island Arc 6, 121142.

Maruyama S., Dohm, J.M., Baker, V.R., 2001a. Mars plate tectonics (1): an Earth prospective. American Geophysical Union, Fall Meeting 2001, 82(47), Suppl., Abstract P32C-0565.

Maruyama, S., Dohm, J.M., Baker, V.R., 2001b. Tharsis superplume (1): Why superplume? Geol. Soc. America Abstracts with Programs, 33(7), A310.

Maruyama, S., Baker, V.R., Dohm, J.M., 2008. Life and Land of Mars, 4.6 Billion Years. Koudansha, Tokyo, 256 p. (In Japanese)

Maruyama, S., Ikoma, M., Genda, H., Hirose, K., Yokoyama, T., Santosh, M., 2013. The naked planet Earth: most essential pre-requisite for the origin and evolution of life. Geosci. Front. 4, 141-165. 
1310 Maruyama, S., Sawaki, Y., Ebisuzaki, T., Ikoma, M., Omori, S., Komabayashi, T., 2014. Initiation of leaking Earth: An ultimate trigger of the Cambrian explosion. Gondwana Res. $25,910-944$.

Matsumoto K., Goossens S., Ishihara Y., et al., 2010. An improved lunar gravity field model from SELENE and historical tracking data: Revealing the farside gravity features. J. Geophys. Res. 115 (E6): E06007.

McCauley, J.F., 1978. Geologic map of the Coprates quadrangle of Mars. US Geol. Survey Map Misc. Invest. Ser. Map I-897, scale 1:5,000,000.

McEwen, A.S., Eliason, E.M., Bergstrom, J.W., 2007. Mars Reconnaissance Orbiter's High Resolution Imaging Science Experiment (HiRISE). J. Geophys. Res. 112, DOI: 10.1029/2005JE002605.

McEwen, A.S., Dundas, C., Mattson, S., et al., 2013. Recurring slope lineae (RSL) in equatorial Mars. European Planetary Science Congress 2013, Abstract \#846.

McGill, G.E., 1978. Geologic map of the Thaumasia quadrangle of Mars: US Geol. Survey Misc. Invest. Ser. Map I-1077, scale 1:5,000,000.

McGill, G.E., 1989. Buried topography of Utopia, Mars: persistence of a giant impact depression. J. Geophys. Res. 94, 2753-2759.

1327 Mest, S.C., Crown, D.A., 2001. Geology of the Reull Vallis region, Mars, Icarus, 153, 89-110.

1328

Milliken, R.E., Mustard, J.F., Goldsby, D.L., 2003. Viscous flow features on the surface of Mars: Observations from high-resolution Mars Orbiter Camera (MOC) images. J. Geophys. Res.

1331 Miyamoto, H., Dohm, J.M., Beyer, R.A., Baker, V.R., 2004. Fluid dynamical implications of anastomosing slope streaks on Mars. J. Geophys. Res. 109, E06008,

1334 Moore, J.M., Wilhelms, D.E., 2007. Geologic map of part of western Hellas Planitia, Mars. US 1335 Geol. Survey Map SIM-2953, 2007.

1336 Morgenstern, A., Hauber, E., Reiss, D., van Gasselt, S., Grosse, G., Schirrmeister, L., 2007. 1337 Deposition and degradation of a volatile-rich layer in Utopia Planitia, and implications for 1338 climate history on Mars. J. Geophys. Res. 112, E06010. doi:10.1029/ 2006JE002869.

1339 Müller, F.,1959. Beobachten über pingos (Observationsonpingos). Medd. Grønl. 153 (3), 127. 1340 Reprintedas Technical Translation 1073 by National Research Council of Canada, Ottawa, 1341 Canada, 1963. 
1342 Muller, P.M., Sjogren, W.L., 1968. Mascons: Lunar mass concentrations. Science 161, 680-684.

1343 Murchie, S., Arvidson, R., Bedini, P., Beisser, K., Bibring, J.-P., Bishop, J., Boldt, J., Cavender, 1344 P., Choo, T., Clancy, R.T., Darlington, E.H., Des Ma-rais, D., Espiritu, R., Fort, D., Green, R., Guinness, E., Hayes, J., Hash, C., Heffernan, K., Hemmler, J., Heyler, G., Humm, D., Hutcheson, J., Izenberg, N., Lee, R., Lees, J., Lohr, D., Malaret, E., Martin, T., McGovern, J.A., McGuire, P., Morris, R., Mustard, J., Pelkey, S., Rhodes, E., Robinson, M., Roush, T., Schaefer, E., Seagrave, G., Seelos, F., Silverglate, P., Slavney, S., Smith, M., Shyong, W.-J., Strohbehn, K., Taylor, H., Thompson, P., Tossman, B., Wirzburger, M., Wolff, M., 2007. CRISM (Compact Reconnaissance Imaging Spectrometer for Mars) on MRO (Mars Reconnaissance Orbiter). J. Geophys. Res. 112, 1-57.

Murchie S.L., Seelos, F.P. Buczkowski, D.L. Mustard, J.F. Ehlmann, B.L. Milliken, R.E. Noe Dobrea, E.Z. Bishop, J.L. McKeown, N.K. Wiseman, S.M. Arvidson, R.E. Wray, J.J. Swayze, G., Clark R.N., 2009a. A synthesis of Martian aqueous mineralogy after one Mars year of observations from the Mars Reconnaissance Orbiter. J. Geophys. Res. 114, E00D06, doi:10.1029/2009JE003342.

Murchie, S.L., Seelos, F.P., Hash, C.D., et al., 2009b. The Compact Reconnaissance Imaging Spectrometer for Mars investigation and data set from the Mars Reconnaissance Orbiter's primary science phase. J. Geophys. Res. 114, E00D07, doi:10.1029/2009JE003344. from the identification of youthful near-surface ground ice. Nature 412, 411-414. doi: $10.1038 / 35086515$.

Mustard, J., Murchie, S., Pelkey, S.M., Ehlmann, B.L., Milliken, R.E., Grant, J.A., Bibring, J-P., Poulet, F., Bishop, J., Noe Dobrea, E., Roach, L., Seelos, F., Arvidson, R.E., Wiseman, S., Green, R., Hash, C., Humm, D., Malaret, E., McGovern, J.A., Seelos, K., Clancy, T., Clark, R., Des Marais, D., Izenberg, N., Knudson, A., Langevin, Y., Martin, T., McGuire, P., Morris, R., Robinson, M., Roush, T., Smith, M., Swayze, G., Taylor, H., Titus, T., Wolff M., 2008. Hydrated silicate minerals on Mars observed by the CRISM instrument on MRO. Nature 454, 305-309.

Nahm, A. L., and R. A. Schultz, 2011. Magnitude of global contraction of Mars from analysis of surface faults: implications for Martian thermal history. Icarus 211, 389-400. relation to the lunar reference system. In Chronology and Evolution of Mars (R. Kallenbach, J. Geiss, and W. K. Hartmann, eds.), Kluwer Academic Publishers, 55-86. structure and signature of major basins. J. Geophys. Res. 101, $16841-16,863$. 
1377 Neumann, G.A., Smith, D.E., Zuber, M.T., 2003. Two Mars years of clouds detected by the Mars $1378 \quad$ Orbiter Laser Altimeter. J. Geophys. Res. Planets 108, 5023. doi:10.1029/2002JE001849.

1379 Ody, A., Poulet, F., Langevin, Y., Bibring, J.-P., Bellucci, G., Altieri, F., Gondet, B., Vincendon, 1380 M., Carter, J., Manaud, N., 2012. Global maps of anhydrous minerals at the surface of Mars from OMEGA/MEx. J. Geophys. Res. 117, E00J14, doi:10.1029/2012JE004117.

1382 Oehler, D.Z., Allen, C.C., 2010. Evidence for pervasive mud volcanism in Acidalia Planitia, 1383 Mars. Icarus 208, 636-657, doi:10.1016/j.icarus.2010.03.031.

1384 Öhman, T., Aittola, M., Kostama, V.-P., Raitala, J., Korteniemi, J., 2008. Polygonal impact 1385 craters in Argyre region, Mars: implications for geology and cratering mechanics.

1386 Meteoritics \& Planetary Science 43, 1605-1628.

1387 Parker, T.J., 1985. Geomorphology and geology of the southwestern Margaritifer Sinus 1388 northern Argyre region of Mars. Master's thesis, Geology Department, California State 1389 University, Los Angeles, 165pp.

1390 Parker, T.J., 1989. Channels and valley networks associated with Argyre Planitia, Mars. Lunar $1391 \quad$ Planet. Sci. XX, 826-827.

1392 Parker, T.J., 1994. Martian paleolakes and oceans. Ph.D. dissertation, Geological Sciences, 1393 University of Southern California, 200pp.

1394 Parker, T.J., 1996. Highlights from 1:500K geologic mapping of central and southern Argyre 1395 Planitia. Lunar Planet Sci. XXVII, 1003-1004.

1396 Parker, T.J., Gorsline, D.S., 1991. Where is the source for Uzboi Vallis, Mars? Lunar Planet Sci. 1397 XXII, 1033-1034.

1398 Parker, T.J., Gorsline, D.S., 1992. Preliminary geologic mapping of the MTM-55036 and -55043 quadrangles, southern Argyre Planitia, Mars (abs.). Lunar Planet Sci. 23, 1031-1032.

1400 Parker, T.J. Gorsline, D.S., 1993. Extent and timing of fluvial and lacustrine events in Argyre

1402 Parker, T.J., Clifford, S.M., Banerdt, W.B., 2000. Argyre Planitia and the Mars global hydrologic 1403 cycle. Lunar Planet Sci. [CD-ROM], 31th, abstract 2033.

1404 Platz, T., Michael, G.G., 2011. Eruption history of the Elysium Volcanic Province, Mars. Earth 1405 and Planetary Science Letters 312, 140-151, doi:10.1016/j.epsl.2011.10.001.

Platz, T., Michael, G.G., Tanaka, K.L., et al., 2013. Crater-based dating of geological units on Mars: Methods and application for the new global geological map. Icarus 225, 806-827, 1408 doi:10.1016/j.icarus.2013.04.021. 
1409 Poulet, F., Bibring, J.P., Mustard, J.F., et al., 2005. Phyllosilicates on Mars and implications for 1410 early Martian climate. Nature 438, 623-627.

1411 Poulet, F., Gomez, C., Bibring J.-P., Langevin, Y., Gondet, B., Pinet, P., Belluci, G., Mustard J., 2007. Martian surface mineralogy from Observatoire pour la Minéralogie, l'Eau, les Glaces et l'Activité on board the Mars Express spacecraft (OMEGA/MEx): Global mineral maps. J. Geophys. Res. 112, E08S02, doi:10.1029/2006JE002840.

1415 Quaide, W.L., Gault, D.E., Schmidt, R.A., 1965. Gravitative effects on lunar impact structures. Annals of the New York Academy of Sciences 123, 641-655.

1417 Raack, J., Reiss, D., Heisinger, H., 2012. Gullies and their relationship to the dust-ice mantle in 1418 the northwestern Argyre Basin, Mars. Icarus 219, 129-141, doi:10.1016/j.icarus.2012.

$1419 \quad 02.0125$.

1420 Robbins, S.J., Hynek, B.M., 2012. A new global database of Mars impact craters $\geq 1$ km: 1 . 10.1029/2011JE003966.

Robbins, S.J., Hynek, B.M., Lillis, R.J., Bottke, W.F., 2013. Large impact crater histories of Mars: The effect of different model crater age techniques. Icarus 225, 173-184. doi: 10.1016/j.icarus.2013.03.019.

Roberts, J.H., Arkani-Hamed, J., 2012. Impact-induced mantle dynamics on Mars. Icarus 218, 278-289.

Roberts, J.H., Lillis, R.J., Manga, M., 2009. Giant impacts on early Mars and the cessation of the Martian dynamo. J. Geophys. Res. 114, E04009, doi: 10.1029/2008JE003287.

1430 Rodriguez, J.A.P., Kargel, J.S., Tanaka, K.L., Crown, D.A., Berman, D.C., Fairén, A.G., Baker, V.R., Furfaro, R., Candelaria, P., Sasaki, S., 2011. Secondary chaotic terrain formation in

1433 Rodriguez, J.A.P., Kargel J.S., et al., 2014. Evidence for Middle Amazonian catastrophic

Rossi, A.P., Gasselt, S.V., Pondrelli, M., Dohm, J.M., Hauber, E., Dumke, A., Zegers, T., Neukum, G., 2011. Evolution of periglacial landforms in Thaumasia Highland, Mars. M.R. Balme, A.S. Bargery, C.J. Gallagher, and S. Gupta (eds.) In Geomorphology on Mars and other planets, Geological Society, London, Special Publications 356, 69-85.

1439 Rotto, S.L., Tanaka, K.L., 1995. Geologic/geomorphologic map of the Chryse Planitia region of Mars. US Geol. Survey Map I-2441 (1:5,000,000). 
1441 Ruiz, J., 2014. The early heat loss evolution of Mars and their implications for internal and environmental history. Sci. Rep. 4, doi:10.1038/srep04338.

1443 Saunders, R.S., 1979. Geologic map of the Margaritifer Sinus quadrangle of Mars. US Geol. Survey Map Misc. Invest. Ser. Map I-1144, scale 1:5,000,000.

1445 Schubert, G., Turcotte, D.L., 2002. Geodynamics, Cambridge University Press.

1446 Schubert, G., Solomon, S.C., Turcotte, D.L., Drake, M.J., Sleep, N.H., 1992. Origin and thermal evolution of Mars. In Mars, University of Arizona Press, Tucson, pp. 147-183.

Schultz, R.A., Tanaka, K.L. (1994) Lithospheric-scale buckling and thrust structures on Mars:

Schulze-Makuch, D., Head, J.N., Houtkooper, J.M., et al. 2012. The biological oxidant and life

1452 Scott, D.H., Carr, M.H., 1978. Geologic map of Mars. US Geol. Survey Map I-1083.

1453 Scott, D.H., Tanaka, K.L., Greeley, R., Guest, J.E., 1986-87. Geologic maps of the western and eastern equatorial and polar regions of Mars. US Geol. Survey Map Misc. Inv. Ser. Map I-

1456 Segura, T.L., Toon, O.B., Colaprete, A., Zahnle, K., 2002. Environmental Effects of Large 1457 Impacts on Mars. Science 298, 1977-1980.

1458 Seibert, N.M., Kargel, J.S., 2001. Small-Scale Martian Polygonal Terrain: Implications for Liquid Surface Water. Geophys. Res. Lett. 28, 899- 903.

Shoemaker, E.M., 1963. Impact mechanics at Meteor crater, Arizona. In Middlehurst, B.M., and Kuiper, G.P., eds., The Moon, Meteorites, and Comets: Chicago, University of Chicago Press, p. 301-336.

Shreve, R.L., 1985. Esker characteristics in terms of glacier physics, Katahdin esker system, Maine. Geol. Soc. Am. Bull. 96, 639-646.

Skinner, J.A., Tanaka, K.L., 2007. Evidence for and implications of sedimentary diapirism and mud volcanism in the southern Utopia highland-lowland boundary plain, Mars. Icarus 186, 41-59.

Skinner, J.A., Mazzini, A., 2009. Martian mud volcanism: terrestrial analogs and implications for formational scenarios. Marine and Petroleum Geology 26, 1866-1878.

Skinner, J.A., Jr., Tanaka, K.L., Platz, T., 2012. Widespread loess-like deposit in the Martian northern lowlands identifies Middle Amazonian climate change. Geology 40, 1127-1130, doi:10.1130/G33513.1. 
1473 Sleep, N. H., 1994. Martian plate tectonics. J. Geophys. Res. 99, 5639-5655.

1474 Smith D.E., et al., 1999. The global topography of Mars and implications for surface evolution.

1475 Science 284, 1495-1503.

1476 Soare, R.J., Conway, S.J., Dohm, J.M., 2012a. Evidence of landscape modification in and around 1477 the Argyre impact basin, Mars, by "wet" periglacial processes. 2012 GSA Annual Meeting 1478 and Exposition, Charlotte, North Carolina, 44, 7, 64.

1479 Soare, R.J., Conway, S.J., Dohm, J.M., Sejourne, A., 2012b. Climate-change and the origin of 1480 ice-rich permafrost in mid Utopia Planitia, Mars. Mars recent climate change workshop, 1481 Ames Research Center, Moffett Field, California.

1482 Soare, R.J., Conway, S.J., Dohm, J.M., El-Maarry, M.R., 2014a. Possible ice-wedge polygons 1483 and recent landscape modification by "wet" periglacial processes in and around the Argyre 1484 impact basin, Mars. Icarus 233, 214-228.

1485 Soare, R.J., Conway, S.J., Dohm, J.M., El-Maarry, M.R., 2014b. Possible open-system 1486 (hydraulic) pingos in and around the Argyre impact regions of Mars. Earth and Planet. Lett. 1487 398, 25-36.

1488 Soare, R.J., Conway, S.J., Gallagher, C., Balme, M.R., Dohm, J.M., 2015. Pre- and post- glacial 1489 periglaciation in Argyre Planitia, Mars. Lunar Planet. Sci. Conf. XXXXVI, Houston, Texas. 1490 Abstract \#1218.

1491 Solomon, S., Head, J.W., 1980. Lunar mascon basins: lava filling, tectonics, and evolution of the 1492 lithosphere. Rev. Geophys. Space Phys. 18, 107-141.

1493 Spagnuolo, M.G., Dohm, J.M., 2004. Triggering the end of plate tectonics by forced climate 1494 changes. Workshop on Martian Hemispheres, Lunar Planetary Institute, \#4001(abstract) 1495 [CD-ROM].

1496 Tanaka, K.L., 1986. The stratigraphy of Mars. Proc. Lunar Planet. Sci. Conf. 17th, Part 1, J. 1497 Geophys. Res., 91, suppl., E139-158, 1986.

1498 Tanaka, K.L., Isbell, N.K., Scott, D.H., Greeley, R., Guest, J.E., 1988. The resurfacing history of 1499 Mars: A synthesis of digitized, Viking-based geology. Proc. Lunar Planet. Sci. Conf. 18, 665$1500 \quad 678$.

1501 Tanaka, K.L., Skinner, J.A., Hare, T.M., 2005. Geologic map of the northern plains of Mars. 1502 USGS Misc. Scientific Investigations. Map 2888, scale 1:15,000,000.

1503 Tanaka, K.L., Skinner, J.A., Dohm, J.M., Rossman, R.P. III, Kolb, E.J., Fortezzo, C.M., Platz, 1504 T., Michael, G.G., Hare, T.M., 2014. Geologic map of Mars. US Geol. Survey Map 1505 Scientific Investigations Map 3292. 
1506 Thomas, G., Masson, H., 1984. Geology and tectonics of the Argyre area on Mars: comparisons with other basins in the solar system. Earth, Moon, and Planets 31, 25-42.

1508 Touma, J., Wisdom, J., 1993. The chaotic obliquity of Mars. Science 259, 1294-1296.

1509 Werner, S.C., Tanaka, K.L., 2011. Redefinition of the crater-density and absolute-age boundaries for the chronostratigraphic system of Mars. Icarus 215, 603-607.

1511 Wichman, R.W., Schultz, P.H., 1989. Sequence and mechanisms of deformation around the 1512 Hellas and Isidis impact basins on Mars. J. Geophys. Res. 94, 17,333-17,357.

1513 Wieczorek, M.A., Phillips, R.J., 1999. Lunar multiring basins and the cratering process. Icarus 1514 139, 246-259.

1515 Wilhelms, D.E., 1987. The geologic history of the Moon. US Geol. Survey Prof. Pap. 1348.

1516 Williams, D.A., Greeley, R., 1994. Assessment of antipodal-impact terrains on Mars. Icarus 110, $1517 \quad$ 196-202.

1518 Williams, J.-P., Dohm, J. M., Lopes, R. M., and Buczkowski, D.L., 2014. A large vent structure 1519 within Argyre Basin, Mars. LPSC XXXXV, abs. 2807, (CD-ROM), Lunar Planet. Inst., Houston, TX.

1521 Wilmes, M., Reiss, D., Hiesinger, H., Zanetti, M., 2012. Surface age of the ice-dust mantle 1522 deposit in Malea Planum, Mars. Planet. and Space Sci. 60, 199-206, doi:1016/j.pss.2011. 08.006.

1524 Yin, A., 2012a. An episodic slab-rollback model for the origin of the Tharsis rise on Mars: implications for initiation of local plate subduction and final unification of kinematically linked global plate-tectonic network on Earth. Lithosphere 4, 553-593, doi: 10.1130/L195.1.

1527 Yin, A., 2012b. Structural analysis of the Valles Marineris fault zone: possible evidence for of scalloped terrain in the southern hemisphere, Mars. Icarus 206, 691-706, 
Table 1. Unit symbols, unit names, and unit areas (see corresponding geologic map shown in Fig. 3). Interpreted sedimentary deposits include aeolian, lacustrine, glacial, periglacial, fluvial, alluvial, and colluvial deposits. Magmatic includes both intrusive (exposed through differential erosion and impact excavation) and volcanic. The primary basin materials (members NAb1, NAb2, NAb3, NAb4b, HAb4a) occur at distinct elevation ranges (see Figs. 3, 5, 6 and Sections 4.2 and 4.3,1). See Table 2 for description and interpretation and Table 3 for relative age information through comprehensive crater statistics. Not shown below are the older impact crater materials (unit $\mathrm{C} 1$ ), younger impact crater materials (unit C2), smooth impact crater materials (unit Cfs), and rough crater floor materials (unit Cfr). Note that the Argyre rim materials are diverse in stratigraphy, topography, and morphology, as thus separated into Argyre rim (unit NAr; mainly rim materials), Argyre rim and basin (Unit NArb; majority being rim materials with interspersed basin (including valley) deposits), Argyre basin and rim (unit NAbr; majority being basin infill deposits with intervening rim materials in the form of knobs and mesas), Argyre rim smooth plains (rim materials with large distinct patches of relatively smooth plains) materials.

\begin{tabular}{|l|l|l|l|}
\hline Unit & Unit Names & $\begin{array}{l}\text { Area } \\
\left.\mathbf{( k m}^{\mathbf{2}}\right)\end{array}$ & Brief Interpretation (see Table 2 for greater details) \\
\hline Nh1 & Highlands member 1 & 327,794 & Sedimentary; impact; magmatic \\
\hline Nh2 & Highlands member 2 & $1,096,085$ & Sedimentary; impact; magmatic \\
\hline HNh3 & Highlands member 3 & 168,887 & Sedimentary; impact; magmatic \\
\hline HNh4 & Highlands member 4 & 262,637 & Sedimentary; impact; magmatic \\
\hline Nhb & Highland basin & 67,049 & Local basins infilled by sedimentary deposits \\
\hline HNTh & Thaumasia highlands & 28,531 & Sedimentary; highly modified basement complex; magmatic; impact \\
\hline AHTp & Thaumasia plateau & 16,282 & Magmatic (e.g., ignimbrites); sedimentary \\
\hline NAr & Argyre rim & 58,067 & $\begin{array}{l}\text { Mantle and lower crustal materials; basement complex; sedimentary; } \\
\text { hydrothermal }\end{array}$ \\
\hline NArb & Argyre rim and basin & 109,274 & $\begin{array}{l}\text { Mantle and lower crustal materials; basement complex; sedimentary; } \\
\text { hydrothermal }\end{array}$ \\
\hline NAbr & Argyre basin and rim & 577,012 & Similar to unit Arb but more basin materials (sedimentary); hydrothermal \\
\hline NArsp & Argyre rim smooth plains & 38,939 & Similar to Arb but plains-forming materials mostly sedimentary \\
\hline NAb1 & Argyre basin, member 1 & 100,203 & Sedimentary deposits \\
\hline NAb2 & Argyre basin, member 2 & 209,887 & Sedimentary deposits \\
\hline NAb3 & Argyre basin, member 3 & 208,086 & Sedimentary deposits \\
\hline HAb4a & Argyre basin, member 4a & 341,499 & Sedimentary deposits \\
\hline NAb4b & Argyre basin, member 4b & 18,541 & $\begin{array}{l}\text { Sedimentary deposits; basin marginal unit, which underlies unit Ab4a, is } \\
\text { related to unit NAb3 }\end{array}$ \\
\hline
\end{tabular}


1546 Table 2. Description and interpretation of map units. For cumulative crater densities and estimated unit ages of the 1547 geologic units in the Argyre and surrounding region of Mars, see Table 3.

\begin{tabular}{|c|c|c|c|}
\hline Unit Name & $\begin{array}{c}\text { Unit } \\
\text { Label }\end{array}$ & Description & Interpretation \\
\hline \multicolumn{4}{|c|}{ Argyre basin sequence stratigraphy (units HAb4a, NAb4b, NAb3, NAb2, NAb1) } \\
\hline $\begin{array}{l}\text { Argyre basin } \\
\text { member } 4 a\end{array}$ & HAb4a & $\begin{array}{l}\text { Younger Argyre plains-forming basin floor } \\
\text { deposits marked by sinuous ridges, knobs, } \\
\text { broken terrain, topographic depressions of } \\
\text { varying geometric shapes, buried/subdued } \\
\text { impact craters, and dune fields. The younger } \\
\text { floor materials are approximately or } \\
\text { gradationally in contact with either unit } \\
\text { HAb4b or unit NAb3 materials. }\end{array}$ & $\begin{array}{l}\text { The upper most part of the Argyre basin infill floor materials representative of } \\
\text { environmental change induced by Stage } 4 \text { (Late Hesperian; for Tharsis-Stage information } \\
\text { see Section } 2 \text { and Fig. 4) Tharsis magmatic-driven activity with lesser activities including } \\
\text { Elysium. This includes ice melt, spring-fed activity, flooding, gelifluction, and lake and } \\
\text { glacier formation along its margin, with subsequent resurfacing, including aeolian, } \\
\text { fluvial, volatile-release, glacial, alluvial, impact cratering including secondaries, and/or } \\
\text { colluvial, some processes of which are active today; the lower parts (those underlying } \\
\text { unit HAb4a materials with associated impact craters exposed at the surface or not totally } \\
\text { buried by unit HAb4a) of the infill deposits (extending at depth to the ancient Argyre } \\
\text { basin floor) were emplaced by earlier perturbations in climate/environmental conditions } \\
\text { from Tharsis and less prominent activities such as Elysium volcanism. The relative } \\
\text { timing of these activities are indicated by stratigraphy and impact crater densities (Table } \\
\text { 3). The rock materials source from diverse provenances, including the Argyre rim and } \\
\text { ejecta deposits (upper mantle materials and older primordial crustal materials excavated } \\
\text { to and near the Martian surface by the impact event and associated overturn and } \\
\text { inversion of stratigraphy; materials also include hydrothermal deposits) and beyond, even } \\
\text { including materials transported from as far north as Tharsis and the Thaumasia highlands } \\
\text { and from as far south as the south pole. Therefore, the rock materials are considered to be } \\
\text { diverse in both geochemistry and the mineralogic record, representative of diverse } \\
\text { environmental conditions. The sinuous ridges located in the southeast part of the basin } \\
\text { floor are eskers, associated with the latter stage of lake formation (margins of the lake } \\
\text { were freezing) and marginal glaciers were connected to the lake. The subglacial rivers } \\
\text { followed topography. }\end{array}$ \\
\hline $\begin{array}{l}\text { Argyre basin } \\
\text { member } 4 b\end{array}$ & NAb4b & $\begin{array}{l}\text { Older Argyre plains-forming basin floor } \\
\text { deposits marked by flows, erosional scarps, } \\
\text { systems of sinuous valleys, and highly } \\
\text { degraded and subdued impact craters, which } \\
\text { partly form the contact separating these } \\
\text { deposits from the younger plains-forming } \\
\text { basin floor deposits. These materials are } \\
\text { buried and/or embayed by unit HAb4a } \\
\text { materials and gradational with generally } \\
\text { higher-standing unit NAb3 materials. }\end{array}$ & $\begin{array}{l}\text { Argyre basin floor materials representing older basin infill materials emplaced largely by } \\
\text { early Tharsis magmatic-driven activity (e.g., Stages 1-2), which includes unit NAb3 } \\
\text { materials with subsequent resurfacing, including aeolian, fluvial, volatile-release, glacial, } \\
\text { alluvial, impact cratering, which includes secondaries, and/or colluvial. The rock } \\
\text { materials source from diverse provenances, including the Argyre rim and ejecta deposits } \\
\text { (upper mantle materials and older primordial crustal materials excavated to and near the } \\
\text { Martian surface by the impact event and associated overturn and inversion of } \\
\text { stratigraphy; materials also include hydrothermal deposits) and beyond, even including } \\
\text { materials transported from as far north as Tharsis and the Thaumasia highlands and from } \\
\text { as far south as the south pole. Therefore, the rock materials are considered to be diverse } \\
\text { in both geochemistry and the mineralogic record, representative of diverse environmental } \\
\text { conditions (e.g., assortment of varying pressure, temperature, and volatile conditions). }\end{array}$ \\
\hline $\begin{array}{l}\text { Argyre basin } \\
\text { member } 3\end{array}$ & NAb3 & $\begin{array}{l}\text { Deposits that are gradationally in contact with } \\
\text { the younger and older plains-forming basin } \\
\text { floor deposits, which are marked by flows, } \\
\text { networking channel systems such as } \\
\text { highlighted in the southeast part of the basin at } \\
\text { the juncture of the floor and rim-associated } \\
\text { slope (e.g., troughs delineated on the geologic } \\
\text { map near the terminus of Nia Vallis; Fig. 3) } \\
\text { and Moanda impact crater in the northeast part } \\
\text { (Figs. 3), aprons along the margins of } \\
\text { promontories and other flow-feature types, } \\
\text { degraded and partly buried impact craters, } \\
\text { knobs and other quasi-circular promontories } \\
\text { with marginal aprons, erosional scarps, and } \\
\text { irregular depressions. In addition, deposits } \\
\text { which occur on the lower-most valley segment } \\
\text { extending from the margin of the basin floor } \\
\text { inset within the Argyre-impact-induced radial } \\
\text { valleys, with distinct breaks in slope } \\
\text { (including terrace-like topography in places) } \\
\text { at the contact between these deposits and the } \\
\text { older deposits of unit NAb2 at higher } \\
\text { elevations along the valley floor, particularly } \\
\text { distinct along the floors of the three valleys } \\
\text { that debouch into the southern and southeast } \\
\text { parts of the Argyre basin, Surius Vallis and } \\
\text { Dzigai and Nia Valles, respectively (Figs. 1, } \\
\mathbf{3} \text { and 6). }\end{array}$ & $\begin{array}{l}\text { Hillslope-forming materials in contact with the basin floor materials related to changes in } \\
\text { environmental conditions/climate, as well as gravity-driven processes of ice-enriched } \\
\text { rock materials through time. Major surface modification related to Tharsis-driven } \\
\text { activity (e.g., Stages 1-3), indicated by stratigraphy and impact crater densities (Table 3), } \\
\text { which includes hydrologic activity (ice melt, flooding, gelifluction, and lake formation, } \\
\text { as well as incisement of the radial valleys related to a changing hydraulic head linked to } \\
\text { the changing hydrologic system of groundwater, surface lakes, and glaciers), with } \\
\text { subsequent surface modification including Tharsis- (Stages 4-5) and obliquity-driven, } \\
\text { aeolian, fluvial, volatile-release, glacial, alluvial, impact cratering, which includes } \\
\text { secondaries, and/or colluvial, some processes of which are active today. Wind and water } \\
\text { (liquid and ice) activity has modified the landscape. The rock materials source from } \\
\text { diverse provenances, including the Argyre rim and ejecta deposits (upper mantle } \\
\text { materials and older primordial crustal materials excavated to and near the Martian } \\
\text { surface by the Argyre impact event and associated overturn and inversion of stratigraphy; } \\
\text { materials also include hydrothermal deposits) and beyond, even including materials } \\
\text { transported from as far north as Tharsis and the Thaumasia highlands and from as far } \\
\text { south as the south pole. Therefore, the rock materials are considered to be diverse in } \\
\text { both geochemistry and the mineralogic record, representative of diverse environmental } \\
\text { conditions (e.g., assortment of varying pressure, temperature, and volatile conditions). } \\
\text { Argyre-impact-induced basement structures are conduits for the internal heat release of } \\
\text { Mars and associated groundwater migration resulting in local geologic and hydrologic } \\
\text { activity, including linear gullies with systems of faults and fractures and open-system } \\
\text { pingos (Soare et al., 2014b). }\end{array}$ \\
\hline
\end{tabular}




\begin{tabular}{|c|c|c|c|}
\hline $\begin{array}{l}\text { Argyre basin } \\
\text { member } 2\end{array}$ & NAb2 & $\begin{array}{l}\text { Deposits are gradationally in contact with rock } \\
\text { materials of units NAb3 and Nab1 and Argyre } \\
\text { rim materials such as unit NArb materials. } \\
\text { The unit is marked by flows, aprons along the } \\
\text { margins of promontories and other flow } \\
\text { feature types, degraded and partly buried } \\
\text { impact craters, knobs and other quasi-circular } \\
\text { promontories with marginal aprons (more } \\
\text { prevalent than the younger unit NAb3), } \\
\text { erosional scarps, and irregular depressions. In } \\
\text { addition, the deposits include valley fill } \\
\text { extending through the rim materials; they are } \\
\text { topographically between unit NAb3 and unit } \\
\text { NAb1, separated by gradational contacts of } \\
\text { which often are breaks in slope such as } \\
\text { terraces, exemplified in the three valleys that } \\
\text { debouch into the southern and southeast parts } \\
\text { of the Argyre basin, Surius Vallis and Dzigai } \\
\text { and Nia Valles, respectively (Figs. 1, 3, and } \\
\text { 6). }\end{array}$ & $\begin{array}{l}\text { Hillslope-forming materials associated with changes in environmental } \\
\text { conditions/climate, as well as gravity-driven processes such as colluvial activity of ice- } \\
\text { enriched rock materials through time. Major surface modification related to Tharsis- } \\
\text { driven activity (e.g., Stages 1-3), indicated by stratigraphy and impact crater densities } \\
\text { (Table 3), which includes hydrologic activity (ice melt, flooding, gelifluction, and lake } \\
\text { formation, as well as incisement of the radial valleys related to a changing hydraulic head } \\
\text { linked to the changing hydrologic system of groundwater, surface lakes, and glaciers), } \\
\text { with subsequent surface modification including obliquity-driven, aeolian, fluvial, } \\
\text { volatile-release, glacial, alluvial, impact cratering which includes secondary impacts, } \\
\text { and/or colluvial. Wind and water (liquid and ice) activity has modified the landscape. } \\
\text { The crater retention age of unit NAb2 is less than unit Nab3 due to higher energy } \\
\text { conditions and activity at higher reaches, including those associated with the incisement } \\
\text { of the valleys radial about the basin such as Surius Vallis and Dzigai and Nia Valles. The } \\
\text { rock materials source from diverse provenances, including the Argyre rim and ejecta } \\
\text { deposits (upper mantle materials and older primordial crustal materials excavated to and } \\
\text { near the Martian surface by the Argyre impact event and associated overturn and } \\
\text { inversion of stratigraphy; materials also include hydrothermal deposits) and beyond, even } \\
\text { including materials transported from as far north as Tharsis and the Thaumasia highlands } \\
\text { and from as far south as the south pole. Therefore, the rock materials are considered to } \\
\text { be diverse in both geochemistry and the mineralogic record, representative of diverse } \\
\text { environmental conditions (e.g., assortment of varying pressure, temperature, and volatile } \\
\text { conditions). }\end{array}$ \\
\hline $\begin{array}{l}\text { Argyre basin } \\
\text { member } 1\end{array}$ & NAb1 & $\begin{array}{l}\text { Deposits are gradationally in contact with unit } \\
\text { NAb2. The unit is marked by flows, aprons } \\
\text { along the margins of promontories and other } \\
\text { flow feature types, degraded and partly buried } \\
\text { impact craters, knobs and other quasi-circular } \\
\text { promontories with marginal aprons (more } \\
\text { prevalent than the younger member NAb3), } \\
\text { erosional scarps, and irregular depressions. In } \\
\text { addition, the deposits include valley fill } \\
\text { extending through the rim materials and onto } \\
\text { the surrounding highlands; they are the } \\
\text { elevationally highest occurring fill deposits in } \\
\text { the valleys that debouch into the Argyre basin. } \\
\text { Prime examples of the stratigraphy are } \\
\text { observed in Surius and Dzigai Valles, which } \\
\text { are the two southern most valley systems that } \\
\text { debouch into the Argyre basin (Figs. 1, 3, and } \\
\text { 6). }\end{array}$ & $\begin{array}{l}\text { High-standing basin-fill deposits which were emplaced directly following the Argyre } \\
\text { impact event, including ice melt at regional and possibly global scale and related } \\
\text { hydrologic conditions, which includes the Mediterranean-size lake that sourced Uzboi } \\
\text { Valles. The Argyre-induced lake formed several million years subsequent to the } \\
\text { termination of the dynamo and a reported ancient phase of plate tectonism (Baker et al., } \\
\text { 2007), as well as a once interacting atmosphere, ocean, and landmass (e.g., southern } \\
\text { cratered highlands as a hypothesized supercontinent (Spagnuolo and Dohm, 2004), } \\
\text { referred to as Habitable-Trinity conditions (Dohm and Maruyama, 2014b). Through time, } \\
\text { the deposits have largely diminished resulting from degradational processes related to } \\
\text { subsequent climatic/environmental perturbations; though, in addition to materials related } \\
\text { to Argyre-induced activity including lake formation which have been largely degrading } \\
\text { through time, this unit also includes rock materials emplaced during subsequent activity } \\
\text { such as related to the growth of the Tharsis Superplume (e.g., the upper reaches of the } \\
\text { Argyre-impact-controlled valleys). Deposits include channel and floodplain materials } \\
\text { related to the initial formation of Uzboi Vallis. The rock materials source from diverse } \\
\text { provenances, including the Argyre rim and ejecta deposits (upper mantle materials and } \\
\text { older primordial crustal materials excavated to and near the Martian surface by the } \\
\text { Argyre impact event and associated overturn and inversion of stratigraphy; materials also } \\
\text { include hydrothermal deposits) and beyond, even including materials transported from as } \\
\text { far north as the Thaumasia highlands and from as far south as the south pole. }\end{array}$ \\
\hline \multicolumn{4}{|c|}{ Argyre rim materials (units NAr, NArb, NAbr, NArsp) } \\
\hline $\begin{array}{l}\text { Argyre rim } \\
\text { materials }\end{array}$ & NAr & $\begin{array}{l}\text { High-relief, heavily cratered massifs tens of } \\
\text { kilometers across and intervening broad linear } \\
\text { troughs and valleys. Massifs of varying } \\
\text { geometric shapes display basins at distinct } \\
\text { breaks in slope with the higher parts of the } \\
\text { massifs, knife-like ridges, amphitheatre-like } \\
\text { valley heads, pyramidal peaks, and u-shape } \\
\text { valleys. The massifs display aprons along } \\
\text { their flanks. Similar to some of the other } \\
\text { Argyre rim and basin materials, but this } \\
\text { particular unit is mostly composed of rim- } \\
\text { related massifs, whereas the other units } \\
\text { include a combination of massifs and valley } \\
\text { and basin infill deposits. The impact retention } \\
\text { ages reflect extremely ancient Argyre impact } \\
\text { rim materials and ejecta deposits with a } \\
\text { significant crater population being destroyed } \\
\text { by processes such as glaciation along steep } \\
\text { slopes of the rim massifs. }\end{array}$ & $\begin{array}{l}\text { Argyre rim materials and ejecta deposits (upper mantle materials and older primordial } \\
\text { crustal materials excavated to and near the Martian surface by the impact event and } \\
\text { associated overturn and inversion of stratigraphy; materials include hydrothermal } \\
\text { deposits) and dissected by basin-related fault structures and erosional valleys, and } \\
\text { degraded through time by wind-, water-, and gravity-driven processes. Glacial activity is } \\
\text { prominent in the geologic and hydrologic records of the Argyre provinces, as highlighted } \\
\text { by the tarns, aretes, cirques, horns, and U-shape valleys that mark the prominent impact- } \\
\text { crater massifs. The chiseled landscape records diverse geologic and hydrologic activity, } \\
\text { including ice melt and associated hydrologic conditions following the giant Argyre } \\
\text { impact event, including lake formation and subsequent perturbations to the climate and } \\
\text { environmental conditions driven by Tharsis pulses and to a lesser extent Elysium and } \\
\text { other volcanic provinces, subsequent impact events such as Lowell and Galle, and } \\
\text { changes in obliquity and eccentricity. }\end{array}$ \\
\hline $\begin{array}{l}\text { Argyre rim } \\
\text { and basin } \\
\text { materials }\end{array}$ & NArb & $\begin{array}{l}\text { High-relief, heavily cratered massifs tens of } \\
\text { kilometers across and intervening basins, } \\
\text { broad linear troughs, and valleys. Massifs of } \\
\text { varying geometric shapes display basins at } \\
\text { distinct breaks in slope with the higher parts } \\
\text { of the massifs, knife-like ridges, amphitheatre- } \\
\text { like valley heads, pyramidal peaks, and u- }\end{array}$ & $\begin{array}{l}\text { Argyre rim materials and ejecta deposits (upper mantle materials and older primordial } \\
\text { crustal materials excavated to and near the Martian surface by the impact event and } \\
\text { associated overturn and inversion of stratigraphy) and dissected by basin-related fault } \\
\text { structures and erosional valleys, and degraded through time by wind-, water-, and } \\
\text { gravity-driven processes. Glacial activity is prominent in the geologic and hydrologic } \\
\text { records of the Argyre provinces, as highlighted by the tarns, aretes, cirques, horns, and - } \\
\text { shape valleys. The chiseled landscape records diverse geologic and hydrologic activity, }\end{array}$ \\
\hline
\end{tabular}




\begin{tabular}{|c|c|c|c|}
\hline & & $\begin{array}{l}\text { shape valleys. The massifs display aprons } \\
\text { along their flanks. Intervening basins display } \\
\text { both relatively smooth plains-forming } \\
\text { materials and massifs which occur isolated or } \\
\text { in groups. }\end{array}$ & $\begin{array}{l}\text { including ice melt and associated hydrologic conditions following the giant Argyre } \\
\text { impact event, including lake formation and subsequent perturbations to the climate and } \\
\text { environmental conditions driven by Tharsis pulses and to a lesser extent Elysium and } \\
\text { other volcanic provinces, subsequent impact events such as Lowell, and changes in } \\
\text { obliquity. These materials are similar to unit NAr but more degraded and thus basins, } \\
\text { which partly mark inversion of topography due to the destruction of the rim materials } \\
\text { through time, and massifs, with more isolated (i.e., individual) promontories when } \\
\text { compared to unit NAr. }\end{array}$ \\
\hline $\begin{array}{l}\text { Argyre basin } \\
\text { and rim } \\
\text { materials }\end{array}$ & NAbr & $\begin{array}{l}\text { High-relief, heavily cratered and degraded } \\
\text { massifs tens of kilometers across with } \\
\text { intervening basins including valleys and broad } \\
\text { linear troughs. Massifs of varying geometric } \\
\text { shapes display basins at distinct breaks in } \\
\text { slope with the higher parts of the massifs, } \\
\text { knife-like ridges, amphitheatre-like valley } \\
\text { heads, pyramidal peaks, and u-shape valleys. } \\
\text { The massifs display aprons along their flanks. } \\
\text { Intervening basins display both relatively } \\
\text { smooth plains-forming materials and massifs } \\
\text { which occur isolated or in groups. Similar to } \\
\text { NArb but basins are more prevalent compared } \\
\text { to the massifs, and the basins are not as } \\
\text { distinct, large, and isolated as those associated } \\
\text { with unit NArsp materials. }\end{array}$ & $\begin{array}{l}\text { Argyre rim materials and ejecta deposits (upper mantle materials and older primordial } \\
\text { crustal materials excavated to and near the Martian surface by the impact event and } \\
\text { associated overturn and inversion of stratigraphy) and dissected by basin-related fault } \\
\text { structures and erosional valleys, and degraded through time by wind-, water-, and } \\
\text { gravity-driven processes; rock materials include those emplaced directly following the } \\
\text { Argyre impact event, such as those associated with the formation of the Uzboi-sourcing } \\
\text { lake, as well as those emplaced during subsequent activity, including major stages of } \\
\text { activity of the Tharsis Superplume (Fig. 4). Local basins which formed during and/or } \\
\text { subsequent to the Argyre impact event. The basins have served as catchments for fluvial, } \\
\text { lacustrine, glacial, periglacial, alluvial, and colluvial deposits. The knobs are markers of } \\
\text { the major degradation of the rim materials which has resulted in an inversion of } \\
\text { topography in places. Major degradation through processes including glacial have highly } \\
\text { degraded the rim materials resulting in massifs and basins. This map unit generally marks } \\
\text { a more significant degradational state when compared to unit NArb, and thus a greater } \\
\text { amount of basin materials vs rim massifs. The CRISM data corroborates the Argyre-rim } \\
\text { materials in part being uplifted ancient upper mantle materials, and that the terrains, } \\
\text { which are distinctly hydrologically modified, contain magnesian lithologies such as } \\
\text { olivine-dominated rocks (Buczkowski et al., 2008a,b, 2010) (Fig. 10). }\end{array}$ \\
\hline $\begin{array}{l}\text { Argyre rim } \\
\text { smooth } \\
\text { plains } \\
\text { materials }\end{array}$ & NArsp & $\begin{array}{l}\text { Smooth plains-forming materials in basins } \\
\text { among the Argyre rim materials, marked by } \\
\text { knobs, valley networks, flows which include } \\
\text { aprons along the flanks of knobs, and dune } \\
\text { fields. These basins are generally more } \\
\text { distinct and isolated than those of unit NAbr. }\end{array}$ & $\begin{array}{l}\text { Distinct local basins which formed during and/or subsequent to the Argyre impact event. } \\
\text { The basins have served as catchments for fluvial, lacustrine, glacial, periglacial, alluvial, } \\
\text { hydrothermal, and colluvial deposits. The knobs are markers of the major degradation of } \\
\text { the rim materials. }\end{array}$ \\
\hline \multicolumn{4}{|c|}{ Highlands materials (units AHTp, NTh, HNh4, HNh3, Nhb, Nh2, Nh1) } \\
\hline $\begin{array}{l}\text { Thaumasia } \\
\text { plateau SE }\end{array}$ & AHTp & $\begin{array}{l}\text { Corresponds to unit HNplt of Dohm et al. } \\
\text { (2001a). Uneven surface dissected by } \\
\text { numerous networking large troughs along the } \\
\text { southeastern margin of the Thaumasia plateau; } \\
\text { many troughs abruptly terminate on up-slope } \\
\text { end at large graben and depressions. Marked } \\
\text { in places by ridges. }\end{array}$ & $\begin{array}{l}\text { Easily eroded (i.e., friable) volcanic materials with morphologic expression appearing } \\
\text { similar to dissected ignimbrites which occur along the margin of the Andes (Fig. } 9 \text { of } \\
\text { Dohm et al. (2001a)). The troughs may have formed in part due to Tharsis-driven } \\
\text { magmatism, such as related to the Thaumasia plateau, and associated groundwater } \\
\text { conditions along the distinct break in slope (at the southeast part of the Thaumasia } \\
\text { plateau where there appears to be a discontinuity between the Thaumasia highlands and } \\
\text { Coprates rise mountain ranges). }\end{array}$ \\
\hline $\begin{array}{l}\text { Thaumasia } \\
\text { highlands }\end{array}$ & HNTh & $\begin{array}{l}\text { Corresponds to unit HNpld of Dohm et al. } \\
\text { (2001a). Highly modified impact crater of the } \\
\text { eastern part of the Thaumasia highlands } \\
\text { mountain range, which is embayed and partly } \\
\text { buried by unit HNh } 4 \text { materials along its } \\
\text { southern margin, at the juncture between the } \\
\text { mountain range and the plains. }\end{array}$ & $\begin{array}{l}\text { Highly degraded ancient impact crater that impacted into the Thaumasia highlands } \\
\text { mountain range; highly dissected and locally deformed. Materials include Thaumasia } \\
\text { highlands mountain-building materials, therefore, the geochemical composition and } \\
\text { environmental conditions of the rock materials are interpreted to be diverse and far- } \\
\text { reaching both in time and space, which includes rocks ranging from basalt to felsic } \\
\text { compositions, and rocks with varying grades of metamorphism such as those associated } \\
\text { with orogenic complexes of Earth (Maruyama, 1997; Maruyama et al., 1997, 2013, 2014; } \\
\text { Dohm and Maruyama, 2014a; Dohm et al., 2014a,b). }\end{array}$ \\
\hline $\begin{array}{l}\text { Highlands } \\
\text { member } 4\end{array}$ & HNh4 & $\begin{array}{l}\text { Moderately smooth plains-forming materials; } \\
\text { wrinkle ridges, ridge crests, troughs, and } \\
\text { lineaments in places. }\end{array}$ & $\begin{array}{l}\text { Undifferentiated impact, volcanic, aeolian, fluvial, alluvial, and colluvial materials; } \\
\text { locally degraded and contractionally deformed. Materials include Argyre ejecta } \\
\text { materials and materials shed from the Thaumasia plateau and the Thaumasia highlands } \\
\text { mountain range. Thus the geochemical composition and environmental records of the } \\
\text { rock materials are interpreted to be diverse and far-reaching both in time and space, } \\
\text { which includes rocks ranging from basalt to felsic compositions, and rocks with varying } \\
\text { grades of metamorphism such as those associated with orogenic complexes of Earth } \\
\text { (Maruyama, 1997; Maruyama et al., 1997). Thus unit includes phyllosilicate through } \\
\text { analysis of CRISM data (Buczkowski et al. (2008a,b)). This is consistent with the } \\
\text { interpretation of resurfacing and weathering which includes aqueous processes as per } \\
\text { above. }\end{array}$ \\
\hline $\begin{array}{l}\text { Highlands } \\
\text { member } 3\end{array}$ & HNh3 & $\begin{array}{l}\text { Moderately smooth plains-forming materials; } \\
\text { wrinkle ridges and lineaments in places. }\end{array}$ & $\begin{array}{l}\text { Undifferentiated impact, volcanic, aeolian, fluvial, alluvial, and colluvial materials; } \\
\text { locally degraded and contractionally deformed. Materials include Argyre ejecta } \\
\text { materials and materials shed from the Thaumasia plateau and the Coprates rise mountain } \\
\text { range. Similar to unit HNh4, the geochemical composition and environmental records of } \\
\text { the rock materials are interpreted to be diverse and far-reaching both in time and space, } \\
\text { which includes rocks ranging from basalt to felsic compositions, and rocks with varying } \\
\text { grades of metamorphism such as those associated with orogenic complexes of Earth } \\
\text { (Maruyama, 1997; Maruyama et al., 1997). }\end{array}$ \\
\hline $\begin{array}{l}\text { Highlands } \\
\text { basin }\end{array}$ & Nhb & $\begin{array}{l}\text { Relatively smooth plains-forming materials in } \\
\text { basins located in the cratered highlands along }\end{array}$ & $\begin{array}{l}\text { Basins, many of which are controlled by Argyre-impact-derived basement structures. } \\
\text { Many of the basins record changing environmental and hydrologic conditions, including }\end{array}$ \\
\hline
\end{tabular}




\begin{tabular}{|c|c|c|c|}
\hline materials & & $\begin{array}{l}\text { the margin of and away from the Argyre rim } \\
\text { materials. Several of the basins are elongated } \\
\text { with linear margins and/or tectonic structures, } \\
\text { including AWMP paleolake basin (Figs. 1, 7, } \\
\text { and 8) on the west-central margin of the } \\
\text { Argyre basin and rim materials. The basins are } \\
\text { similar to those of unit NArsp, but many occur } \\
\text { away from the rim materials, and many appear } \\
\text { to have more numerous valley networks along } \\
\text { their margins. }\end{array}$ & $\begin{array}{l}\text { those that were influenced by changing conditions with the Argyre basin. For example, } \\
\text { AWMP was occupied by a lake at least at the zero datum, though there is evidence that } \\
\text { the lake and associated hydraulic head could have reached at least } 1 \mathrm{~km} \text { above the } \\
\text { Martian datum. The basins also record glacial, periglacial, fluvial, aeolian, alluvial, } \\
\text { colluvial, and/or hydrothermal activity, as well as groundwater activity along the } \\
\text { basement structures possibly indicated by channels which occur along the structures (Fig. } \\
\text { 15-16). Though, the channels could be structurally-controlled surface runoff. Many of } \\
\text { the basins occur away from the rim materials and in many cases appear to have margins } \\
\text { dissected by more numerous valley networks when compared to the basins of the unit } \\
\text { NArsp. The distinct younger crater-retention age of unit Nhb when compared to unit } \\
\text { NArsp (see Table 3) possibly reflects greater resurfacing of the former, in part due to } \\
\text { possible enhanced geologic and hydrologic activity in the transition zone that connects } \\
\text { the Thaumasia highlands and plateau with the Argyre rim and basin (Figs 1-3.). The } \\
\text { basins contain sedimentary, lacustrine, evaporite, and hydrothermal deposits, as well as } \\
\text { lower crustal materials and/or upper mantle materials largely related to the Argyre impact } \\
\text { event and eolian deposits sourcing from nearby (rim materials) and distant provenances } \\
\text { (e.g., Tharsis). }\end{array}$ \\
\hline $\begin{array}{l}\text { Highlands } \\
\text { member } 2\end{array}$ & Nh2 & $\begin{array}{l}\text { Rolling topography marked by scarps, } \\
\text { structurally-controlled basins, faults, troughs, } \\
\text { channels, and ridges. Highly dissected in } \\
\text { places such as along the margin of the unit } \\
\text { Nhb materials which infill the AWMP } \\
\text { paleolake basin (Figs. 1, 3, 7). }\end{array}$ & $\begin{array}{l}\text { Undifferentiated impact, volcanic, fluvial, lacustrine, alluvial, colluvial, and basin infill } \\
\text { materials including sedimentary deposits, moderately to heavily degraded. This includes } \\
\text { modified Argyre rim and ejecta deposits (upper mantle materials and older primordial } \\
\text { crustal materials transferred at and near the Martian surface by the impact event and } \\
\text { associated overturn and inversion of stratigraphy). Materials also include those } \\
\text { transported from as far north as Tharsis and the Thaumasia highlands, such as recorded in } \\
\text { the outcrops in the transitional zone between the Thaumasia highlands and the Argyre } \\
\text { basin and rim materials emplaced by fluvial, colluvial, alluvial, and glacial activities } \\
\text { (Fig. 3), and from as far south as the south pole, as recorded in the outcrops which occur } \\
\text { to the south of the Argyre basin and rim materials primarily by glacial and fluvial } \\
\text { activities. The geochemical composition and environmental records of the rock materials } \\
\text { are interpreted to be diverse and far-reaching both in time and space, which includes } \\
\text { rocks ranging from basalt to felsic compositions, and rocks with varying grades of } \\
\text { metamorphism such as those associated with orogenic complexes of Earth (Maruyama, } \\
\text { 1997; Maruyama et al., 1997). For example, an Argyre-impact, structurally-controlled } \\
\text { basin with drainages along its margins (Fig. 16) are shown to include phyllosilicate } \\
\text { (Buczkowski et al., 2008). This is consistent with the interpretation of resurfacing and } \\
\text { weathering which includes aqueous processes as per above. }\end{array}$ \\
\hline $\begin{array}{l}\text { Highlands } \\
\text { member } 1\end{array}$ & Nh1 & $\begin{array}{l}\text { High plateau-forming outcrops extending } \\
\text { hundreds of kilometers, many controlled by } \\
\text { basement structures related to the Argyre } \\
\text { impact event. Densely cratered and valley } \\
\text { networks and scarps mark the landscape. }\end{array}$ & $\begin{array}{l}\text { Extremely ancient crustal materials, which includes igneous, sedimentary, and } \\
\text { metamorphic rocks, buried by Argyre impact ejecta deposits mixed through time due to } \\
\text { impact cratering and water (liquid and ice), wind, and gravity-driven processes. The } \\
\text { elongated and high-standing plateaus are in part due to the Argyre impact and other } \\
\text { tectonism, including pre-Argyre basement structures. Elongated mesas have faults along } \\
\text { their margins, and thus are structurally controlled. }\end{array}$ \\
\hline \multicolumn{4}{|c|}{ Impact crater materials post-dating the Argyre impact event (units C1, C2, Cfs, Cfr) } \\
\hline $\begin{array}{l}\text { Young crater } \\
\text { materials }\end{array}$ & $\mathrm{C} 2$ & $\begin{array}{l}\text { Relatively pristine impact crater materials of } \\
\text { the } \sim 230 \text {-km-diameter Galle impact crater } \\
\text { overly surrounding rock materials of various } \\
\text { units, including younger smooth-plains- } \\
\text { forming basin floor deposits. }\end{array}$ & $\begin{array}{l}\text { Stratigraphically-young, relatively large impact crater. The event contributed to major } \\
\text { change in the topography/terrain of the east-central margin of the Argyre basin and rim } \\
\text { materials. Compared to the } ~ 200-\mathrm{km} \text {-diameter Lowell impact crater, which impacted } \\
\text { into a relatively large basin located to the west of the Argyre province influenced by } \\
\text { ancient tectonism and impact cratering, as well as triggered major ice melt and associated } \\
\text { flooding and valley network formation (Lias et al., 1997; Dohm and Tanaka, 1999), Galle } \\
\text { does not appear to have triggered major flood events. This might be explained by the } \\
\text { impact occurring in the rim materials along the margin of the basin where there are } \\
\text { massifs composed of upper mantle and ancient crustal materials with intervening water- } \\
\text { enriched valleys and local basins (i.e., less volume of water). In addition there may have } \\
\text { been ice melt in the basin, but due to the relatively low gradient, distinct valley networks } \\
\text { did not develop. There are troughs, however, mapped along parts of the southern margin } \\
\text { of the Galle ejecta blanket that could be the result of impact-generated flooding. }\end{array}$ \\
\hline $\begin{array}{l}\text { Old crater } \\
\text { materials }\end{array}$ & $\mathrm{C} 1$ & $\begin{array}{l}\text { Degraded impact crater rims and ejecta } \\
\text { deposits. }\end{array}$ & $\begin{array}{l}\text { Most impact }>50 \text {-kilometer-diameter craters are highly degraded due to the subsequent } \\
\text { impact events and diverse geologic and hydrologic activities in the Argyre province } \\
\text { through time. In the case of Hale crater, CRISM-based identification of low- and high- } \\
\text { calcium pyroxenes and prehnite and chlorite on the floor, the central peak, and the rim of } \\
\text { Hale crater (Fig. 11) are consistent with Argyre-impact-modified terrain, including the } \\
\text { excavation of relatively olivine-rich, deep mantle and/or primordial crustal materials } \\
\text { transferred at or near the Martian surface by the impact event and associated overturn and } \\
\text { inversion of stratigraphy. In addition, the mineralogy is also consistent with hydrothermal } \\
\text { activity possibly associated both with the initial Argyre impact event followed by the } \\
\text { Hale impact event into a potentially water-enriched target materials associated with } \\
\text { hydrologic conditions associated of the Uzboi-Vallis spillway. }\end{array}$ \\
\hline Smooth & Cfs & Smooth plains-forming materials in the highly & Impact basin infill deposits with remnants of rim materials and central peaks. \\
\hline
\end{tabular}




\begin{tabular}{|c|c|c|c|}
\hline $\begin{array}{l}\text { crater floor } \\
\text { materials }\end{array}$ & & $\begin{array}{l}\text { degraded impact basins. Some basins display } \\
\text { knobs. }\end{array}$ & \\
\hline $\begin{array}{l}\text { Rough crater } \\
\text { floor } \\
\text { materials }\end{array}$ & Cfr & $\begin{array}{l}\text { Occurrence only in few impact crater basins, } \\
\text { including Galle impact crater. Irregular } \\
\text { topography, including knobs, depressions, and } \\
\text { scarps. }\end{array}$ & $\begin{array}{l}\text { Degradation of central peak materials, but also disruption of the terrain due to hydrologic } \\
\text { conditions such as Galle-impact-driven following the impact cratering event. }\end{array}$ \\
\hline
\end{tabular}

\section{8}


1549 Table 3. Cumulative crater densities and unit ages of geologic units in the Argyre and surrounding region of Mars.

1550 Note that (1) average crater density N (D) equals number of craters larger than diameter D per million square

1551 kilometers, (2) relative ages based on time-stratigraphic scale from Tanaka (1986), (3) "ALL" refers to both highly

1552 degraded and "Superposed" (pristine impact craters with distinct rims and ejecta blankets that are not visibly

1553

1554

1555

1556

1557

resurfaced). See Tables 1 and 2 for unit names, description, and interpretation. Estimated absolute ages are based on the Hartmann (2005) (referred to as Hartmann in column 2) and Neukum et al. (2001) (referred to as Neukum in column 2) chronology systems. These ages were assigned a range of chronostratigraphic epochs based on the boundaries defined in Neukum et al. (2001), Hartmann (2005), and Werner and Tanaka (2011), also compared with that shown in Tanaka et al. (2014). Epochs include Early Noachian (EN), Middle Noachian, (MN), Late Noachian (LN), Early Hesperian (EH), Late Hesperian (LH), Early Amazonian (EA), Middle Amazonian (MA), and Late Amazonian.

1560

\begin{tabular}{|c|c|c|c|c|c|c|c|c|}
\hline $\begin{array}{l}\text { Unit } \\
\text { Symbol }\end{array}$ & Model & $\operatorname{Area}\left(\mathrm{km}^{2}\right)$ & $\begin{array}{l}\text { Total } \\
\text { Craters }\end{array}$ & $\begin{array}{l}N(3) \text { Age, } \\
\text { Ga }\end{array}$ & $\begin{array}{l}N(5) \text { Age, } \\
\text { Ga }\end{array}$ & $\begin{array}{l}N(16) \text { Age, } \\
\text { Ga }\end{array}$ & $\begin{array}{l}\text { Isochron Age, } \\
\text { Ga/Epoch }\end{array}$ & $\begin{array}{l}\text { Estimated } \\
\text { Range of } \\
\text { Epochs }\end{array}$ \\
\hline \multicolumn{9}{|c|}{ Highlands materials } \\
\hline Nh1 All & Hartmann & 327,794 & 290 & $3.63 \pm 0.01$ & $3.72 \pm 0.02$ & $3.89 \pm 0.02$ & $3.82 \pm 0.03$ & LN-MN \\
\hline Nh1 All & Neukum & 327,794 & 290 & $3.88 \pm 0.01$ & $3.82 \pm 0.01$ & $3.95 \pm 0.02$ & $3.94 \pm 0.02$ & MN-EN \\
\hline $\begin{array}{l}\text { Nh1 } \\
\text { Superposed }\end{array}$ & Hartmann & 327,794 & 71 & $2.25 \pm 0.27$ & $2.94^{+0.26} 0.44$ & $\begin{array}{r}3.39+0.14 \\
0.70\end{array}$ & $3.17^{+0.20} 0.60$ & EA-LH \\
\hline $\begin{array}{l}\text { Nh1 } \\
\text { Superposed }\end{array}$ & Neukum & 327,794 & 71 & $3.61 \pm 0.03$ & $3.63 \pm 0.04$ & $3.54^{+0.09} 0.23$ & $3.61^{+0.04} 0.06$ & LH-EH \\
\hline Nh2 All & Hartmann & $1,096,085$ & 846 & $3.60 \pm 0.01$ & $3.71 \pm 0.01$ & $3.86 \pm 0.01$ & $3.78 \pm 0.01$ & LN- MN \\
\hline Nh2 All & Neukum & $1,096,085$ & 846 & $3.85 \pm 0.01$ & $3.90 \pm 0.01$ & $3.82 \pm 0.01$ & $3.90 \pm 0.01$ & LN- MN \\
\hline $\begin{array}{l}\text { Nh2 } \\
\text { Superposed }\end{array}$ & Hartmann & $1,096,085$ & 189 & $1.78 \pm 0.13$ & $2.70^{+0.22}+0.25$ & $\begin{array}{r}2.89+0.37 \\
0.72\end{array}$ & $2.64^{+0.33}$ & EA \\
\hline $\begin{array}{l}\text { Nh2 } \\
\text { Superposed }\end{array}$ & Neukum & $1,096,085$ & 189 & $3.54 \pm 0.02$ & $3.61 \pm 0.03$ & $3.36^{+0.11} 0.33$ & $3.56 \pm 0.04$ & EA-LH \\
\hline HNh3 All & Hartmann & 168,887 & 108 & $3.55 \pm 0.03$ & $3.62 \pm 0.04$ & $3.75 \pm 0.05$ & $3.66 \pm 0.07$ & EH-LN \\
\hline HNh3 All & Neukum & 168,887 & 108 & $3.82 \pm 0.02$ & $3.84 \pm 0.02$ & $3.82 \pm 0.05$ & $3.83 \pm 0.04$ & LN-MN \\
\hline $\begin{array}{l}\text { HNh3 } \\
\text { Superposed }\end{array}$ & Hartmann & 168,887 & 39 & $2.41 \pm 0.38$ & $3.22^{+0.15} 0.44$ & $2.87_{1.88}^{+0.56}$ & $3.11^{+0.25} 0.79$ & EA \\
\hline $\begin{array}{l}\text { HNh3 } \\
\text { Superposed }\end{array}$ & Neukum & 168,887 & 39 & $3.62 \pm 0.04$ & $3.67 \pm 0.05$ & $3.36^{+0.20} 1.93$ & $3.62+0.05$ & EA -EH \\
\hline HNh4 All & Hartmann & 262,637 & 129 & $3.46 \pm 0.04$ & $3.58 \pm 0.04$ & $\begin{array}{r}3.72^{+0.04} \\
0.06 \\
\end{array}$ & $3.63 \pm 0.05$ & EH-LN \\
\hline HNh4 All & Neukum & 262,637 & 129 & $3.78 \pm 0.02$ & $3.81 \pm 0.02$ & $3.78 \pm 0.05$ & $3.80 \pm 0.03$ & $\mathrm{LN}$ \\
\hline $\begin{array}{l}\text { HNh4 } \\
\text { Superposed }\end{array}$ & Hartmann & 262,637 & 81 & $3.10^{+0.14} 0.25$ & $3.39+0.07$ & $\begin{array}{r}3.22^{+0.25} \\
1.39\end{array}$ & $3.35^{+0.10} 0.22$ & EA-LH \\
\hline $\begin{array}{l}\text { HNh4 } \\
\text { Superposed }\end{array}$ & Neukum & 262,637 & 81 & $3.69 \pm 0.03$ & $3.72 \pm 0.03$ & $3.46^{+0.13} 0.83$ & $3.68 \pm 0.04$ & LH -LN \\
\hline Nhb All & Hartmann & 67,049 & 44 & $3.58 \pm 0.05$ & $3.67 \pm 0.05$ & $\begin{array}{r}3.80+0.06 \\
0.09\end{array}$ & $\begin{array}{r}3.71^{+0.06} \\
0.09\end{array}$ & $\mathrm{LN}$ \\
\hline
\end{tabular}




\begin{tabular}{|c|c|c|c|c|c|c|c|c|}
\hline Nhb All & Neukum & 67,049 & 44 & $3.84 \pm 0.03$ & $3.87 \pm 0.04$ & $3.86^{+0.05} 0.09$ & $3.86^{+0.04} 0.06$ & $\mathrm{MN}$ \\
\hline $\begin{array}{l}\text { Nhb } \\
\text { Superposed }\end{array}$ & Hartmann & 67,049 & 12 & $2.25^{+0.62} 0.65$ & $3.18^{+0.23} 0.92$ & $3.58^{+0.12} 1.09$ & $3.44^{+0.14} 1.01$ & EA- LN \\
\hline $\begin{array}{l}\text { Nhb } \\
\text { Superposed }\end{array}$ & Neukum & 67,049 & 12 & $3.60^{+0.06} 0.10$ & $3.66^{+0.06} 0.10$ & $3.67^{+0.10} 0.43$ & $3.66^{+0.08} 0.16$ & LH- EH \\
\hline HNTh All & Hartmann & 28,531 & 19 & $\begin{array}{r}3.57^{+0.05} \\
0.08 \\
\end{array}$ & $3.59 \begin{array}{r}+0.07 \\
0.13\end{array}$ & $\begin{array}{r}3.73^{+0.10} 0.38 \\
\end{array}$ & $3.60^{+0.07} 0.14$ & $\mathrm{LN}$ \\
\hline HNTh All & Neukum & 28,531 & 19 & $3.83^{+0.03} 0.05$ & $\begin{array}{r}3.82^{+0.05} 0.07 \\
\end{array}$ & $\begin{array}{r}3.80^{+0.09} \\
0.28 \\
\end{array}$ & $\begin{array}{r}3.82+0.05 \\
0.07 \\
\end{array}$ & $\mathrm{LN}$ \\
\hline $\begin{array}{l}\text { HNTh } \\
\text { Superposed }\end{array}$ & Hartmann & 28,531 & 13 & $3.44^{+0.09} 0.23$ & $3.56^{+0.08} 0.18$ & & $3.57_{0.28}^{+0.09}$ & $\mathrm{EH}-\mathrm{LN}$ \\
\hline $\begin{array}{l}\text { HNTh } \\
\text { Superposed }\end{array}$ & Neukum & 28,531 & 13 & $3.77^{+0.04} 0.06$ & $3.80^{+0.05} 0.08$ & & $3.78_{0.11}^{+0.06}$ & $\mathrm{LN}$ \\
\hline AHTp All & Hartmann & 16,282 & 3 & $2.88^{+0.54} 1.65$ & $2.29^{+1.07} 1.88$ & & $2.29^{+1.06} 1.83$ & EA \\
\hline AHTp All & Neukum & 16,282 & 3 & $\begin{array}{r}3.66+0.09 \\
0.29 \\
\end{array}$ & $\begin{array}{r}3.56^{+0.14} \\
2.31 \\
\end{array}$ & & $\begin{array}{r}3.57^{+0.13} \\
1.98 \\
\end{array}$ & LH -EH \\
\hline $\begin{array}{l}\text { AHTp } \\
\text { Superposed }\end{array}$ & Hartmann & 16,282 & 3 & $2.88^{+0.54} 1.65$ & $2.29^{+1.07} 1.88$ & & $2.29^{+1.06} 1.83$ & EA \\
\hline $\begin{array}{l}\text { AHTp } \\
\text { Superposed }\end{array}$ & Neukum & 16,282 & 3 & $3.66^{+0.09} 0.29$ & $3.56^{+0.14}$ & & $3.57_{1.98}^{+0.13}$ & LH -EH \\
\hline \multicolumn{9}{|c|}{ Argyre materials } \\
\hline \multicolumn{9}{|c|}{ Rim materials } \\
\hline NAr All & Hartmann & 58,067 & 31 & $\begin{array}{r}3.50+0.05 \\
0.08 \\
\end{array}$ & $\begin{array}{r}3.63^{+0.05} \\
0.07 \\
\end{array}$ & $3.78^{+0.06}$ & $3.71_{0.10}^{+0.06}$ & EH-LN \\
\hline NAr All & Neukum & 58,067 & 31 & $3.79 \pm 0.04$ & $3.84 \pm 0.04$ & $\begin{array}{r}3.84^{+0.06} \\
0.10 \\
\end{array}$ & $\begin{array}{r}3.84^{+0.05} \\
0.07 \\
\end{array}$ & LN-MN \\
\hline $\begin{array}{l}\text { NAr } \\
\text { Superposed }\end{array}$ & Hartmann & 58,067 & 1 & & & & & \\
\hline $\begin{array}{l}\text { NAr } \\
\text { Superposed }\end{array}$ & Neukum & 58,067 & 1 & & & & & \\
\hline NArb All & Hartmann & 109,274 & 70 & $3.56 \pm 0.04$ & $3.66 \pm 0.04$ & $3.88 \pm 0.04$ & $3.75^{+0.05} 0.07$ & EH- MN \\
\hline NArb All & Neukum & 109,274 & 70 & $3.83 \pm 0.02$ & $3.87 \pm 0.03$ & $3.94 \pm 0.04$ & $3.88 \pm 0.05$ & $\mathrm{LN}-\mathrm{MN}$ \\
\hline $\begin{array}{l}\text { NArb } \\
\text { Superposed }\end{array}$ & Hartmann & 109,274 & 8 & $1.06 \pm 0.37$ & $1.05 \pm 0.50$ & & $0.92 \pm 0.47$ & MA-EA \\
\hline $\begin{array}{l}\text { NArb } \\
\text { Superposed }\end{array}$ & Neukum & 109,274 & 8 & $3.27^{+0.18} 0.88$ & $3.07^{+0.35} 1.40$ & & $2.78^{+0.57} 1.36$ & EA- LN \\
\hline NAbr All & Hartmann & 577,012 & 432 & $3.60 \pm 0.01$ & $3.68 \pm 0.01$ & $3.89 \pm 0.02$ & $3.78 \pm 0.02$ & $\mathrm{LN}-\mathrm{MN}$ \\
\hline NAbr All & Neukum & 577,012 & 432 & $3.85 \pm 0.01$ & $3.88 \pm 0.01$ & $3.95 \pm 0.02$ & $3.90 \pm 0.02$ & MN- EN \\
\hline $\begin{array}{l}\text { NAbr } \\
\text { Superposed }\end{array}$ & Hartmann & 577,012 & 50 & $0.91 \pm 0.13$ & $1.23 \pm 0.24$ & $3.35^{+0.13} 0.50$ & $1.54 \pm 0.35$ & MA- LH \\
\hline $\begin{array}{l}\text { NAbr } \\
\text { Superposed }\end{array}$ & Neukum & 577,012 & 50 & $3.13^{+0.15} 0.32$ & $3.28_{0.30}^{+0.12}$ & $3.51^{+0.08} 0.16$ & $3.30_{0.31}^{+0.12}$ & EA-LH \\
\hline
\end{tabular}




\begin{tabular}{|c|c|c|c|c|c|c|c|c|}
\hline NArsp All & Hartmann & 38,939 & 39 & $3.67 \pm 0.04$ & $3.75 \pm 0.04$ & $3.98 \pm 0.05$ & $3.93 \pm 0.06$ & MN-EN \\
\hline NArsp All & Neukum & 38,939 & 39 & $3.90 \pm 0.03$ & $3.94 \pm 0.04$ & $4.04 \pm 0.05$ & $4.02 \pm 0.05$ & MN-EN \\
\hline $\begin{array}{l}\text { NArsp } \\
\text { Superposed }\end{array}$ & Hartmann & 38,939 & 7 & $1.88 \pm 0.71$ & $1.86^{+1.07} 1.11$ & & $1.90^{+1.06} 1.11$ & EA \\
\hline $\begin{array}{l}\text { NArsp } \\
\text { Superposed }\end{array}$ & Neukum & 38,939 & 7 & $3.56^{+0.08} 0.19$ & $3.50^{+0.13}$ & & $3.51_{0.87}^{+0.12}$ & LH \\
\hline \multicolumn{9}{|c|}{ Basin materials } \\
\hline NAb1 All & Hartmann & 100,203 & 42 & $3.39^{+0.07} 0.12$ & $3.59^{+0.04} 0.06$ & $3.91 \pm 0.04$ & $\begin{array}{r}3.95^{+0.05} 0.08\end{array}$ & LH-MN \\
\hline NAb1 All & Neukum & 100,203 & 42 & $3.75 \pm 0.03$ & $3.82 \pm 0.04$ & $3.96 \pm 0.04$ & $4.01^{+0.05} 0.09$ & LN-EN \\
\hline $\begin{array}{l}\text { NAb1 } \\
\text { Superposed }\end{array}$ & Hartmann & 100,203 & 6 & $0.66 \pm 0.27$ & $1.03 \pm 0.51$ & & $0.91 \pm 0.55$ & MA \\
\hline $\begin{array}{l}\text { NAb1 } \\
\text { Superposed }\end{array}$ & Neukum & 100,203 & 6 & $2.38^{+0.77} 0.97$ & $3.03^{+0.39}$ & & $2.57^{+0.77}+.47$ & $\mathrm{LN}$ \\
\hline NAb2 All & Hartmann & 209,887 & 105 & $3.47 \pm 0.05$ & $3.57 \pm 0.04$ & $3.72 \pm 0.06$ & $3.63 \pm 0.06$ & EH-LN \\
\hline NAb2 All & Neukum & 209,887 & 105 & $3.78 \pm 0.02$ & $3.81 \pm 0.02$ & $3.78 \pm 0.05$ & $3.80 \pm 0.04$ & $\mathrm{LN}$ \\
\hline $\begin{array}{l}\text { NAb2 } \\
\text { Superposed }\end{array}$ & Hartmann & 209,887 & 15 & $0.80 \pm 0.21$ & $1.03 \pm 0.36$ & $1.78^{+1.25} 1.33$ & $1.12 \pm 0.57$ & MA-EA \\
\hline $\begin{array}{l}\text { NAb2 } \\
\text { Superposed }\end{array}$ & Neukum & 209,887 & 15 & $2.85^{+0.40} 0.72$ & $3.04^{+0.33} 0.99$ & $2.55^{+0.85} 1.91$ & $2.83_{1.21}^{+0.51}$ & EA \\
\hline NAb3 All & Hartmann & 208,086 & 127 & $3.54 \pm 0.03$ & $3.65 \pm 0.03$ & $3.79 \pm 0.05$ & $3.72 \pm 0.05$ & EH-LN \\
\hline NAb3 All & Neukum & 208,086 & 127 & $3.81 \pm 0.02$ & $3.86 \pm 0.02$ & $3.85 \pm 0.04$ & $3.87 \pm 0.04$ & LN-MN \\
\hline $\begin{array}{l}\text { NAb3 } \\
\text { Superposed }\end{array}$ & Hartmann & 208,086 & 18 & $0.98 \pm 0.23$ & $1.45 \pm 0.42$ & $2.63^{+0.74} 1.63$ & $1.76 \pm 0.78$ & MA-EA \\
\hline $\begin{array}{l}\text { NAb3 } \\
\text { Superposed }\end{array}$ & Neukum & 208,086 & 18 & $3.22^{+0.17} 0.53$ & $3.39^{+0.11} 0.36$ & $3.29+0.24$ & $3.34^{+0.16} 0.87$ & EA-LH \\
\hline HAb4a All & Hartmann & 341,499 & 125 & $3.31_{0.09}^{+0.06}$ & $3.45^{+0.05} 0.06$ & $3.55^{+0.07} 0.13$ & $3.46^{+0.06} 0.10$ & LH-EH \\
\hline HAb4a All & Neukum & 341,499 & 125 & $3.73 \pm 0.02$ & $3.74^{+0.02} 0.03$ & $\begin{array}{r}3.65^{+0.06} \\
0.09 \\
\end{array}$ & $3.72 \pm 0.03$ & EH-LN \\
\hline $\begin{array}{l}\text { HAb4a } \\
\text { Superposed }\end{array}$ & Hartmann & 341,499 & 21 & $0.70 \pm 0.15$ & $1.11 \pm 0.29$ & $1.67 \pm 1.02$ & $1.29 \pm 0.56$ & MA-EA \\
\hline $\begin{array}{l}\text { HAb4a } \\
\text { Superposed }\end{array}$ & Neukum & 341,499 & 21 & $2.51^{+0.49} 0.55$ & $3.17^{+0.21}$ & $\begin{array}{r}2.40^{+0.90} \\
1.46\end{array}$ & $2.91^{+0.43} \begin{array}{r}1.07 \\
\end{array}$ & EA \\
\hline NAb4b All & Hartmann & 18,541 & 11 & $\begin{array}{r}3.53+0.07 \\
0.15 \\
\end{array}$ & $3.62^{+0.08} 0.16$ & $\begin{array}{r}3.88^{+0.07} \\
0.15 \\
\end{array}$ & $3.71^{+0.07} 0.14$ & EH- MN \\
\hline NAb4b All & Neukum & 18,541 & 11 & $\begin{array}{r}3.81^{+0.04} 0.06 \\
\end{array}$ & $\begin{array}{r}3.84^{+0.06} \\
0.09 \\
\end{array}$ & $\begin{array}{r}3.94^{+0.07} \\
0.14 \\
\end{array}$ & $\begin{array}{r}3.86^{+0.06} \\
0.10 \\
\end{array}$ & LN-MN \\
\hline $\begin{array}{l}\text { NAb4b } \\
\text { Superposed }\end{array}$ & Hartmann & 18,541 & 1 & & & & & \\
\hline $\begin{array}{l}\text { NAb4b } \\
\text { Superposed }\end{array}$ & Neukum & 18,541 & 1 & & & & & \\
\hline
\end{tabular}


Table 4. Locations and diameters of impact craters that were subtracted from unit polygons and either deleted (if embayed or buried by the geologic-unit materials) or added to older adjacent polygons, if the impact craters were insufficent in size to map at scale (impact craters $<50 \mathrm{~km}$ were not mapped) and that form part of the basement of 1565 an adjacant unit.

\begin{tabular}{|c|c|c|c|c|}
\hline Crater Latitude & Crater Longitude & Crater Diameter & Original Unit & New Unit \\
\hline-40.305 & -28.184 & 9.75 & NAb1 & NAbr \\
\hline-36.638 & -44.771 & 14.79 & NAb1 & NAbr \\
\hline-39.801 & -30.932 & 18.02 & NAb1 & NAbr \\
\hline-37.044 & -44.678 & 25.36 & NAb1 & NAbr \\
\hline-53.828 & -60.247 & 26.26 & NAb1 & NAbr \\
\hline-54.075 & -60.848 & 33.1 & NAb1 & NAbr \\
\hline-51.854 & -56.198 & 32.57 & NAb2 & NAb1 \\
\hline-36.417 & -34.001 & 13.33 & NAb2 & NAbr \\
\hline-49.567 & -57.932 & 15.36 & $\mathrm{NAb} 2$ & NAbr \\
\hline-47.44 & -56.569 & 19.99 & $\mathrm{NAb} 2$ & NAbr \\
\hline-39.722 & -50.336 & 20.18 & $\mathrm{NAb} 2$ & NAbr \\
\hline-38.712 & -36.819 & 21.86 & $\mathrm{NAb} 2$ & NAbr \\
\hline-40.061 & -50.62 & 30 & $\mathrm{NAb} 2$ & NAbr \\
\hline-47.25 & -51.091 & 30.31 & $\mathrm{NAb} 2$ & $\mathrm{NAr}$ \\
\hline-55.86 & -28.366 & 17.63 & $\mathrm{NAb} 2$ & NAbr \\
\hline-45.429 & -51.322 & 21.64 & $\mathrm{NAb} 2$ & NAbr \\
\hline-55.077 & -28.822 & 29.97 & $\mathrm{NAb} 2$ & NAbr \\
\hline-58.758 & -37.004 & 31.71 & $\mathrm{NAb} 2$ & NAbr \\
\hline-54.424 & -30.015 & 40.3 & NAb2 & NAbr \\
\hline-60.278 & -31.703 & 34.99 & $\mathrm{NAb} 2$ & $\mathrm{C} 1$ \\
\hline-59.801 & -32.414 & 88.48 & NAb2 & $\mathrm{C} 1$ \\
\hline-57.532 & -47.336 & 15.77 & $\mathrm{NAb} 2$ & DELETED \\
\hline-57.321 & -47.132 & 22.4 & $\mathrm{NAb} 2$ & DELETED \\
\hline-57.711 & -47.689 & 23.27 & $\mathrm{NAb} 2$ & DELETED \\
\hline-37.414 & -45.548 & 65.84 & $\mathrm{NAb} 2$ & $\mathrm{Nh} 2$ \\
\hline-37.663 & -44.297 & 24.88 & NAb3 & NAb1 \\
\hline-41.183 & -44.762 & 10.88 & NAb3 & $\mathrm{NAb} 2$ \\
\hline-36.456 & -40.301 & 12.41 & NAb3 & NAb2 \\
\hline-41.452 & -45.804 & 26.73 & NAb3 & $\mathrm{NAb} 2$ \\
\hline-43.959 & -35.512 & 37.55 & NAb3 & $\mathrm{NAb} 4 \mathrm{~b}$ \\
\hline-38.684 & -40.428 & 7.07 & NAb3 & NAbr \\
\hline-59.475 & -34.64 & 13.25 & NAb3 & NAbr \\
\hline-38.493 & -40.22 & 17.02 & NAb3 & NAbr \\
\hline-38.617 & -40.194 & 18.65 & NAb3 & NAbr \\
\hline
\end{tabular}




\begin{tabular}{|c|c|c|c|c|}
\hline-44.446 & -50.275 & 19.05 & NAb3 & NAbr \\
\hline-42.065 & -42.51 & 19.53 & NAb3 & NAbr \\
\hline-42.374 & -40.675 & 22.18 & NAb3 & NAbr \\
\hline-40.849 & -45.449 & 22.76 & NAb3 & NAbr \\
\hline-37.562 & -40.259 & 24.17 & NAb3 & NAbr \\
\hline-35.936 & -39.94 & 39.08 & NAb3 & NAbr \\
\hline-56.377 & -48.634 & 33.93 & NAb3 & NAbr \\
\hline-44.244 & -47.438 & 44.76 & NAb3 & NAbr \\
\hline-45.635 & -53.679 & 55.35 & NAb3 & NAbr \\
\hline-48.295 & -51.868 & 12.25 & $\mathrm{HAb} 4 \mathrm{a}$ & NAb3 \\
\hline-45.997 & -45.204 & 17.43 & $\mathrm{HAb} 4 \mathrm{a}$ & NAb3 \\
\hline-45.164 & -48.919 & 21.76 & $\mathrm{HAb} 4 \mathrm{a}$ & NAb3 \\
\hline-44.109 & -43.14 & 25.08 & HAb4a & NAb3 \\
\hline-49.686 & -51.647 & 41.16 & HAb4a & NAb3 \\
\hline-50.331 & -52.102 & 50.74 & HAb4a & NAb3 \\
\hline-44.555 & -44.613 & 61.66 & HAb4a & NAb3 \\
\hline-44.921 & -44.396 & 137.65 & HAb4a & NAb3 \\
\hline-44.662 & -41.999 & 13.39 & HAb4a & NAb4b \\
\hline-44.655 & -42.172 & 31.36 & HAb4a & NAb4b \\
\hline-56.185 & -38.817 & 16.12 & HAb4a & NAbr \\
\hline-58.668 & -43.38 & 40.02 & NAbr & NAbr \\
\hline-37.595 & -48.313 & 16.77 & NAbr & $\mathrm{C} 1$ \\
\hline-38.721 & -51.999 & 9.75 & NAbr & NH1 \\
\hline-46.861 & -59.793 & 46.16 & NAbr & NH1 \\
\hline-35.02 & -38.202 & 29.98 & NAbr & $\mathrm{NH} 2$ \\
\hline-51.892 & -25.252 & 5.65 & NAb1 & NAbr \\
\hline-52.208 & -25.259 & 18.01 & Nab1 & NAbr \\
\hline-43.181 & -27.659 & 18.88 & NArsp & NAbr \\
\hline-43.062 & -21.139 & 31.6 & NArsp & NAbr \\
\hline-41.351 & -21.413 & 37.88 & NArsp & NAbr \\
\hline-42.975 & -24.089 & 92.95 & NArsp & NAbr \\
\hline-57.411 & -41.322 & 16.92 & NArsp & NAbr \\
\hline-44.129 & -32.156 & 79.2 & Cfs & NAbr \\
\hline-37.056 & -60.805 & 30.2 & $\mathrm{Nh} 2$ & Nh1 \\
\hline-64.622 & -24.344 & 30.95 & $\mathrm{Nh} 2$ & Nh1 \\
\hline-63.796 & -20.772 & 50.89 & $\mathrm{Nh} 2$ & Nh1 \\
\hline-64.161 & -24.627 & 52.77 & $\mathrm{Nh} 2$ & Nh1 \\
\hline-63.402 & -22.169 & 65.09 & $\mathrm{Nh} 2$ & Nh1 \\
\hline-38.218 & -61.205 & 105.4 & HNh4 & Nh1 \\
\hline
\end{tabular}




\begin{tabular}{|c|c|c|c|c|}
\hline-57.335 & -60.314 & 34.04 & Nhb & Nh1 \\
\hline-57.532 & -61.383 & 36.48 & Nhb & Nh1 \\
\hline-37.224 & -47.579 & 27.2 & Nhb & Nh2 \\
\hline-51.377 & -64.965 & 30.86 & Nhb & Nh2 \\
\hline-51.692 & -65.646 & 34.66 & Nhb & Nh2 \\
\hline-49.95 & -67.362 & 36.85 & Nhb & Nh2 \\
\hline-35.987 & -47.608 & 47.77 & Nhb & Nh2 \\
\hline-50.833 & -68.723 & 101.32 & Nhb & Nh2 \\
\hline
\end{tabular}

1566 



Fig. 1. Mars Orbiter Laser Altimeter Map showing the planet shape with the zonal spherical harmonic degree 1 removed (Smith et al. 1999) and nomenclature and general locations of features of interest, including Argyre basin, Tharsis and Elysium, both interpreted here as superplumes, Uzboi Vallis, the Argyre western-margin-paleolake basin (AW), Thaumasia plateau (TP), Thaumasia highlands mountain range (TH), Coprates rise mountain range (CR), Claritas Rise (Clr), Prometheus crater (Pr), Dorsa Argentea (DA), Ladon basin (LB), the northwestern slope valleys (NSVs), the ancient Europe-size drainage basin which may have contributed floodwaters to the circumChryse outflow channel system (black arrowheads pointing to the northern, eastern, southern, and western margins), Malea Planum volcanic province (MP), Tyrrhenus/Hadriacus volcanic province (T/H), Syrtis Major volcanic provice (SM), Pathfinder landing site (xPF), Viking 1 landing site (xV1), Viking 2 landing site (xV2), Spirit landing site $(\mathrm{xS})$, and Opportunity landing site $(\mathrm{xO})$. Note that this geologic investigation points to the dark blue patches in the Argyre province (see Fig. 2 for outline of province), representative of relatively low topography, being inundated by water directly following the Argyre impact event (please also compare with Fig. 9). Also note the southeastern margin of the Thaumasia plateau paralleling the multi-ring structure of the Agyre impact, and as such, one of the many pieces of evidence of the influence that Tharsis and Argyre had on one another (also see Fig. 2). 


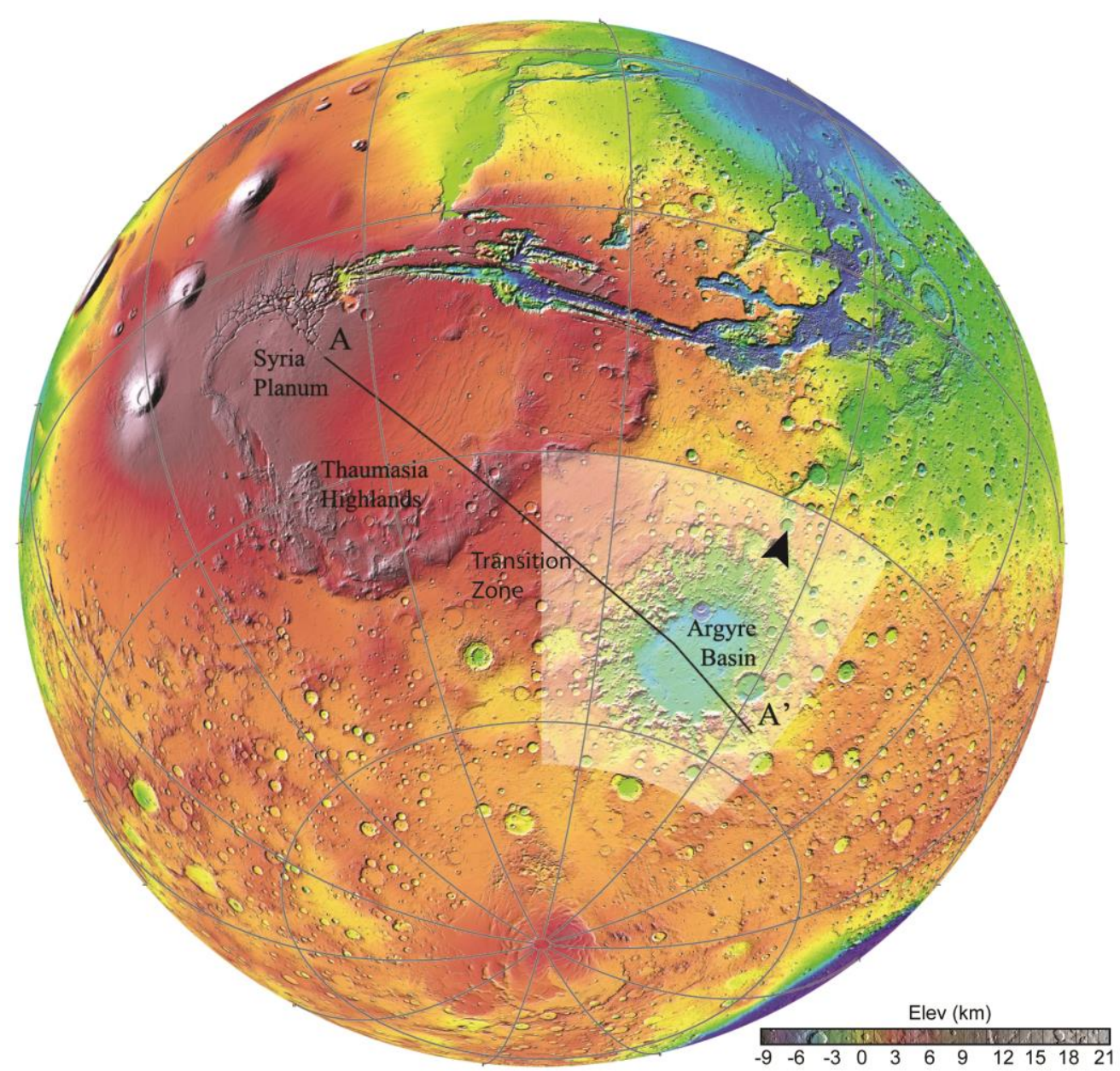

A

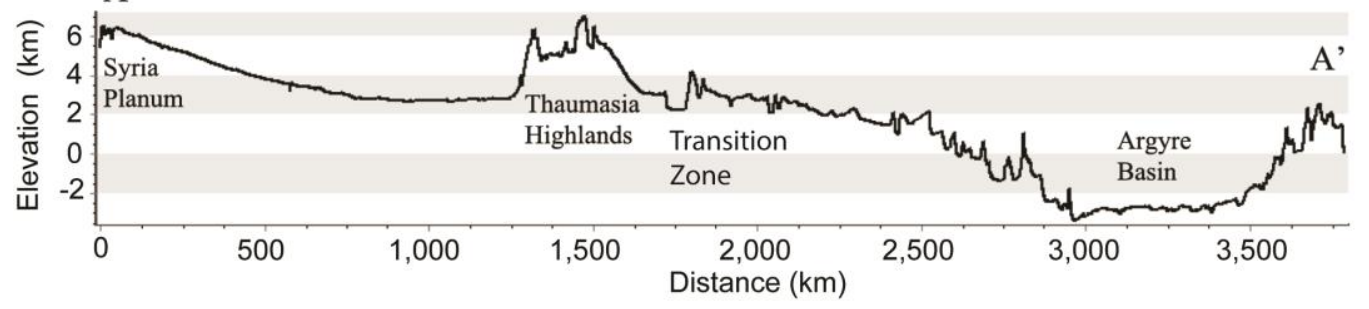

Fig. 2. MOLA map (top) with transect line of corresponding topographic profile (bottom) through Syria Planum (i.e., a shield complex and one of the major components of Tharsis), Thaumasia Highlands (i.e., mountain range with a length nearing 2,400 km, or approximating that of the Himalayas), Transition Zone, and the Argyre Basin. The Argyre province is also highlighted at top (transparent box). Also shown is the possible headwaters of Uzboi Vallis (arrow). Note the rugged topography in the Argyre province resulting from the giant impact event including mountainous rim materials and structurally-controlled basins, including the deep primary basin. Both Tharsis and Argyre had a major influence on one another. For example, Tharsis magmatic-driven hydrological cycling included floods and associated inundations in the northern plains and associated precipitation in and surrounding the Argyre basin to form lakes and grow glaciers, as well as groundwater activity along Argyre impact-induced basement structures, which includes the possible migration at great distances (e.g., thousands of kilometers from Tharsis through the ancient Thaumasia highlands mountain range and eventually into the deep Argyre basin). Other diverse climatic and hydrologic phenomena may include fog in the Argyre basin and local precipitation due to the regional topographic variation. Yin (2012a) proposed an oblique impact event to help explain the distinct topography to the northwest of the Argyre basin, and the development of Tharsis, while other hypotheses for the origin of Tharsis include focused subduction of hydrated crustal materials through an ancient phase of plate tectonism (Baker et al., 2007). 




1601

1602

1603

1604

1605

1606

1607

1608

Fig. 3. Geologic map of the Argyre and surrounding region of Mars showing stratigraphy and structure (Dohm et al., USGS map in preparation). Map units are detailed in Tables 1-3. Also highlighted are the major valley systems, Uzboi Vallis (Uzboi), Surius Vallis (SV), Dzigai Vallis (DV), and Nia Vallis (NV), the Argyre western-marginpaleolake basin (AWMP), and locations of Figs. 10, 11, 12, 13, 14, 15, 16, and 19. 




Fig. 4. Modified from Dohm et al. (2007a), chart comparing the major stages of the Tharsis Superplume, which includes circum-Chryse, NSVs, and Tharsis drainage basin/aquifer system, with: (1) heat flow; note the maximum effective heat flow from the core to lithosphere in the Early and Middle Noachian (black line) and non-steady-state decline in subjective heat flow extending from part of the Early Noachian to present (red line) compared to proposed steady-state decline in mantle temperature with time (black line; Schubert et al., 1992) based on published geologic information (e.g., Dohm and Tanaka, 1999; Dohm et al., 2001a,b, 2007a, 2013; Anderson et al., 2001; Fairén et al., 2003; Baker et al., 2007), (2) hypothesized Tharsis-triggered inundations in the northern plains ranging from oceans to lakes (Shorelines 1 and 2 as per Fairén et al. (2003)), (3) inferred absolute time (Hartmann, 2005), and (4) System information of Scott et al. (1986-87). Sizes of solid areas are roughly proportional to degree of exposed activity. The estimated timing of the Argyre impact is also shown (black arrowhead), based on Robbins and Hynek (2012) and Robbins et al. (2013). The onset of Tharsis and other features are queried. Based on uncertainties in the unit age ranges and error in crater statistics, we conservatively show overlap among the stages with sawtooth lower and upper bounds of each column. Subjective heat flow greater than $4.0 \mathrm{Ga}$ is queried, with consideration of a dynamo and plate tectonism reportedly active at that time (Baker et al., 2007; Dohm et al., 2013). 




Fig. 5. Mean elevations for Argyre map units detailed in Tables 1-3. Note the distinct step-like mean elevation ranges of the basin units (NAb1, NAb2, NAb3, NAb4b, HAb4a) representative of distinct stratigraphy within the basin. 



Fig. 6. Merged Daytime THEMIS with MOLA topography using Geographic Information Systems with approximate geologic contacts delineating distinct stratigraphic relations highlighted in and surrounding Dzigai Vallis (left), as portrayed in the geologic map of Fig. 3 (right; part of the geologic map shown at the right; note the structure symbols are not shown), one of three distinct valleys that debouch into the Argyre basin (the other two being western Surius Vallis and eastern Nia Vallis). Note the spatial correlations among the map units, scarps, and distinct elevation ranges generally highlighted by the topographic-based color scheme with (from young to old generally with increasing mean elevations shown in Fig. 5): dark blue to violet demarking the lowest and youngest basin materials - unit HAb4a (gray on geologic map), dark blue to light blue — unit Nab3 (violet on map), light blue - unit NAb2 (dark blue on map), and light green delineating the oldest and highest standing — unit Nab1 (light blue on map). These stratigraphic sequences, which generally occur at elevational ranges, are consistently observed around the basin, interpreted to mark changing hydraulic head and associated major changes in basin conditions 
1648

1649

1650

1651

1652

1653

1654

1655

1656

1657

Fig. 7. Based on Dohm et al. (2011a), MOLA color shaded relief map coupled with a THEMIS IR daytime mosaic highlighting the western part of the Argyre western margin paleolake (AWMP, left) and its location with respect to the Argyre basin as shown on part of the geologic map of Fig. 3 (right). Argyre-induced tectonic structures (left, black lines), drainage systems that debouched into the basin (left, representative drainages highlighted by blue lines), and a possible spillway (right, white arrow which also marks a graben-like structure that may have influenced water flow or later deformed the possible spillway). Note that the drainage systems terminate within a contour interval generally ranging from 0 to $1.5 \mathrm{~km}$ (within the green-highlighted topography, which could mark a topographic bench and once associated high-standing lake); the latter elevation occurs at a possible spillway divide (right, dashed black line) at present-day topography (see Fig. 8).







c.


Fig. 8. Topographic profiles (A. red, B. violet, C. blue, and D. black) and associated transects annotated on a MOLA map (top) through the Argyre west margin paleolake (AWMP), Uzboi spillway (USR), Argyre primary basin (APB), and Argyre rim materials. Note the potential equipotential surface of the highest standing Argyre lake, AWMP, and USR, and the mean elevation of the highest occurring and oldest member/sequence of the basin infilling materials (unit NAb1) at a similar elevation shown in Fig. 5 (hovering around an elevation of zero (light blue arrows)), as well as an even higher potential equipotential surface indicated by benches, terraces, possible spillway of AWMP into the primary Argyre impact basin, and higher reaches of unit NAb1 (nearing $1.5 \mathrm{~km}$ (dark blue arrows)). Hydrologic activity would have involved the margins at higher reaches, and the Uzboi drainage system would have cut into the impact crater rim materials. 

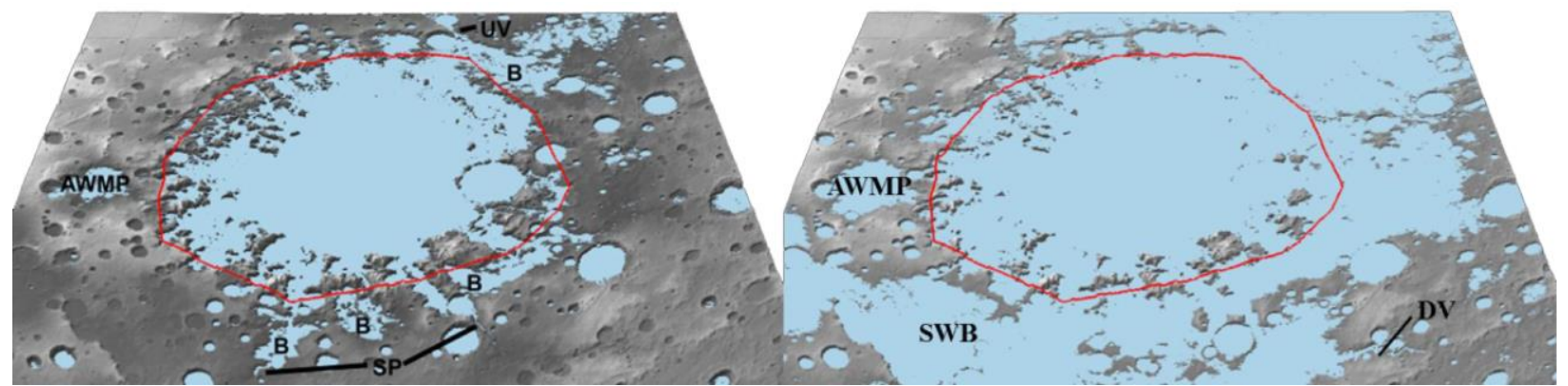

Fig. 9. (left) Based on Dohm et al. (2011a), schematic paleolake map of the Argyre basin using a maximum topographic elevation of $0 \mathrm{~km}$ based on MOLA topography (regions in blue). An estimated extent of the hypothesized Argyre lake based on geomorphologic and topographic analyses, as well as detailed geologic mapping is also shown (red line). In addition to the estimated extent, dendritic channel systems (SP), local basins (B) which occur among the crater rim materials, and the Uzboi Vallis system (UV) correspond to the blue-highlighted region. Also shown is a small extent (near base level) of AWMP. The volumes of the hypothesized AWMP and Argyre lakes are estimated to be $1.6 \times 10^{4}$ and $1.9 \times 10^{6} \mathrm{~km}^{3}$, respectively, using MOLA. There is significant evidence of water-ice modification (e.g., glaciation) as shown by e.g., Hiesinger and Head (2002). Ever changing conditions in the Argyre basin includes a possible interplay among lakes, ice sheets, and glaciers through time, including waning water bodies. Also compare with Figs. 3, 5-8. (right) Similar to left, but at $1 \mathrm{~km}$ with an estimated volume of 3.1 million $\mathrm{km}^{3}$, nearing that of the Mediterranean Sea. Note that the potential water extent maps to a greater extent of the AWMP lake, the drainage basin located to the southwest of the Argyre basin (SWB), which displays drainage networks along its margins, and a distinct dendritic valley located to the southeast of the primary Argyre basin (DV). 



1685

1686

1687

1688

1689

1690

1691

1692

1693

1694

1695

1696

1697

1698

1699

1700

1701
Fig. 10. CRISM-based information combined with the MOLA data and geologic map of this investigation and for spectroscopic/stratigraphic investigation (spectroscopic information corresponds with unit NAbr-Argyre basin and rim materials; see location on geologic map of Fig. 3). Example of olivine and low-calcium pyroxene outcrops in the Neridium Montes; these are mountainous highly degraded Argyre rim materials mapped as unit NAbr materials. a) Mosaic of CRISM FRT observations 7A9C and 985D, with location shown on a MOLA map (top right), draped over MOLA topography (vertical exaggeration x5). b) Mosaic of summary parameters of FRT 7A9C and 985D. Red indicates olivine, green indicates low-calcium pyroxene and blue indicates high-calcium pyroxene. c) Sample ratioed spectra from FRT 7A9C and 985D. Location of where each spectrum was acquired is indicated by arrows in part a. Dark red arrow indicates location of dark red olivine spectrum, bright red arrow indicates location of bright red olivine spectrum, teal arrow indicates location of teal low-calcium pyroxene spectrum. The CRISM data corroborates the Argyre-rim materials in part being uplifted ancient upper mantle materials, and that the terrains, which are distinctly hydrologically modified, contain magnesian lithologies such as olivine-dominated rocks (Buczkowski et al., 2008a,b, 2010). 



1703

1704

1705

1706

1707

1708

1709

1710

1711

1712

1713

1714

1715

1716

1717

1718

1719

1720

1721

1722

1723

1724

1725

1726 e)





Green: high-calcium pyroxene

Fig. 11. CRISM-based information combined with the MOLA data and geologic map of this investigation for spectroscopic/stratigraphic investigation (spectroscopic information corresponds with unit C1-old crater materials; see location on geologic map of Fig. 3).

Location of CRISM images FRT94F9 and FRT 9BDA observations covering parts of the rim and floor materials of Hale crater shown on a MOLA map ((a) white arrows). b) Sample spectra from CRISM FRT 9BDA (black line) and 94F9 (red line). Blue spectrum is of a library prehnite (USGS spectral library splib06a). Black vertical lines mark out wavelengths of interest. c) Georeferenced CRISM image FRT 94F9 (left) and summary parameter image (right). Arrows point to location where spectrum in part (b) was sampled. d) Tetracorder analysis of FRT 94F9 indicates that chlorite and prehnite are common on the Hale crater rim, while both low- and highcalcium pyroxenes are present both on the crater floor and outside the crater. e) Geo-referenced CRISM image FRT 9BDA (left) and summary parameter image (right). Arrows point to location where spectrum in part (b) was sampled. These minerals are consistent with Argyre-impactmodified terrain, including the excavation of relatively olivine-rich, deep mantle and/or primordial crustal materials transferred at or near the Martian surface by the impact event and associated overturn and inversion of stratigraphy, as well as hydrothermal activity possibly persisting for millions of years following the Argyre impact event. The Hale-crater-forming impact event occurred near the spillway of Uzboi Vallis, and thus possible water enrichment of the Hale target materials may have contributed to hydrothermal activity related to the Hale impact event subsequent to the relatively long-lived Argyre-driven hydrothermal activity (estimated to have persisted for $10 \mathrm{Ma}$ (Abramov and Kring, 2005) following the $\sim 3.93 \mathrm{Ga}$ Argyre impact event (based from Robbins et al., 2013). 



Fig. 12. Based on Williams et al. (2014), possible vent structure at the floor of Argyre basin (see location on geologic map of Fig. 3). The landform could be a sedimentary (e.g., mud volcano), volcanic (e.g., cinder cone or maar), or impact-related feature, either formed before (i.e., now exhumed through differential erosion), during emplacement of unit $\mathrm{HAb} 4 \mathrm{a}$, or following emplacement of unit HAb4a; high-standing 'rim' is $\sim 1 \mathrm{~km}$ higher than interior and surrounding terrain. (top) MOLA DEM and (bottom) THEMIS daytime IR (middle) CTX superposed on MOLA. Late Hesperian (or younger) venting of volatiles during the emplacement of unit HAb4a sediments, which includes flooding, ponding to form a lake, and rapid sedimentation during the final sequence of the basin infill deposits, could have resulted in mud volcanism along the floor of the basin. 




Fig. 13. Based on El Maarry et al. (2013), CTX image of the Moanda crater-valley system (MCVS) deposits (see location on geologic map of Fig. 3) showing several stages of environmental change and associated surface modification (white arrows point to multiple resurfacing events by varying processes, including possible glacial, alluvial, periglacial, fluvial, among others). Several small valleys dissect the MCVS deposits, which may have covered the whole region after their emplacement, as is evident from the deposits filling a $1.5-\mathrm{km}$-wide impact crater at the upper right of the view. Note the circular hills (white box) and flow materials partly covering the impact crater (black box) which may yet contain significant amounts of volatiles beneath a dry mantle (El Maarry et al., 2013). 




Fig. 14. The northern part of HiRISE image PSP_006888_1410 (see location on geologic map of Fig. 3) clearly shows gullies that source at a geologic contact (blue arrows), which separates the overlying layered deposits (yellow arrows) from more massive-appearing deposits (red arrows). The gullies occur within distinct topographic depressions (terrestrial thermokarst- or karst-like; white arrows) with associated debris aprons partly infilling the depressions, as well as partly burying dune deposits (black arrow). Groundwater and stratigraphic control appear 1755 influential on gully formation. 



Fig. 15. Based on Soare et al. (2014b), gullies and graben-like cavities upslope of candidate open system pingos (OSP, red arrows), with arcuate ridges in between, interpreted to be moraines (blue arrows) (see location on geologic map of Fig. 3). HiRISE image ESP_020720_1410. (a) Overview of the site, showing the locations of insets $\mathrm{b}-\mathrm{d}$ and the downslope position of the putative OSPs relative to the gullies and arcuate ridges. (b) Top of the alcove of the eastern gully, showing an abrupt start of the channel embedded in the graben-like elongated depression. A possible landslide scar is located at the northern tip of the cavity. (c) Top of the alcove of the western gully, with rill-like features running into the graben-like cavity; the features seem to originate upslope from the nonpolygonised terrain. Note the polygonal network within the cavity and in the surrounding terrain; black arrow points to location with low-centered polygons. (d) Mid-part of the eastern gully, with multiple terraces (i,ii) and multiple self-blocking digitate deposits (iii,iv), as indicated by black arrows. Note the distinct lineaments, which we interpret to be fractures and faults, as well as a polygonal network within the cavity and in the surrounding terrain. Image credits: NASA/JPL/University of Arizona. 


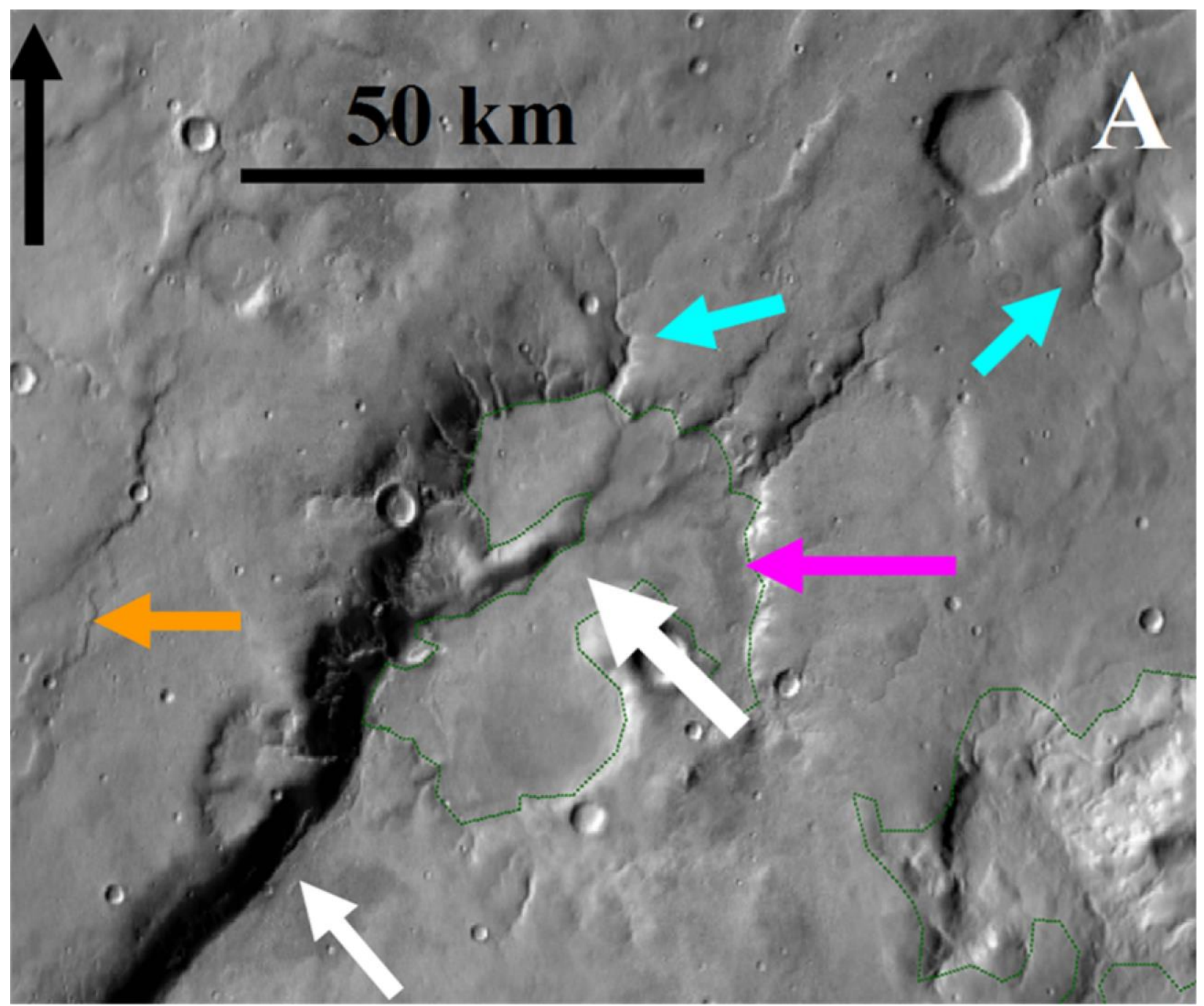

Fig 16. (left) THEMIS IR daytime images showing an Argyre impact-induced prominent fault (narrow white arrow) that splays out to the north-northeast (broad white arrow), deforming a drainage basin (violet arrow) (see location on geologic map of Fig. 3); this indicates post-Argyre-impact isostatic adjustment of basement structures. Also shown are drainages (blue arrows) and a wrinkle ridge (orange arrow), some of which appear to be controlled by underlying faults generated by the Argyre impact event. The structural feature is identified as a macrostructure (a structure 
a


1786

Fig 17. (A) MOLA topography (B) and free-air gravity derived from the Mars gravity field MRO110B2 (Konopliv 1787 et al., 2011) of Argyre Province. Lines show ground tracks of profiles in Fig. 18. 



Fig. 18. (a) Topography and (b) free-air gravity anomaly profiles through the center of the Argyre basin. 

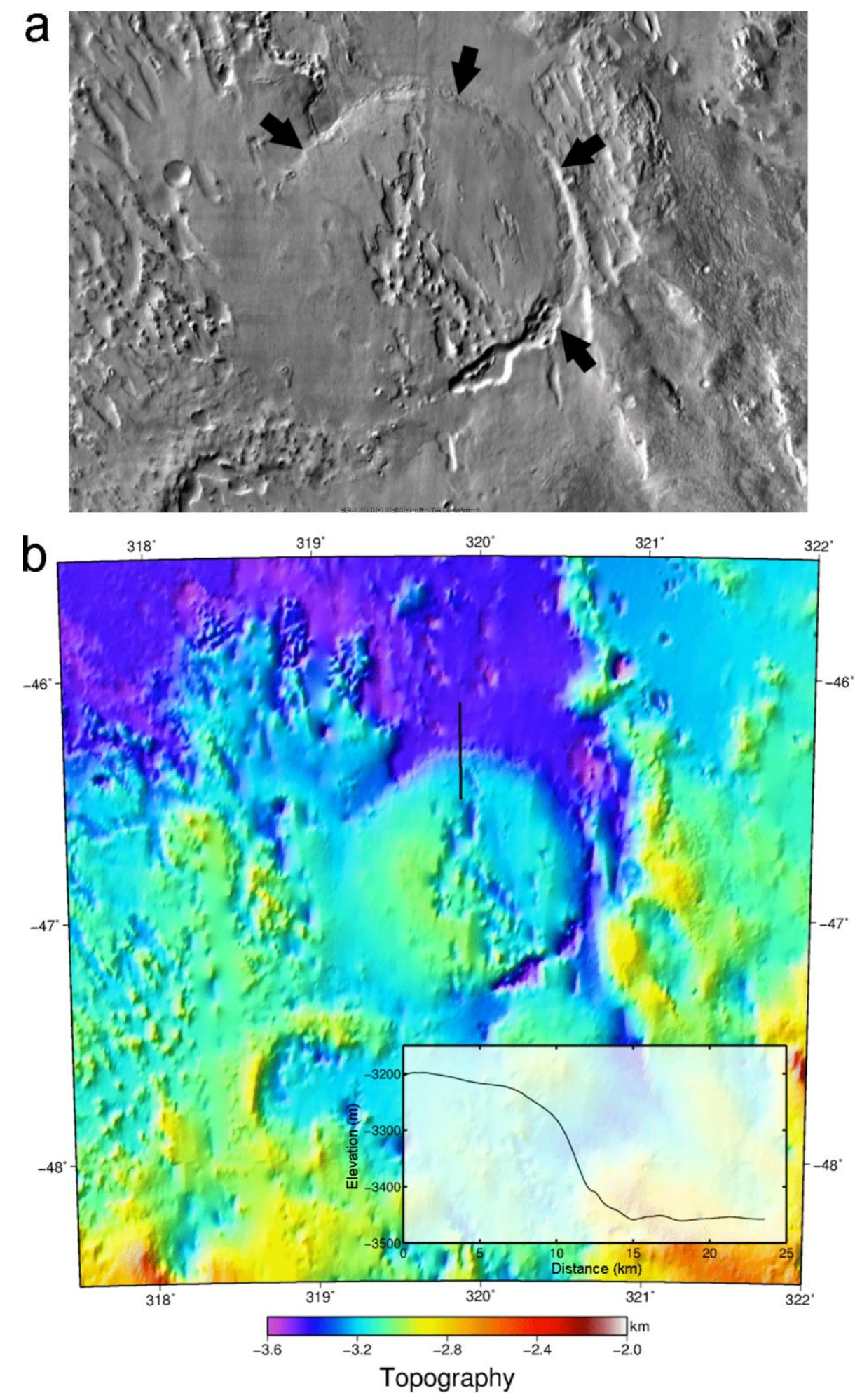

Fig. 19. (a) THEMIS daytime IR image of the floor of Argyre basin. The quasi-circular feature (black arrows) is interpreted to be a $\sim 60 \mathrm{~km}$ diameter buried crater. (b) Topography of the putative buried impact structure. The northern edge appears to have been exhumed creating a nearly $300 \mathrm{~m}$ arcuate scarp seen in the inset profile (location 1797 shown with black line). 


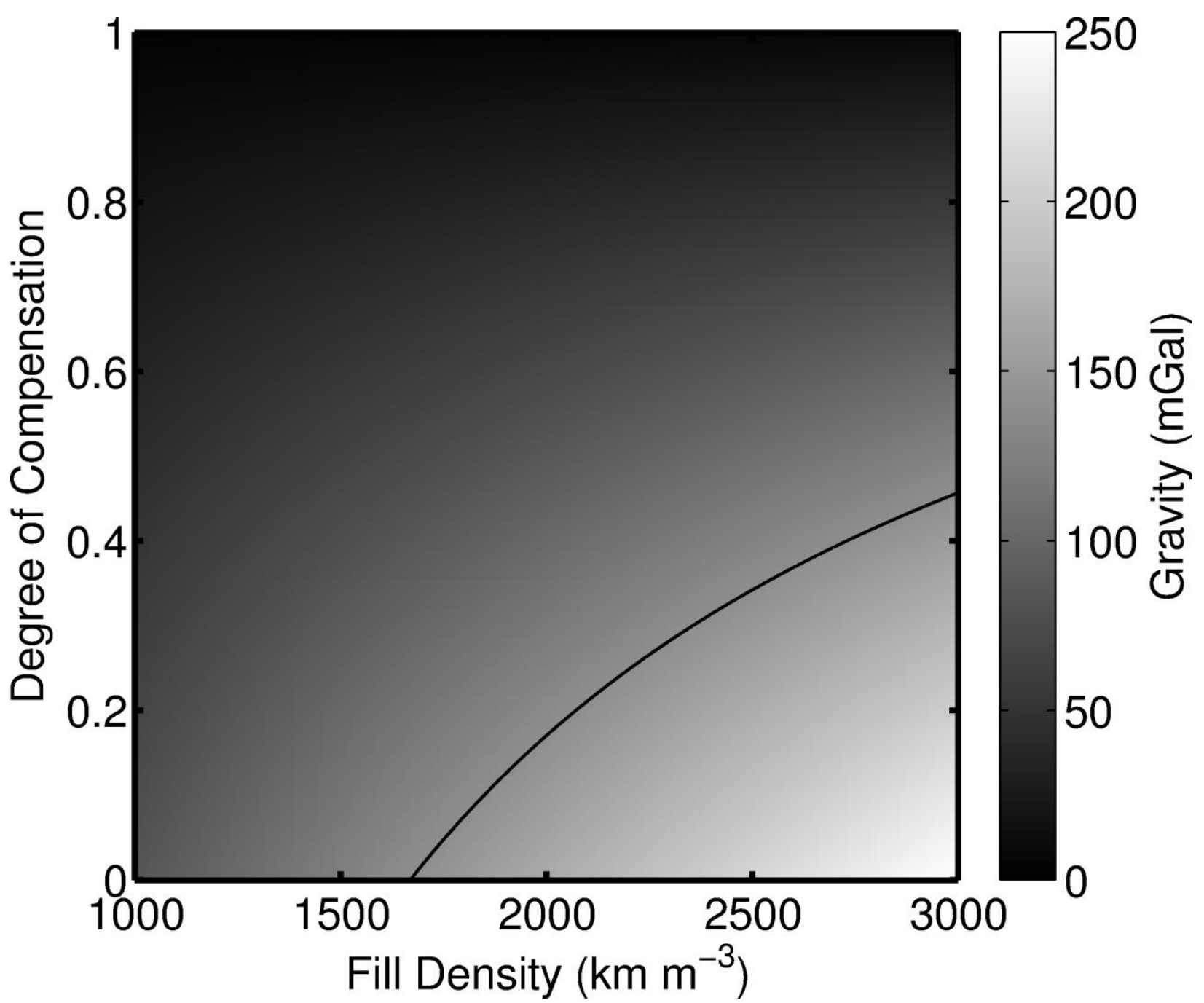

Fig. 20. The free-air gravity anomaly for a slab of material $2 \mathrm{~km}$ thick as a function of material density and degree 1800 of compensation. The $140 \mathrm{mGal}$ contour (black curve), the approximate magnitude of the mascon within the basin 1801 interior, is shown for reference. 